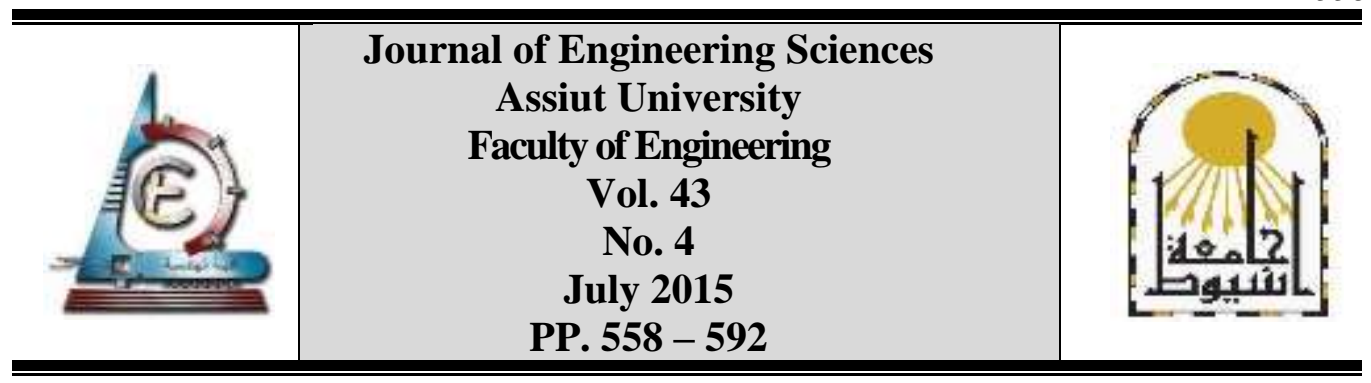

\author{
تقييم ما بعد الإشغال لمساكن الطارف الجديدة \\ رضا محمود حمادة 1 $\quad$ محمد عبد الحميد فاوي 2، \\ 1 أستاذ مساعد بقسم العدارة كلية العندسة بالقاهرة - جامعة الأزهر

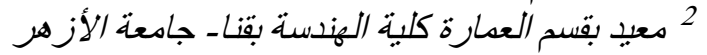

(Received 9 June 2015; Revised 24 June 2015; Accepted 10 July 2015)

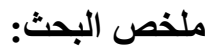

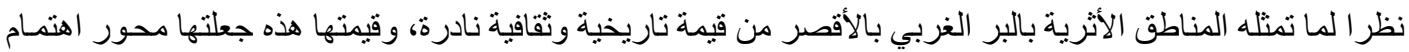

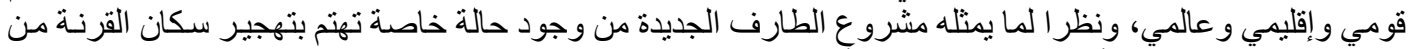

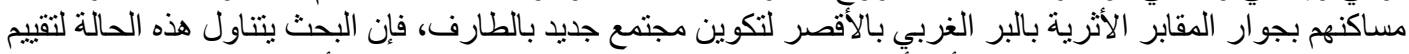

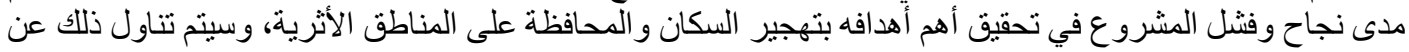
طريق تطبيق منهج تقييم ما بعد الإشغال على مساكن مدينة الطارف الجن الجديدة.

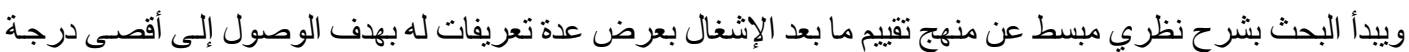

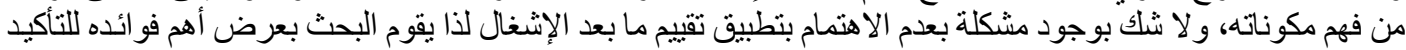

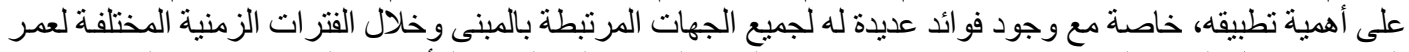

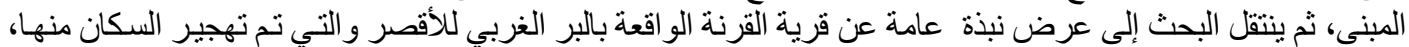

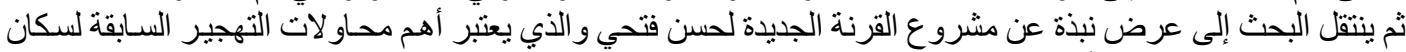

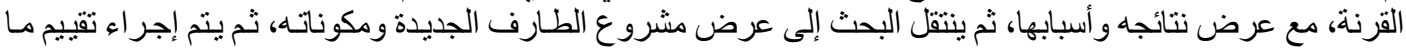

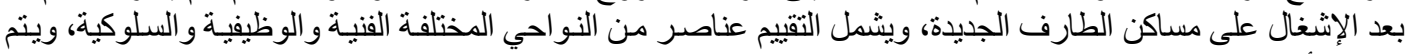

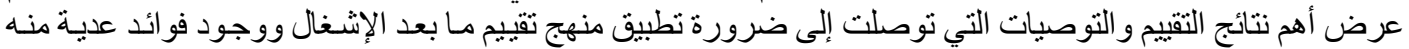

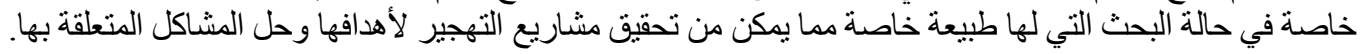

كلمات مفتاحيه: تقييم ما بعد الإشغال، البر الغربي بالأقصر، الطارف الجديدة.

\section{مقدمة:}

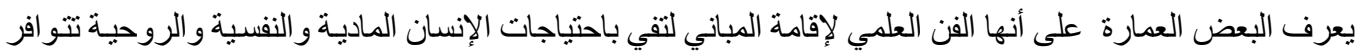

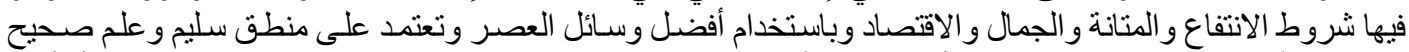

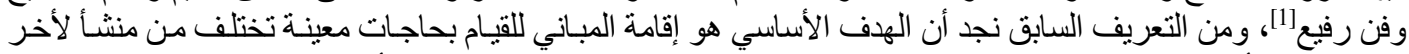

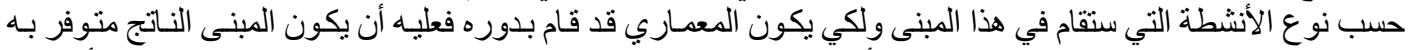

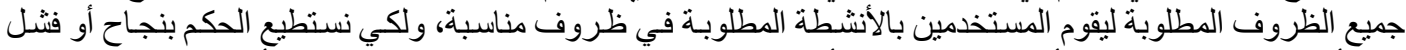

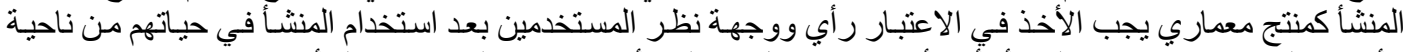

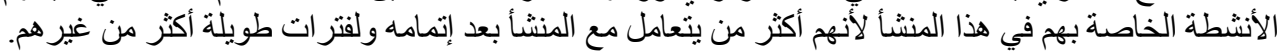

* Corresponding author.

Email address: thebestarcman@yahoo.com 
وفي وقتـا الحـالي نجد أن مصمدو ومنتجو أي منتج يقومو ا بعمل تقيبم لمنتجاتهم ،بمـا في ذلك المنتجات الاستتهلاكية،

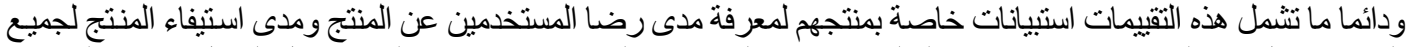

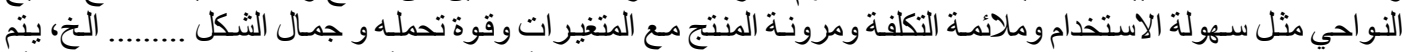

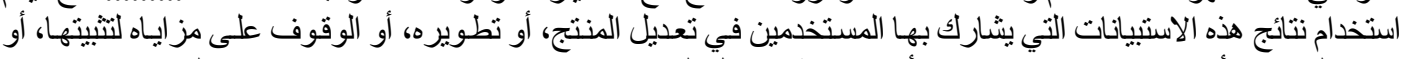

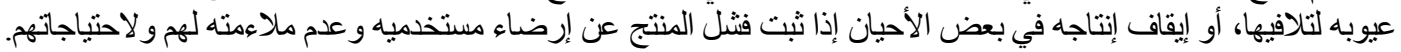

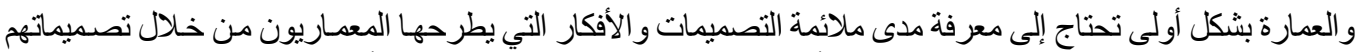

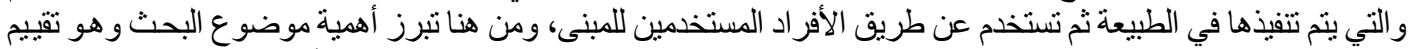

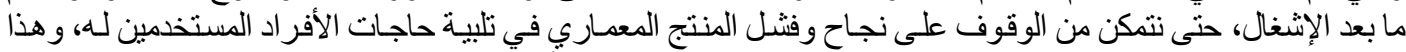

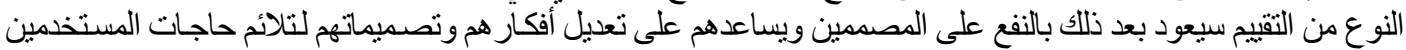

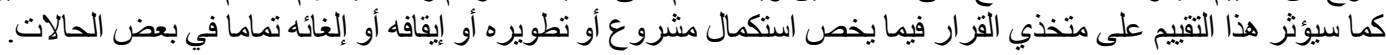

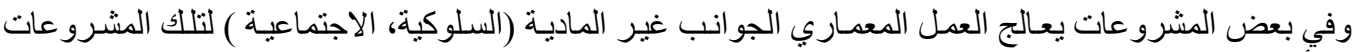

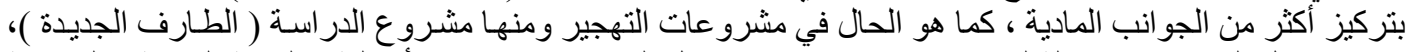

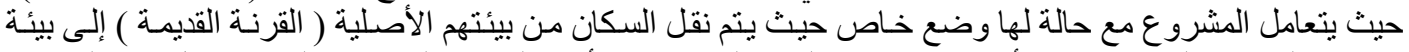

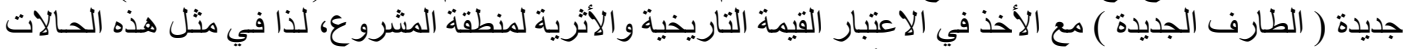

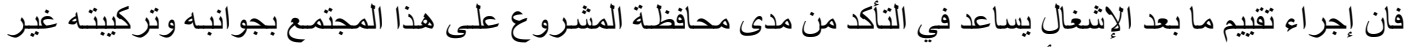

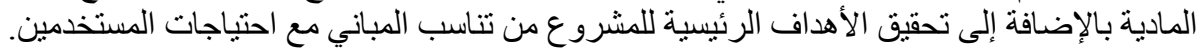

\section{إثكالية البحث:}

المشكلة التي يناقثها البحث هي مشكلة ذات تركيبة معقدة من عدة عوامل وهي:

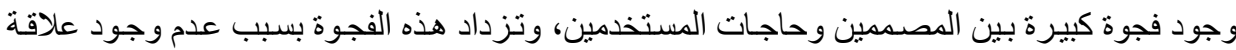

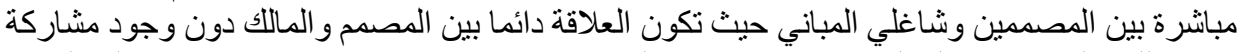

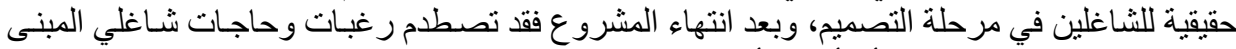

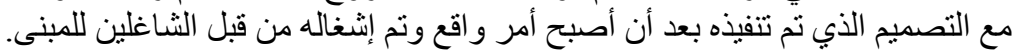

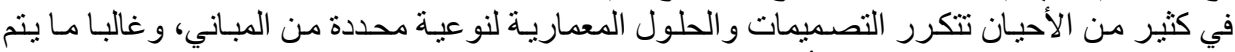

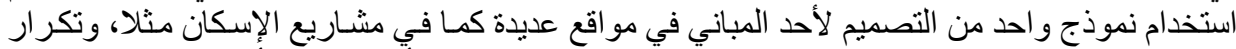

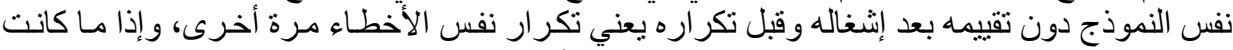

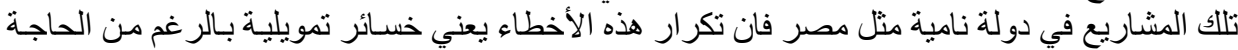

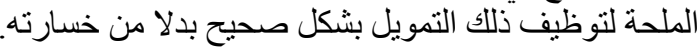

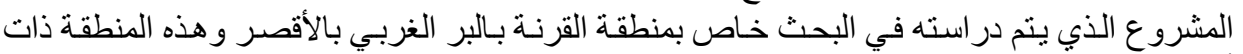

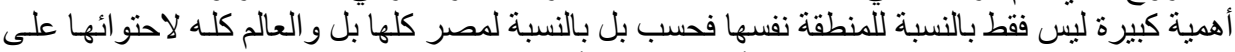

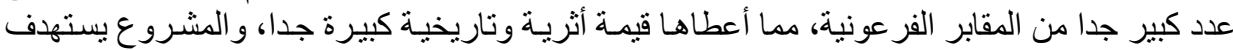

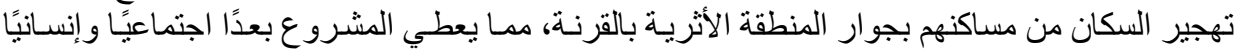

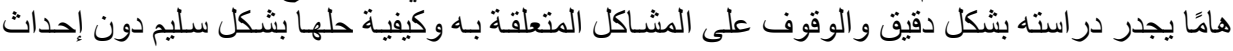

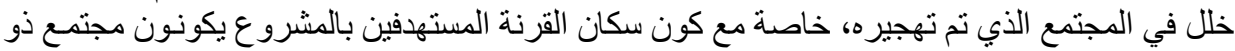

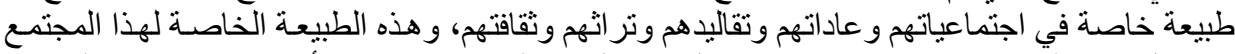

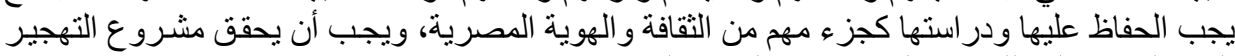
البيئة المناسبة لهم للحفاظ على طبيعتهم الممتدة إلى جذور ناريخهم ونتر الثهر.

\section{فرضية البحث:}

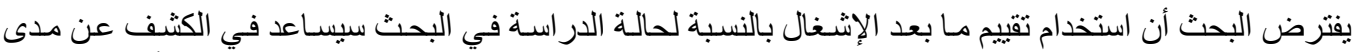

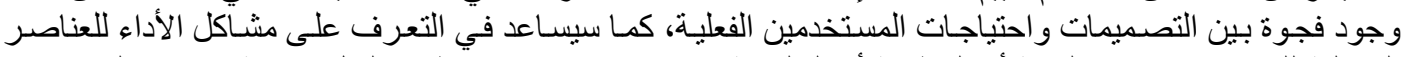

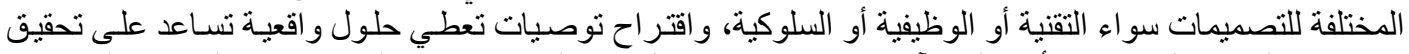

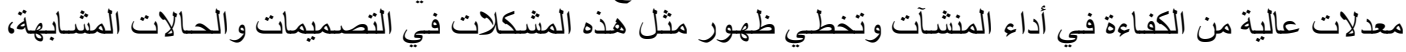
ويوضح الثكل رقم 1 فرضية البحن. 


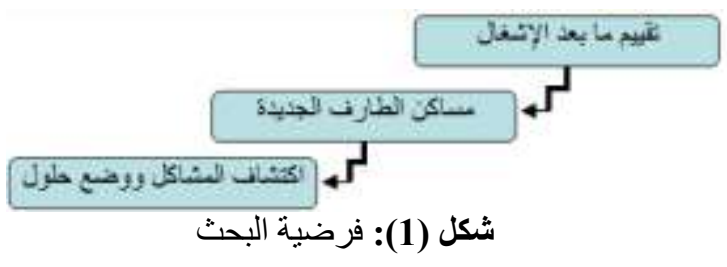

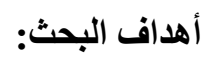

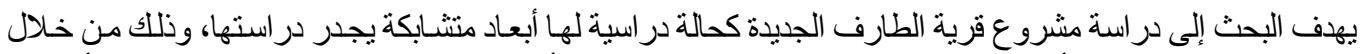

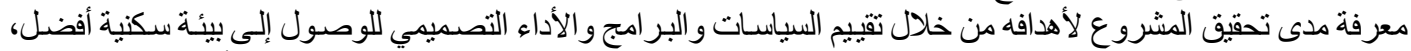

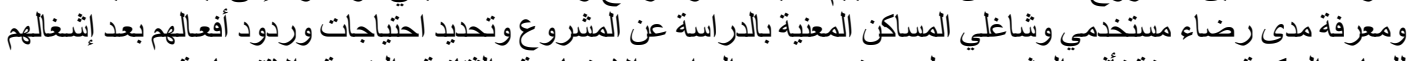

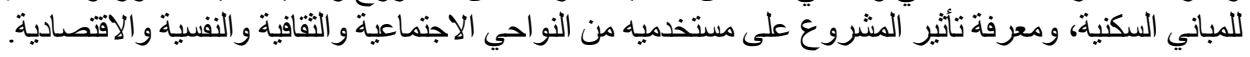

\section{منهج البحث:}

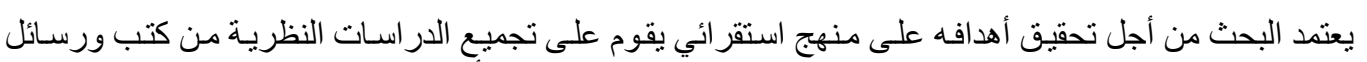

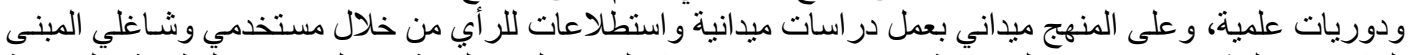

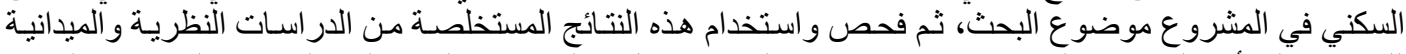

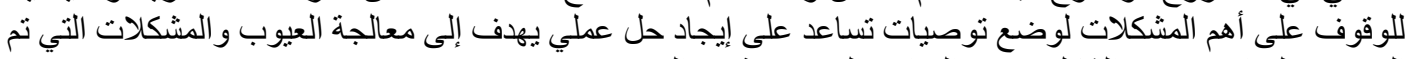
الوقوف عليها، ويوضح الثم الثكل رقم 2 المناهج المستخدمة في البحث.

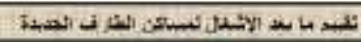

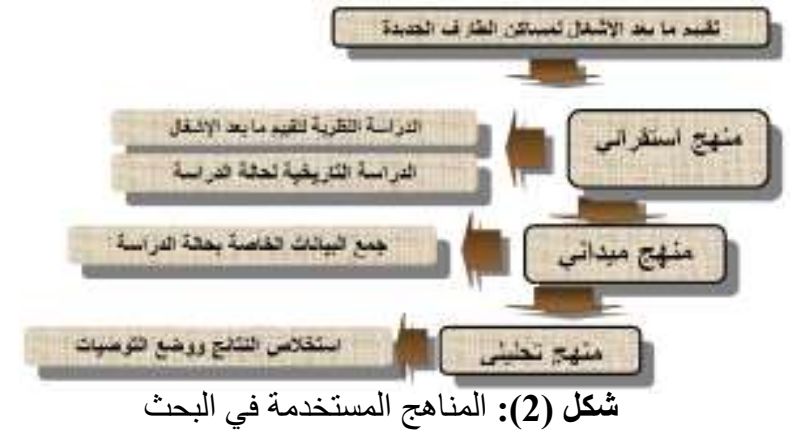

\section{1. منهج تقييم ما بعد الإشغال ( تعريفه، وفوائده ):}

يعتبر البعض تقييم ما بعد الإشغال أحد مر احل التصميم الأساسية والتي يأتي دور هـا بعد إثـغال المبنى ثم

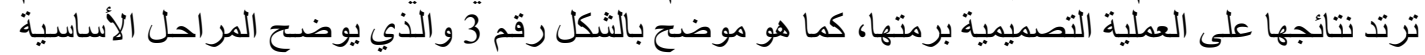

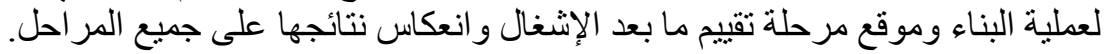

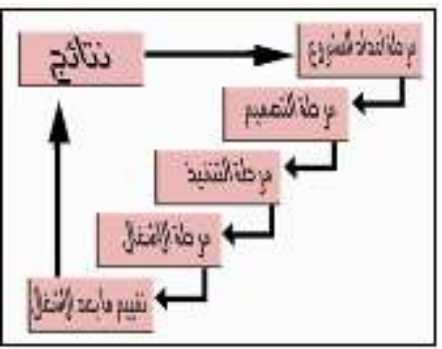

شكل (3): مر احل إنشاء المبنى وموقع مرحلة تقييم ما بعد الإشغال منها. (المصدر الباحث)

وتعتمد فكرة تقييم ما بعد الإشغال بشكل أساسي على وجودها بشكل تلقائي حيث يتم تقييم مـا بعد الإشـغال

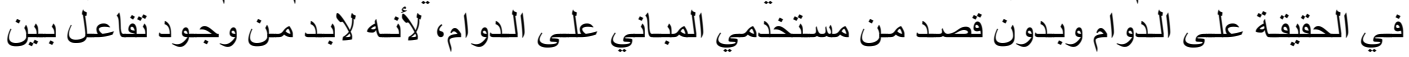




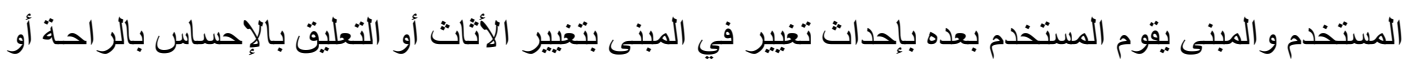

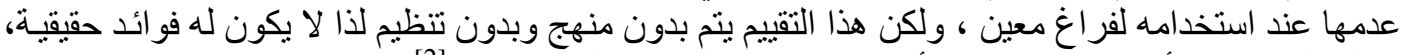

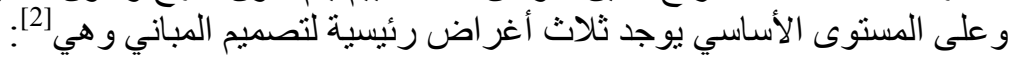

حماية الأشخاص و المعدات من العو امل الخارجية.

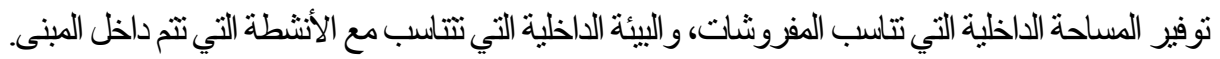

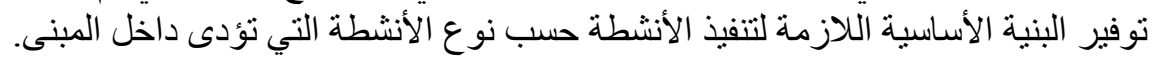

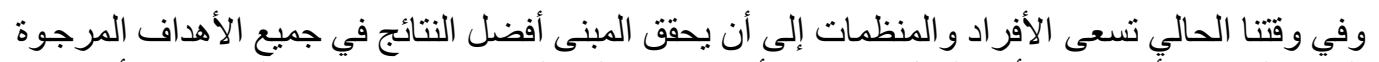

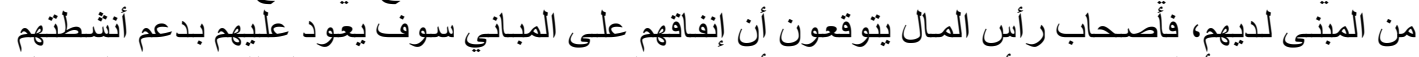

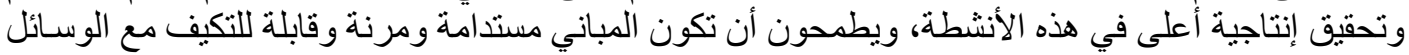

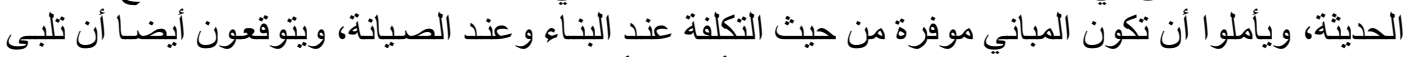

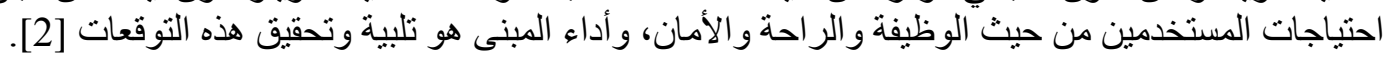

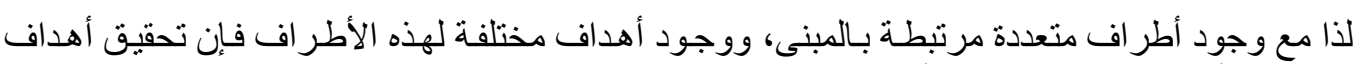

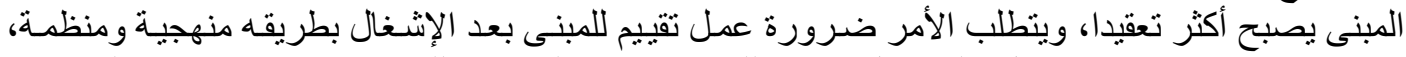

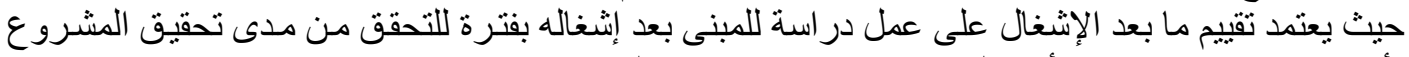

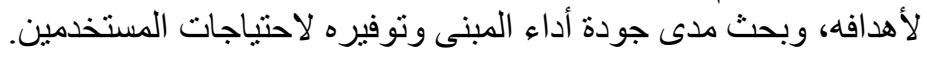

$$
\text { 1.1. تعريف تقبيم ما بعد الإشغال: }
$$

لا يوجد تعريف مقبول بشكل قاطع لتقييم ما بعد الإشغال، وقد حاول العديد من المتخصصين إنتاج تعريف شـامل

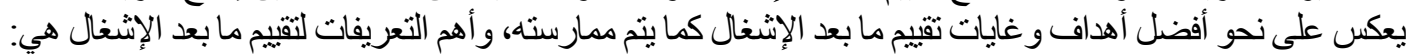

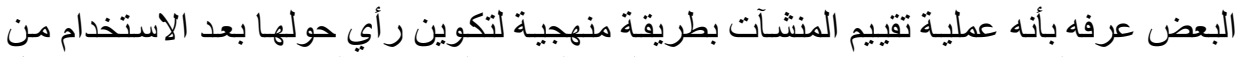

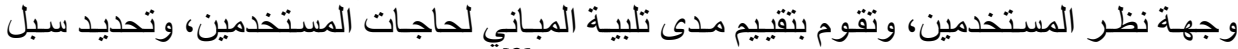

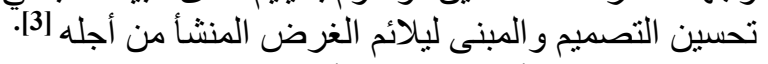

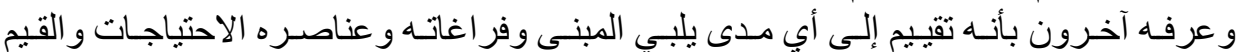

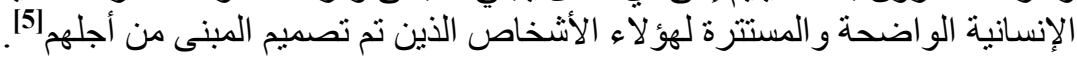

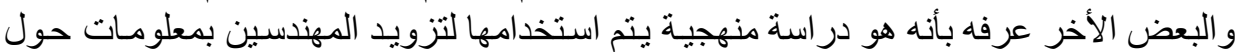

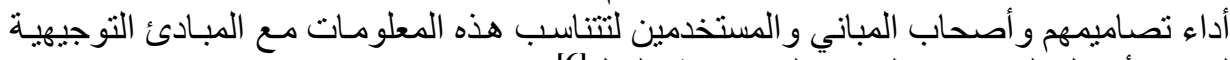

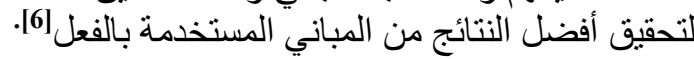

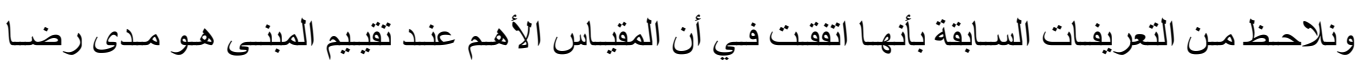
المستخدمين عن تحقيق المبنى لاحتياجاتهم الرئيسية.

$$
\text { 2.1 فوائد تقبيم أداء ما بعد الإشغال: }
$$

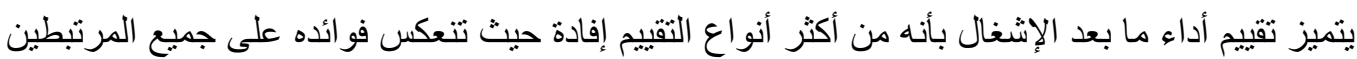

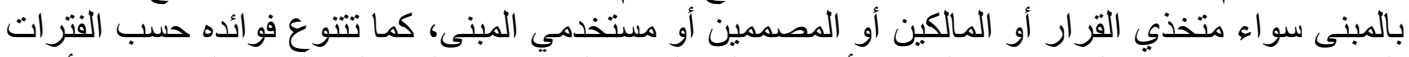

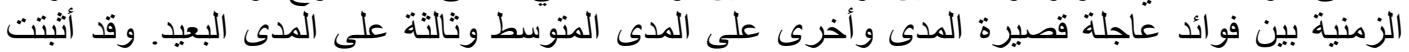

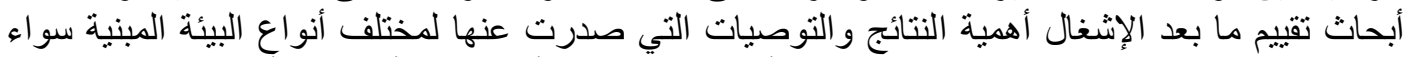

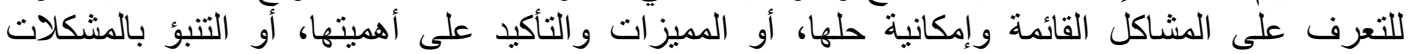

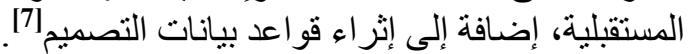


رضا محمود حمادة و محد عبد الحمبل فاوي، تقبيم ما بعد الإشغال لمساكن الطارف الجديبة

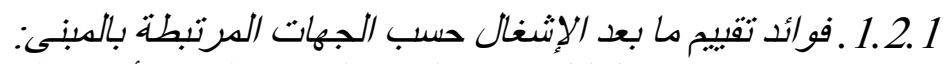

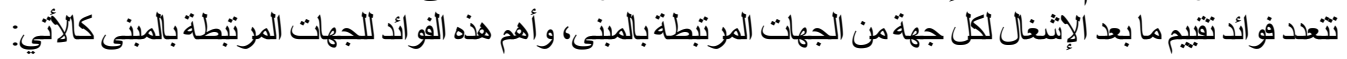

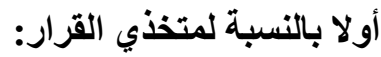

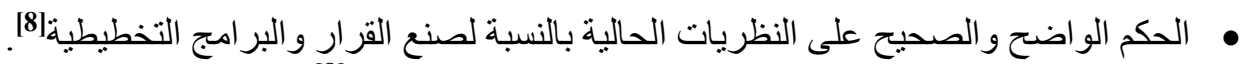

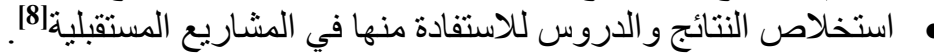

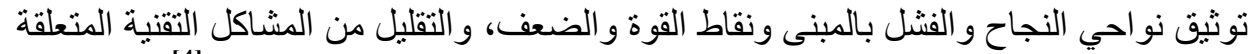

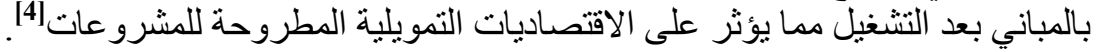

\section{ثثانيا بالنسبة للجهات العاملة بصناعة المباني:}

• دعم وضع السياسات التخطيطية ومدى صلاحيات النماذج الأساسية للتصميمات المتكررة لبعض المباني

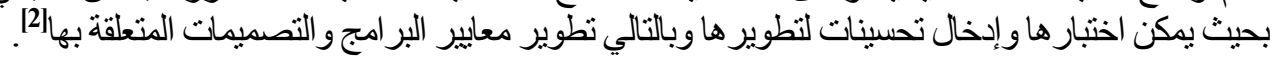

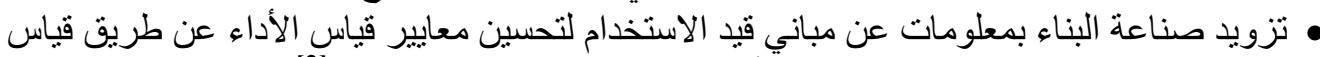

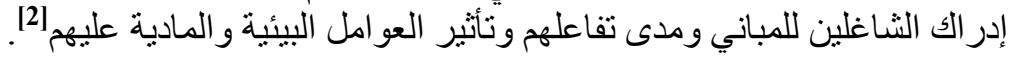

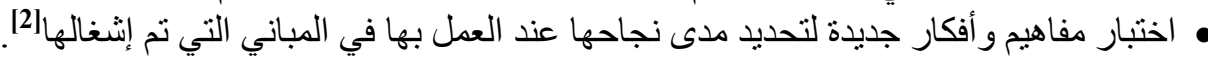

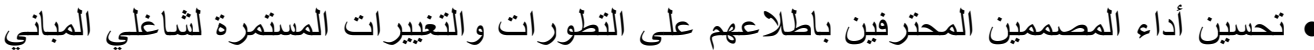

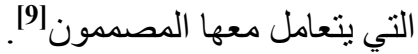

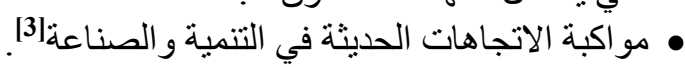

• اختبار وقياس مدى نجاح العمل بالاشتر اطات والأكو اد الموجودة بالفعل و المتعلقة بالعناصر الفنية[3].

\section{ثالثا بالنسبة للجهات الشاغلة للمباني:}

• تحسين أداء المباني في كافة أنحاء دورة حياته وذللك بإجر اء تقييم دوري للمبنى على مدى فترات زمنية

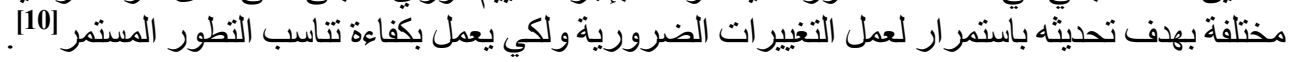

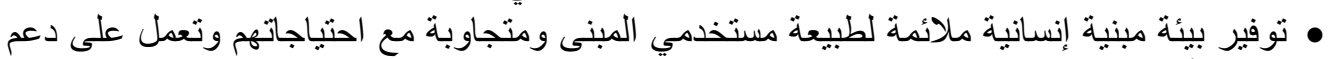

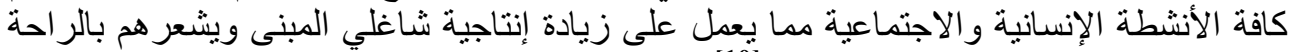

النفسية ويحسن انطباعهم العام عن المبنى [10] • تجنب المشاكل التي تعوق الفاعلية والإنتاج في أماكن العمل و البيئات المعيشية[11].

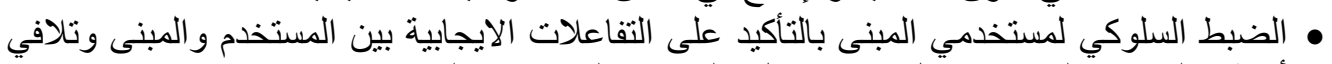

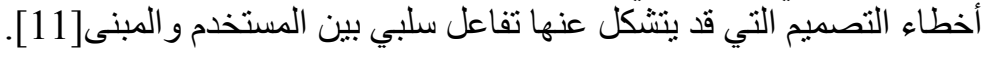

$$
\text { 2.2.1 . فوائد تقبيم ما بعد الإشغال حسب الفترات الزمنبية: }
$$

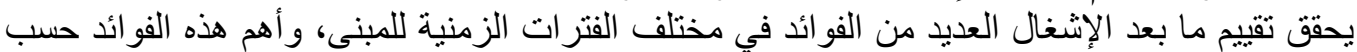
الفتر ات الزمنية كالأتي: تصنيم أولا الفوائد قصيرة المدى: ويقصد بها الفوائد التي تتحقق بعد تشغيل المبنى مباشرة في السنة الأولى من

تشغيل المبنى و أهمها ما يليز المدئ:

$$
\text { • تحديد المشاكل الأولية وحلها. }
$$

• عمل التسهيلات اللازمة لتحقيق معدلات الاستعمال المطلوبة.

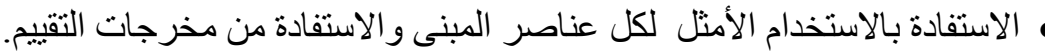
تحسين سلوك المنشآت خلال تفاعلها مع البيئة المحيطة. 
ثانيا الفوائد متوسطة المدى: ويقصد بها الفو ائد التي تتحقق في إطار زمني في حدود خمس سنوات من

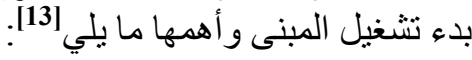
• إمكانية تعديل المبنى من الداخل حسب التغير و النمو المؤسسي طوال الوقت و إمكانية إعادة استخدام

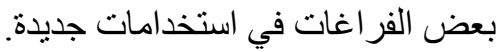

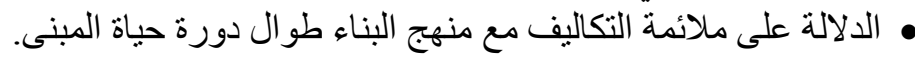
• إمكانية مر اقبة أداء المبنى بو اسطة التكالف المصممين و المالكين.

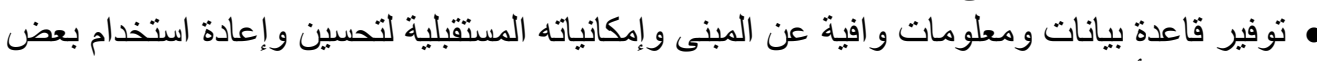
الفر اغات، أو القيام ببعض بيات ومغلتومات التعديلات. ثالثا الفوائد طويلة المدى: ويقصد بها الفو ائد التي تتحقق في إطار زمني في حدود من عشر سنوات إلى إلى

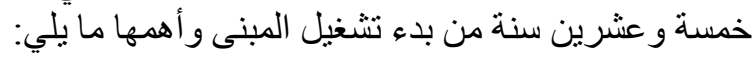

$$
\text { • • تطوير وتجديد قو اعد ومعايير التصميم] [10]. }
$$

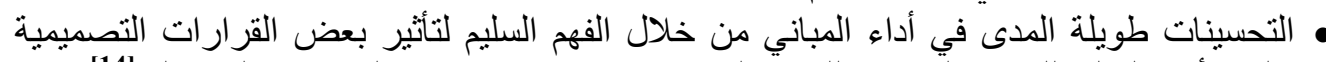

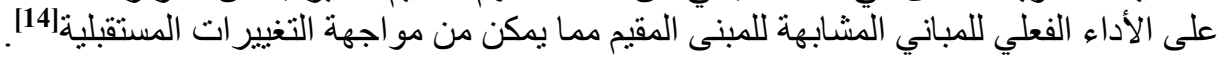

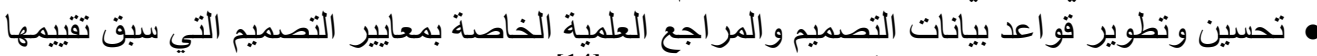

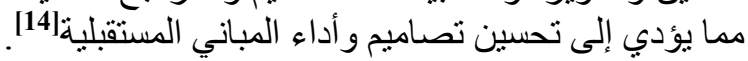
ومن خلال ما سبق نستخلص في الجدول رقم 1 أهم فوائد تقييم ما بعد الإشخال المتحققة للجهات المرتبطة بالمبنى في الفتر ات الزمنية المختلفة.

\begin{tabular}{|c|c|c|c|}
\hline الجهات الثاغلة للمباني & الجهات العاملة بصناعة المباني & متخذي القرار & نو عية الفو ائد \\
\hline تلتشغين أداءع المبنى في مر آحل & 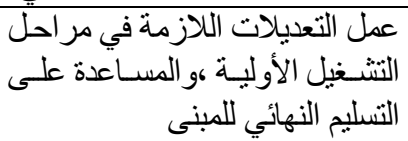 & المشــــاعل العاجلة علـى حـلـل & قصيرة المدى \\
\hline 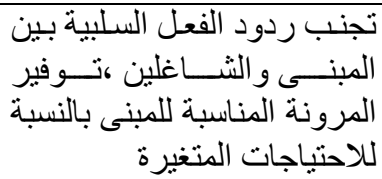 & للمباني المشابهة الحلول التصميمية المناسبة & تتشغيل المبنى التمويل المناسب & متوسطة المدى \\
\hline 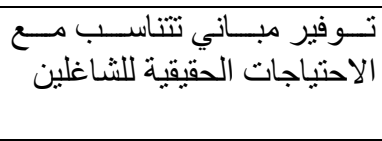 & 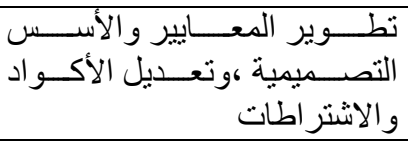 & 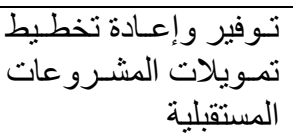 & بعيدة المدى \\
\hline
\end{tabular}
جدول (1): أهم الفو ائد المتحققة للجهات المرتبطة بالمبنى في الفترات الزمنية المختلفة

\section{2. القرنة: من القرنة القديمة إلى الطارف الجديدة}

1.2

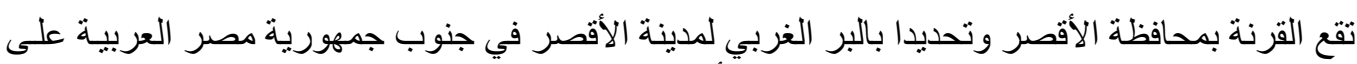

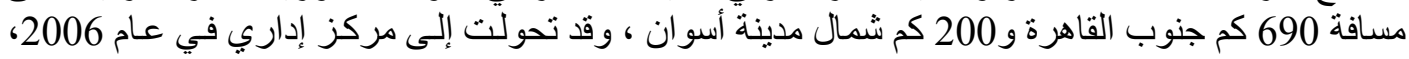

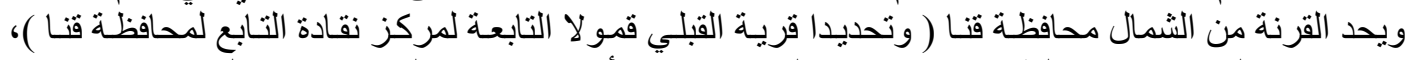

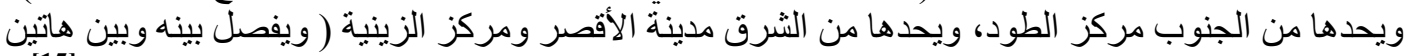

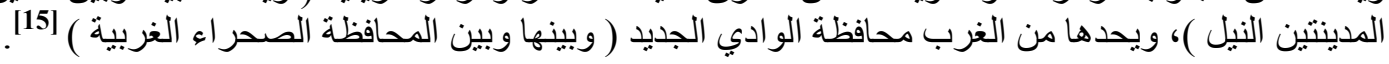




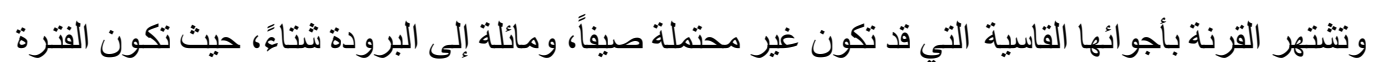

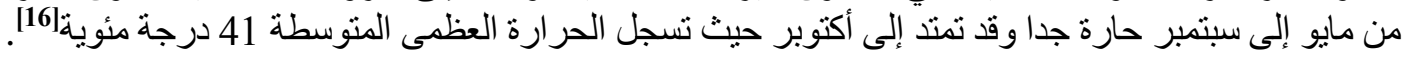

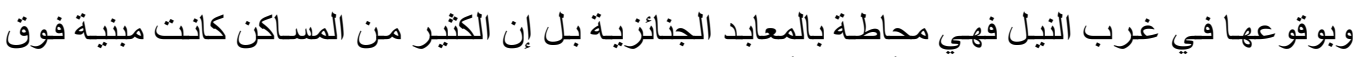

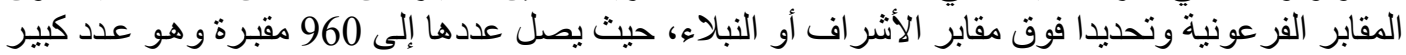

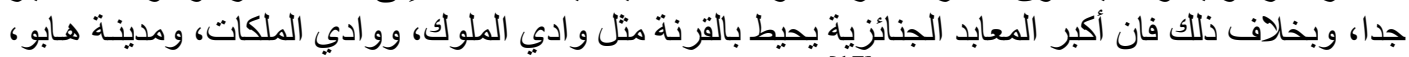
و الرمسيوم ، وديخلوف ذاك فان ألمدينة (قرية العمال) [17).

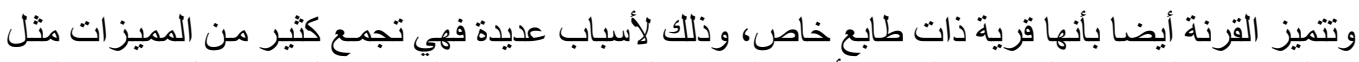

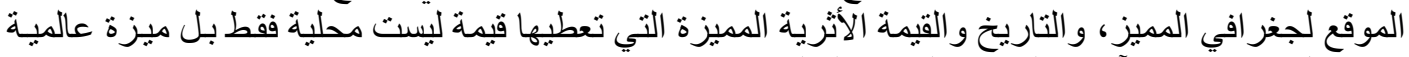

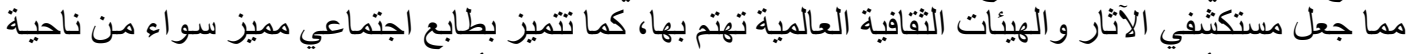

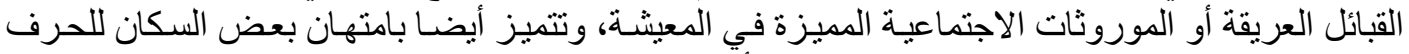

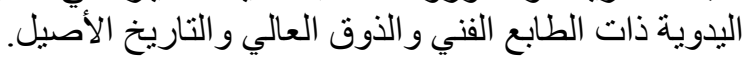

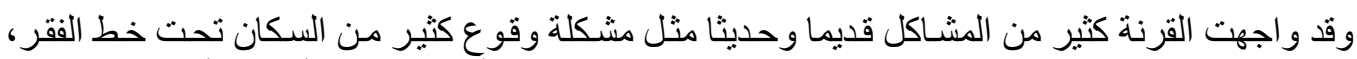

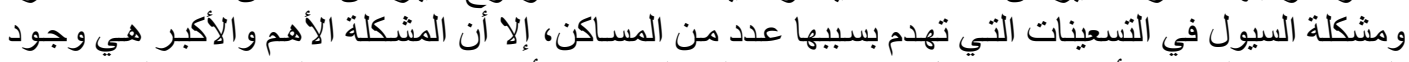

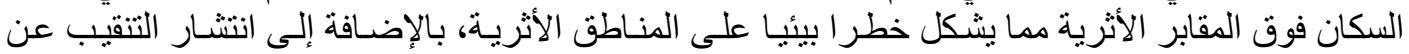

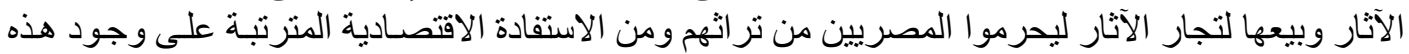

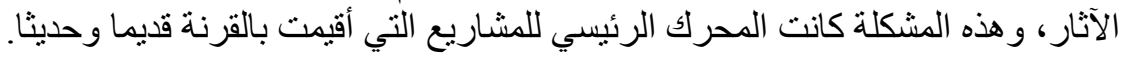

$$
\text { 2.2.2.2.2 تهجبر سكان القرنة ( تجربة القرنة الجدبية لحسن فتحي ): }
$$

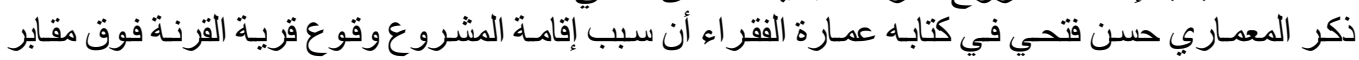

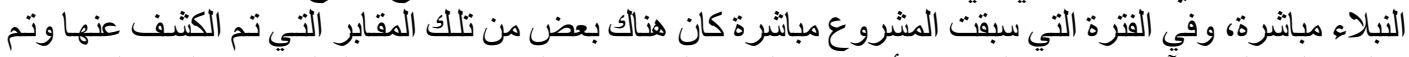

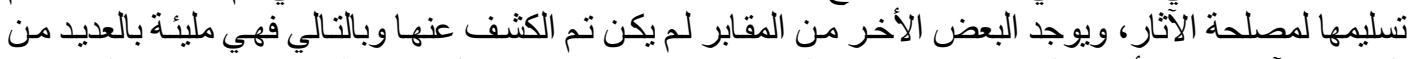

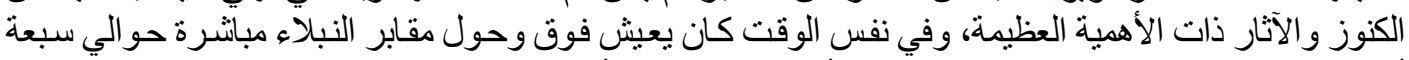

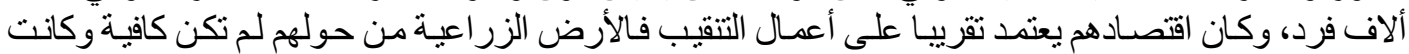

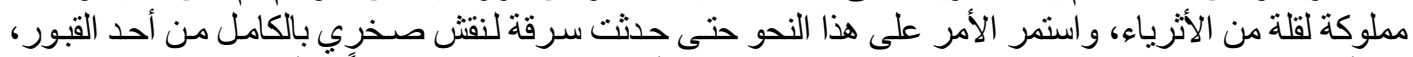

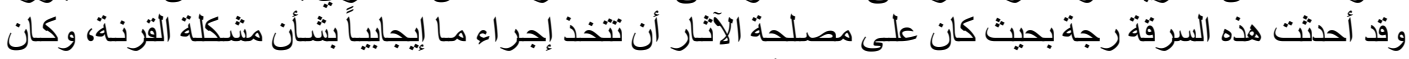

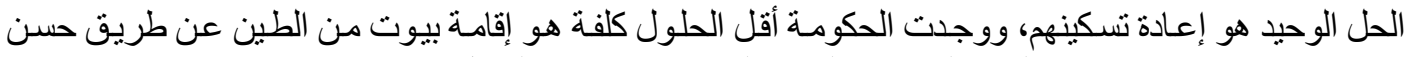

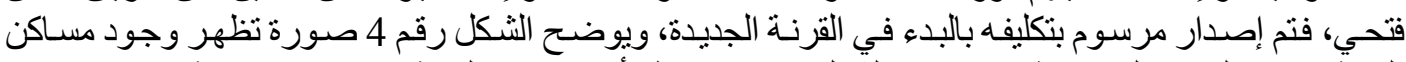
القرنة بجوار المقابر الفرعونية ، ويوضح الثّكل رقم 5 مسقط لأحد مساكن القرنة به مقبرة فرعونية.

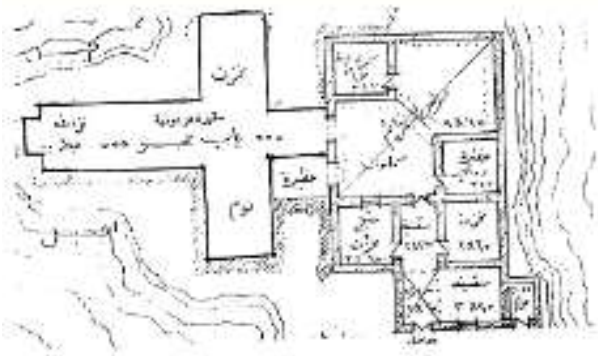

شكل (5): مسقط لأحد بيوت القرنة وبه مقبرة فرعونية]20]

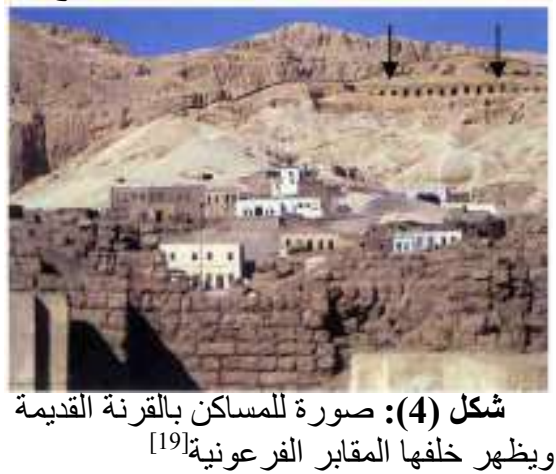




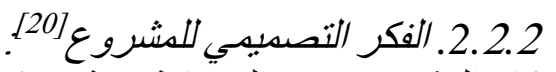

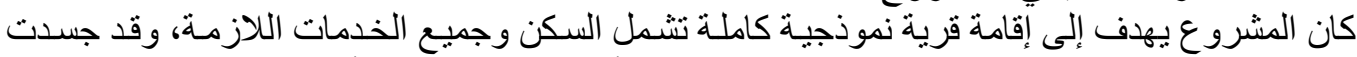

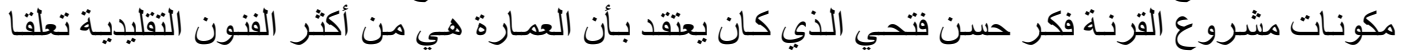

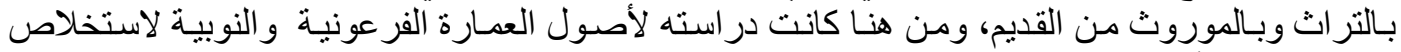

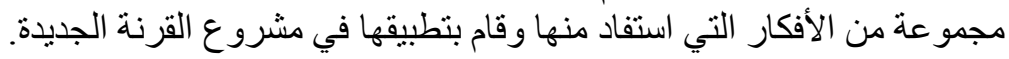

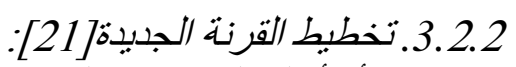

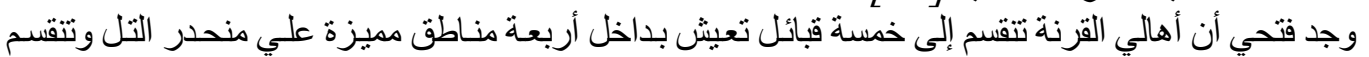

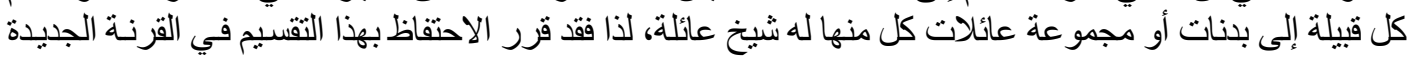

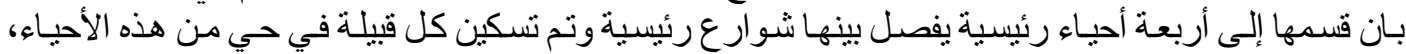
ويوضح الثكل رقم 6 الموقع العام لتخطيط القرنة وتظهر البلوكات باللون الأخضر المساكن التي تم بنائها بالفعل.

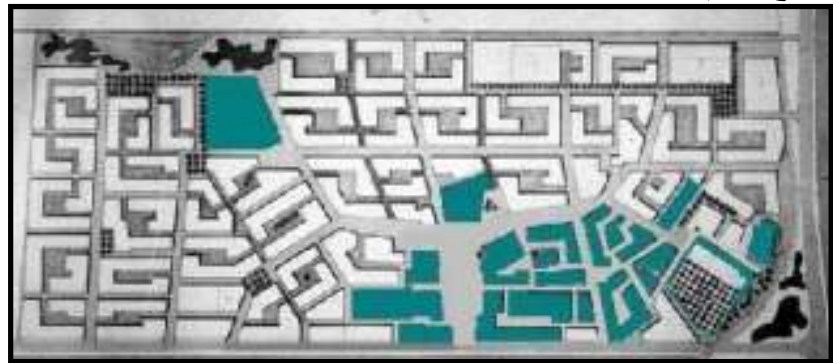

شكل (6): مخطط عام لقرية القرنة الجديدة [21]

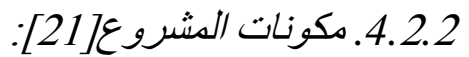

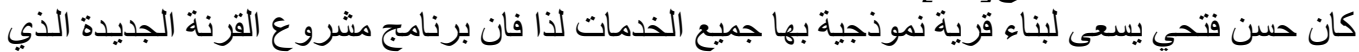

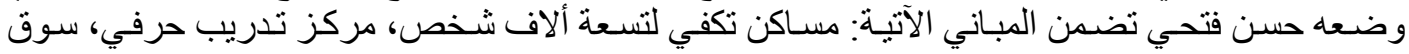

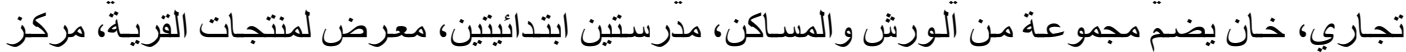

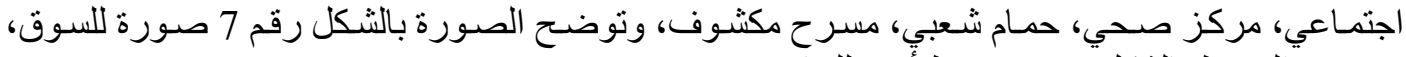

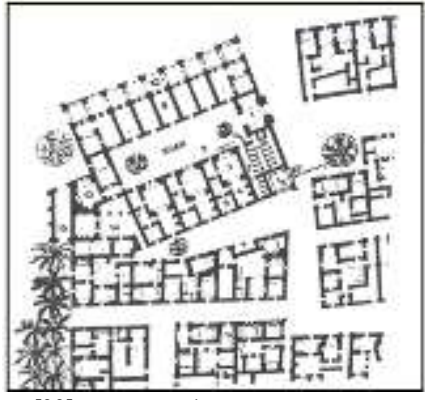

شكل (8): مسقط أفقي للخان[222

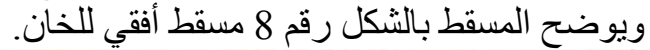

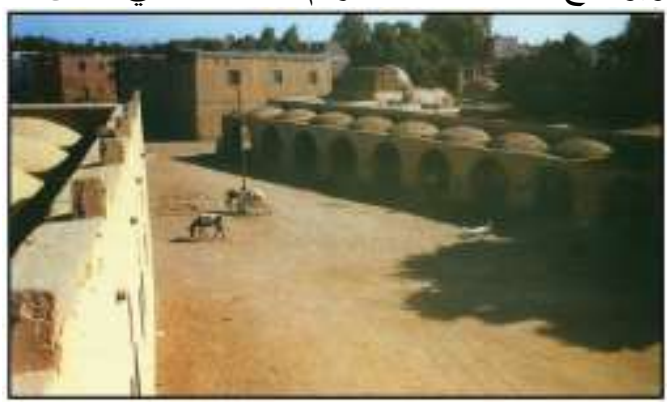

شكل (7): صورة السوق في القرنة الجديدة:

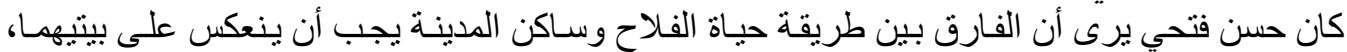

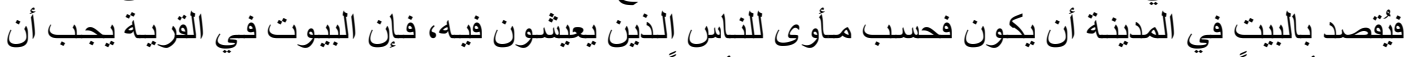

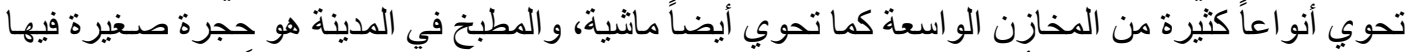

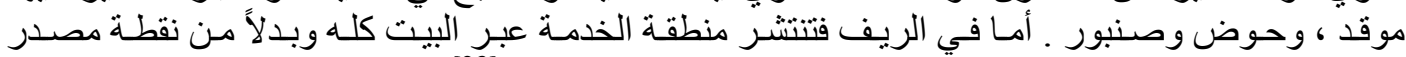

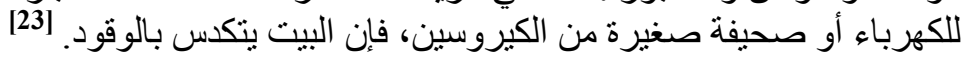




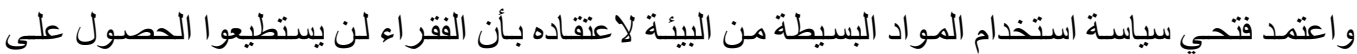

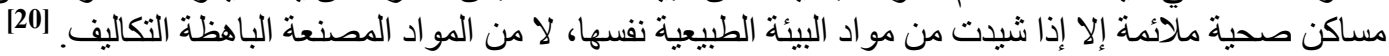
كما اعتمد حسن فتحي عند تصميم مساكن القرنة الجديدة بتصميم مسكن مختلف لكل أسرة حسب إمكان إنياتها

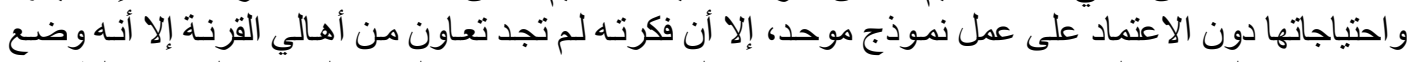

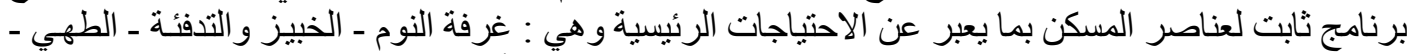

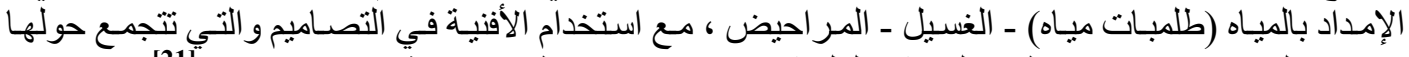

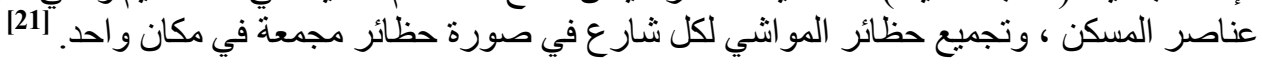

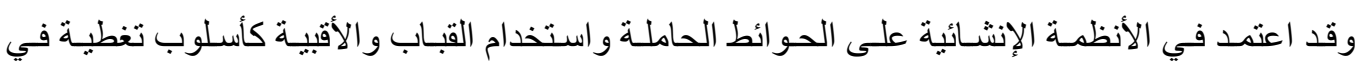

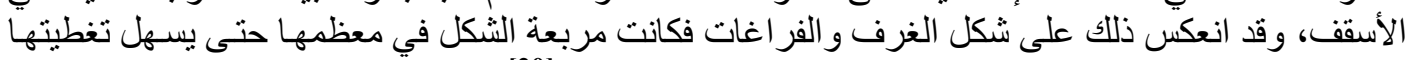

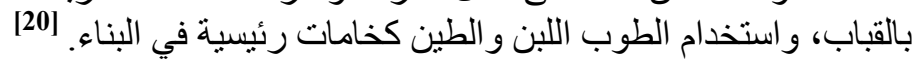

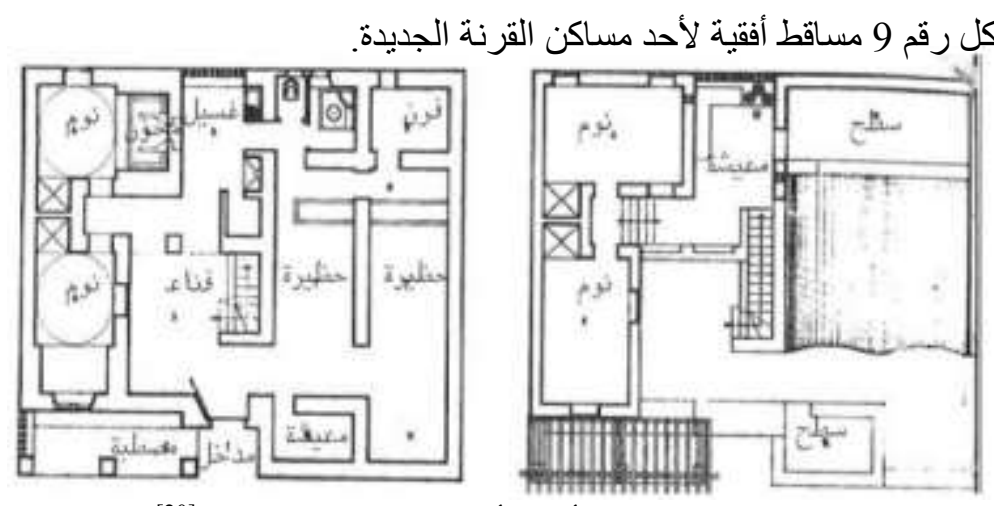

شكل (9): مساقط أفقية لأحد مساكن القرنة الجديدة [20]

$$
\text { 6.2.2 6.2. نتائج مشروع القرنة الجديبة: }
$$

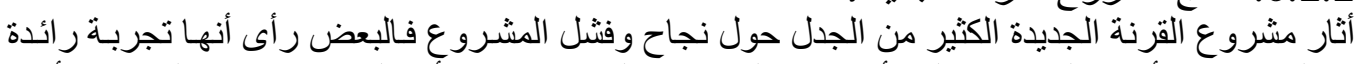

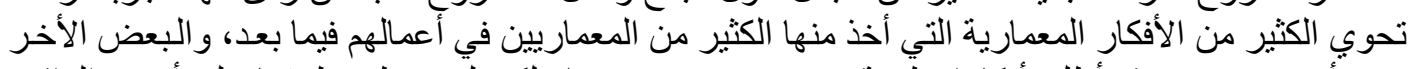

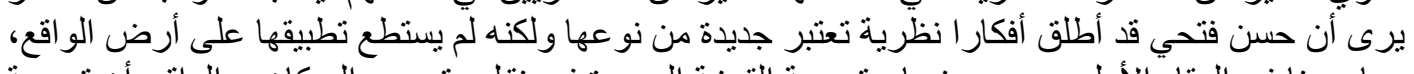

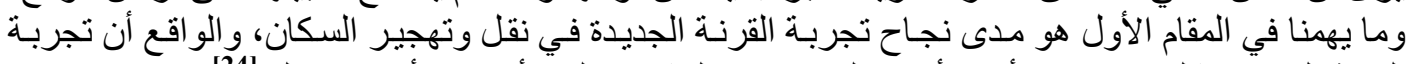

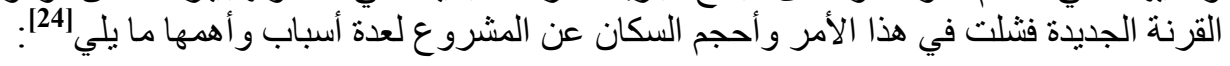

$$
\text { • عدم تو افق المشروع مع البعد الاقتصادي للسكان. }
$$

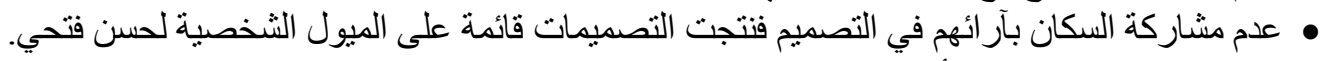

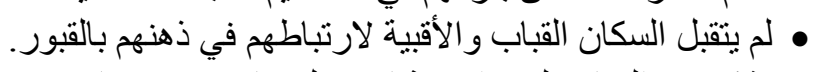

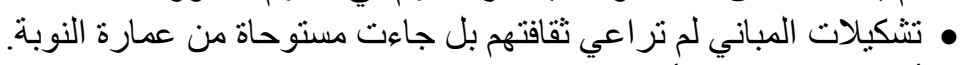

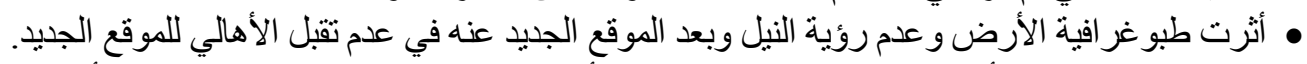

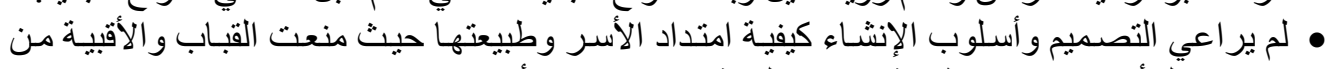

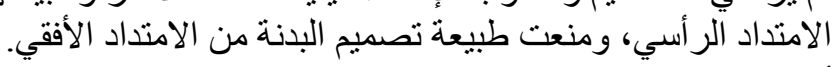

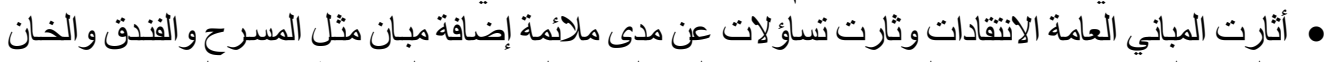
و الحمام التركي واتهم فتحي بالرومانسية ونقص الفهم الحقيقي لعادات ونقاليد ونمط معيشة الفئة الفلاحين. وتوضح الصور بالأشكال أرقام 10، 11 صور لمنزل أحمد عبد الرسول وهو أول مسكن قام فتحي بينائهـ وقد تم ترميمه ليصبح مز ار سياحي. 


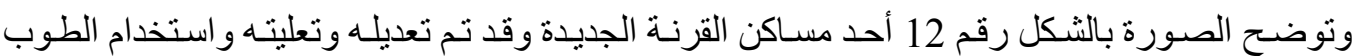
الطفلي و الخرسانة المسلحة بـه، وتوضدح الصورة بالثكل رقم 13 أحد مساكن القرنة الجديدة ويظهر بـهـ العديد

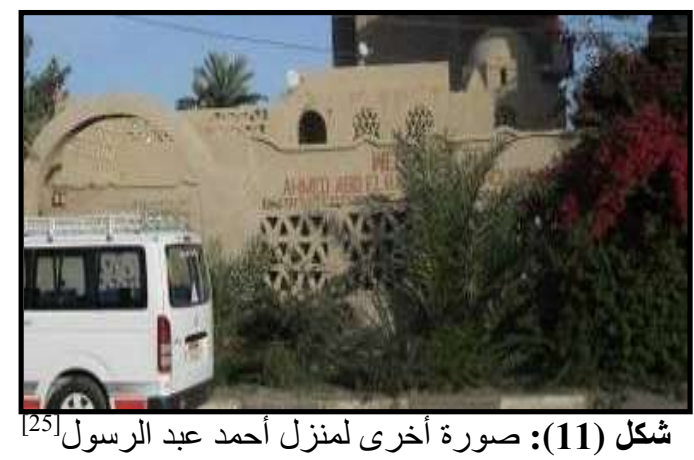

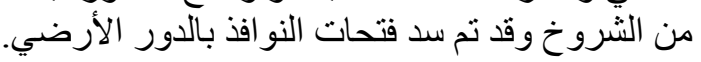

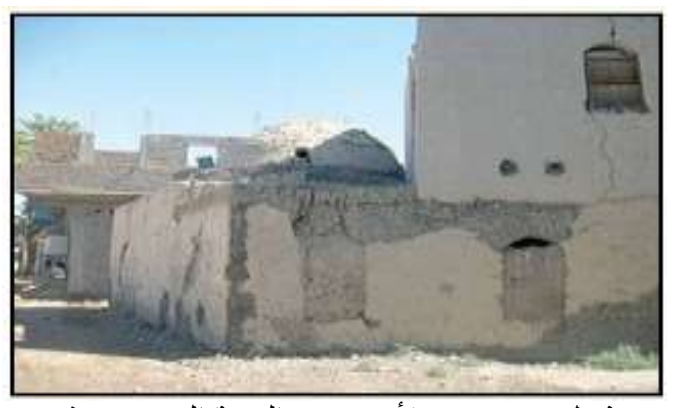

شكل 13 صورة لأحد بيوت القرنة الجديدة به شروخ

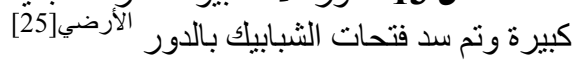

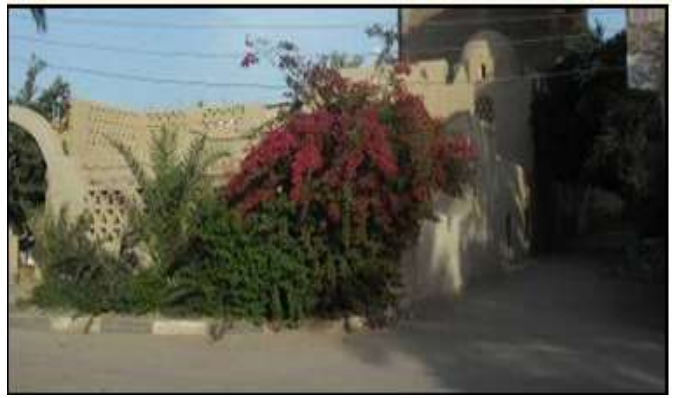

شكل (10): صورة لمنزل أحمد عبد الرسول

أول مسكن بالقرنة الجديدة:

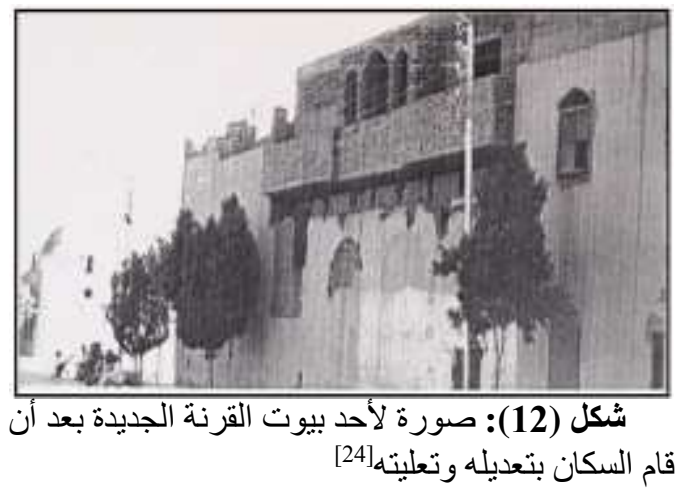

3.2. الظروف المحبطة بسكان القرنتة قبل إقامة مشروع الطارف الجدبية: 1.3.2 الظروف والعو/مل السباسبة [27].

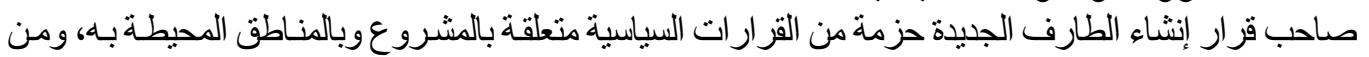

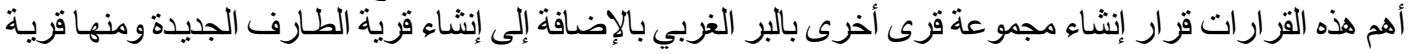

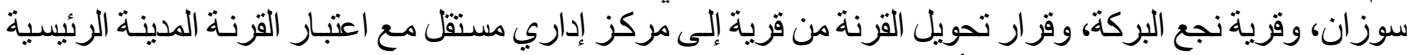

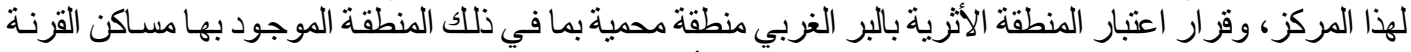

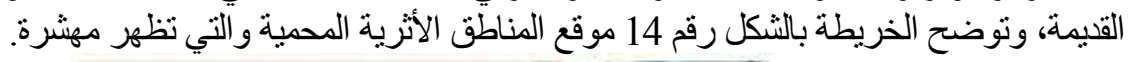

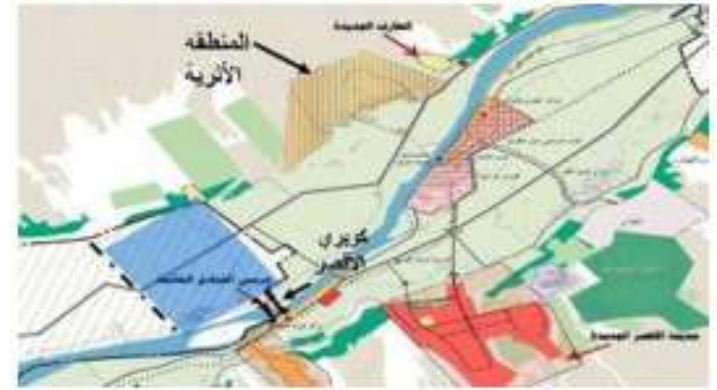

شكل (14): خريطة نوضح المنطقة الأثرية المحمية والتي تظهر مهشرة [28] 
2.3.2. الظروف والعوامل الاجتماعية:

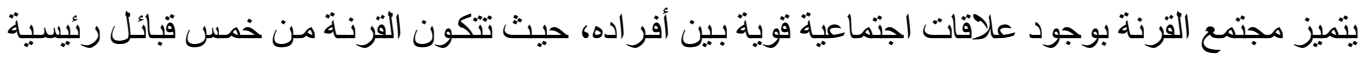

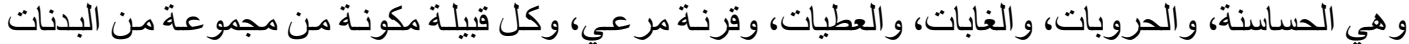

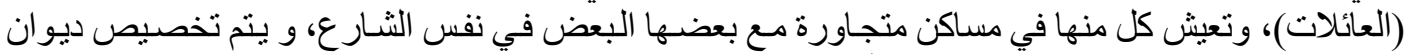

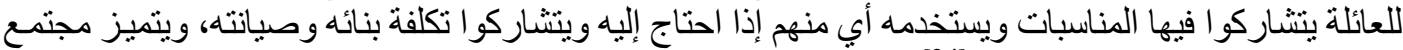
القرنة بثلاث سمات اجتماعية وهي [24]: التكوين الأسري من أسر ممتدة، الخصوصية العالية، جوار الأقارب. وتوضح الأشكال رقم 15، 16 صور التجمعات السكنية التي كانت بالقرنة.

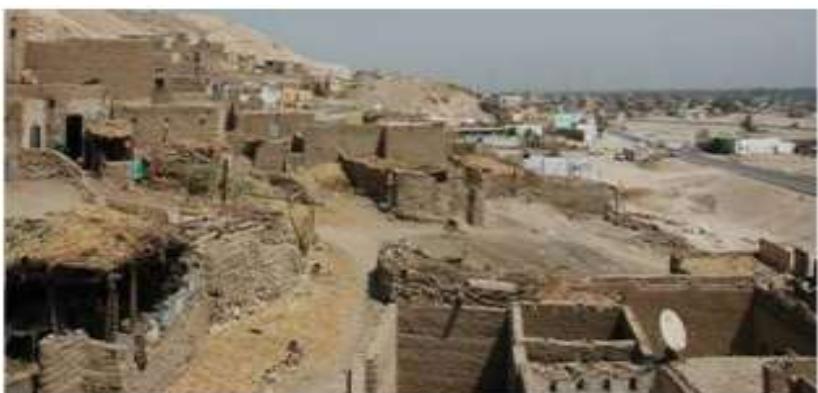

شكل (16): صورة للثكل العام من داخل أحد التجمعات السكنية

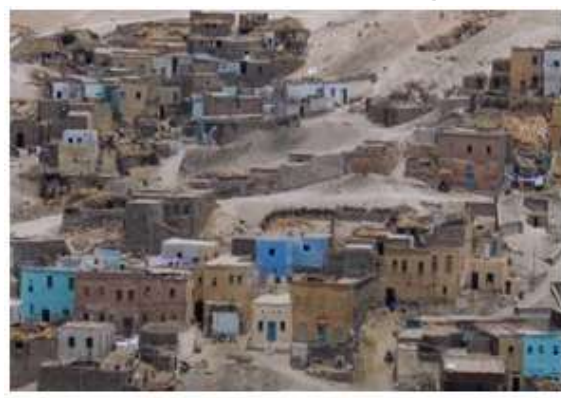

شكل (15): صورة لعدة تجمعات سكنية

للعائلات بالقرنة

3.3.2. الظروف و العوامل الاقتصادية:

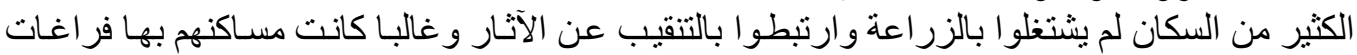

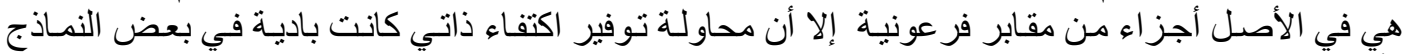

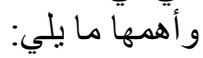

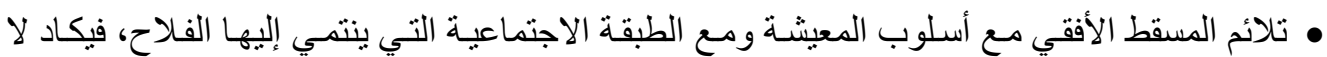

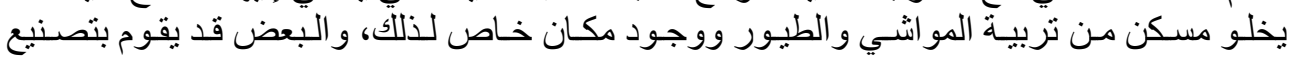

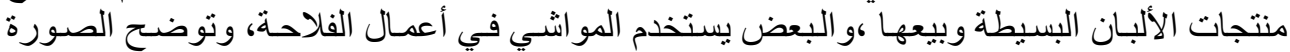

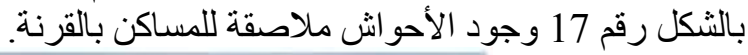

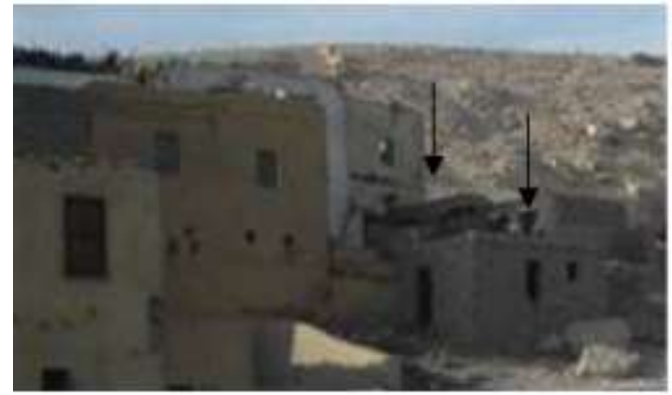

شكل (17): صورة للأحو اش ملاصقة للمساكن في القرنة[25]

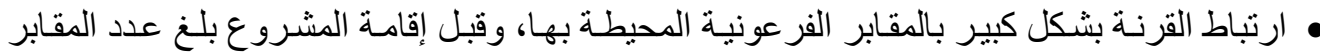

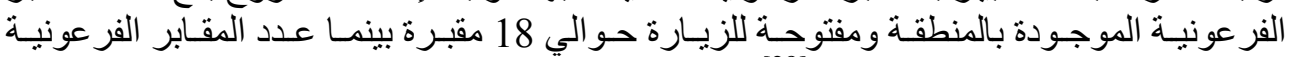

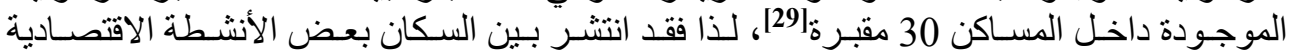

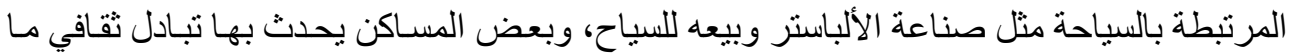

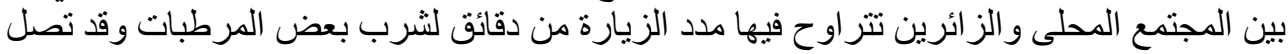




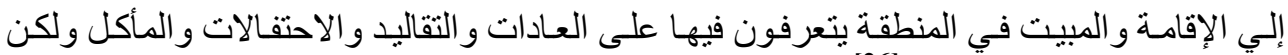

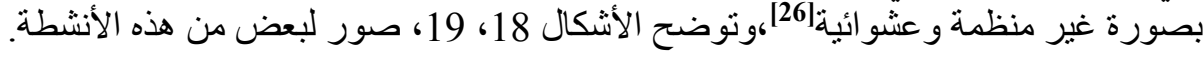

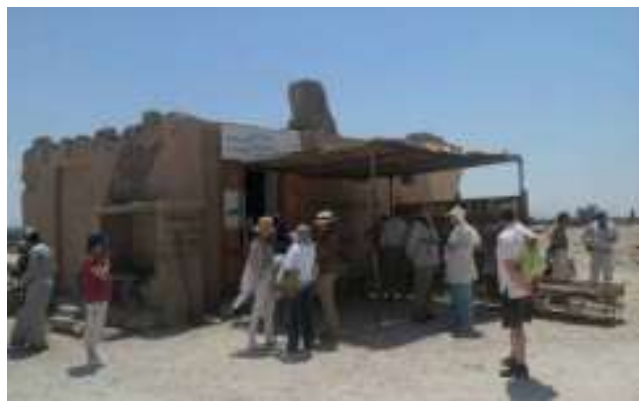

شكل (19): صورة لمكان لبيع الهدايا للسائحين

عن طريق السكان (19) ع

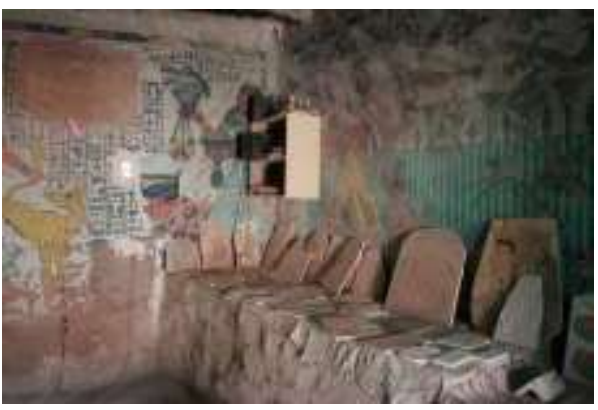

شكل (18): صورة لمكان لبيع الألباستر عن طريق السكان [29)

\section{3. مشروع الطارف الجديدة:}

تعتبر بداية التجهيز لمشروع الطارف الجديدة في تسعينيات القرن الماضي حيث اتجهت الدولة إلى تحديد

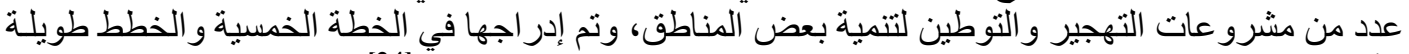

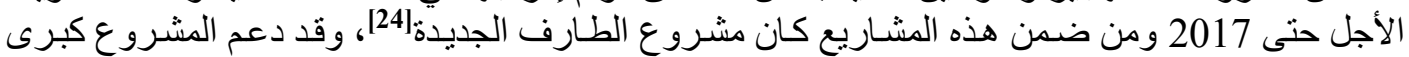

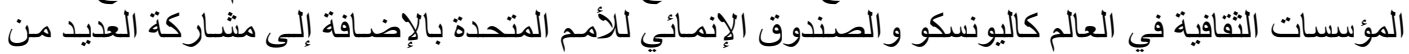

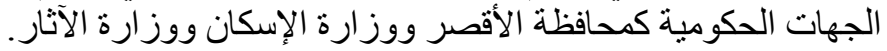

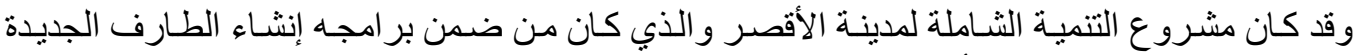

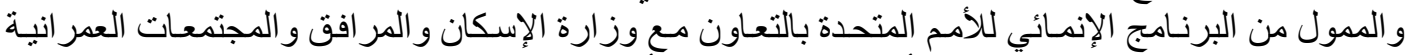

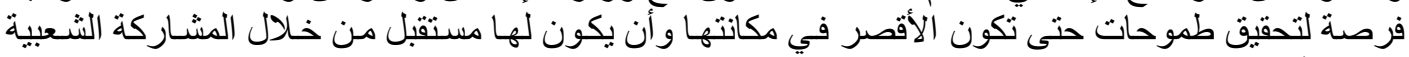

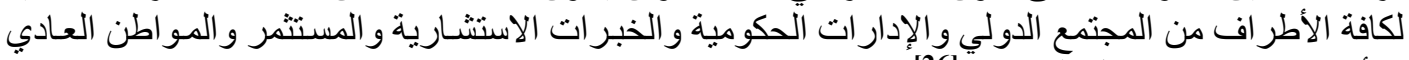

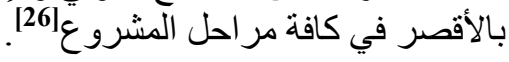
1.3

• اسم المشروع: إنشاء مدينة الطارف الجديدة.

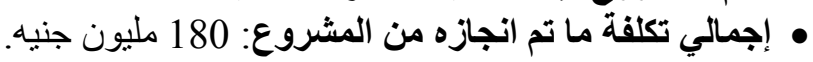

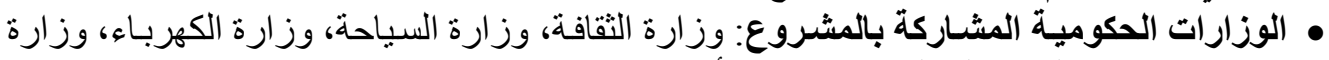

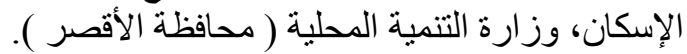

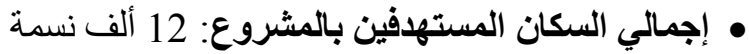

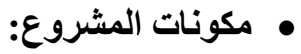

قطساع الإسكان: 1800 وحدة سكنية (تم تنفيذ 600 وحدة فقط) + 2200 قطعـة أرض (تم تجهيز ها لمن لا ير غب الإن بوحدات سكنية) • مباني خدمية: مدرسة تجريبية ابتدائي إعدادي، مدرسة لونة ابتدائية للغـات، مدرسـة ثانويـة، سوق

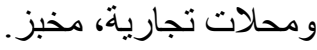

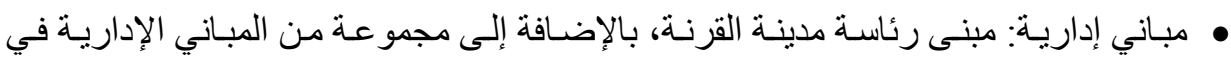
قطاعات مختلفة. • مباني ترفيهية: مجمع ثقافي ( مسرح، وسينما، ومكتبة )، ومبنى مركز شباب، وملعب خماسي. • البنية الأساسية: شبكات مياه، وصرف صحسي، وفيك وغاز طبيعي، و المباني اللازمة لها. 
ويوضح الثكل رقم 20 الموقع العام للطارف الجديدة.

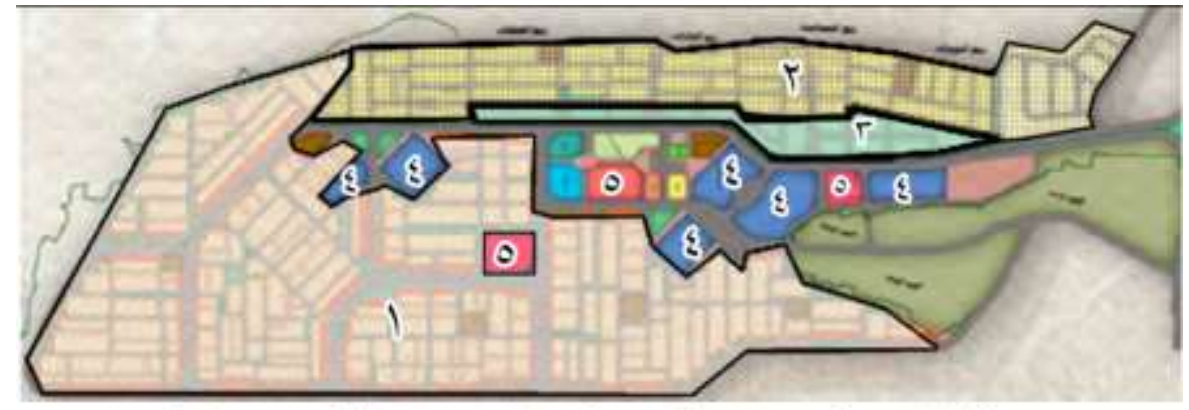

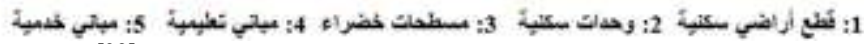

شكل (20): الموقع العام لمشروع الطارف الجديدة [32]

• إعادة توطين السكان من القرنة القديمة وترميم المنطقة التي تم إخلائها، و إعادة توظيف قريتين اثتتين من القرى

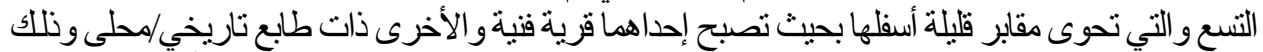

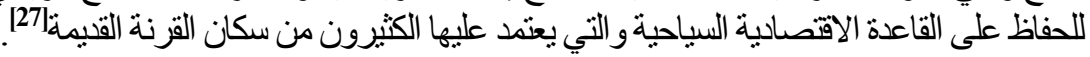

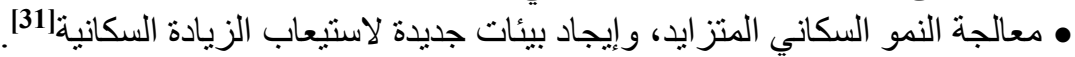

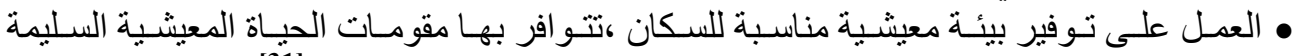

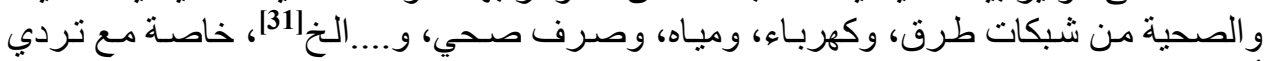

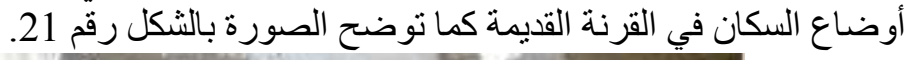

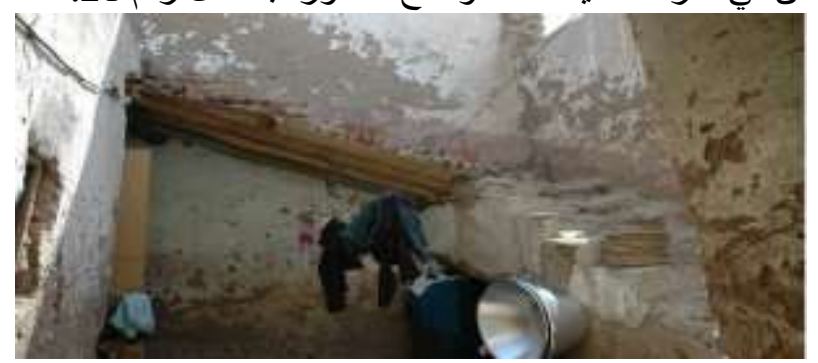

شكل (21): صورة لتردي حالة المساكن في القرنة [29]

• تدعيم كافة أوجه النظام السياحي عن طريق التتمية البيئية من أجل الحفاظ على الموارد الأثرية و الثقافية

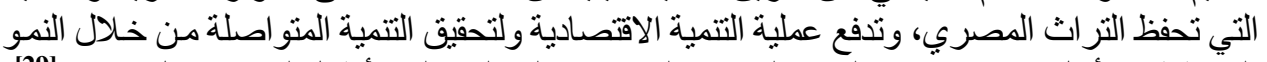

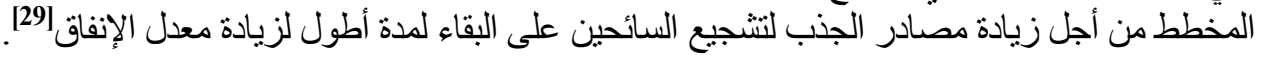

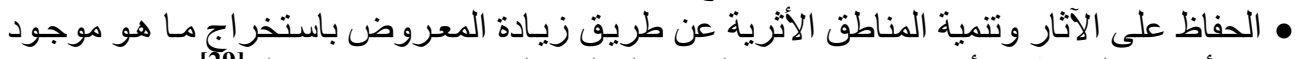

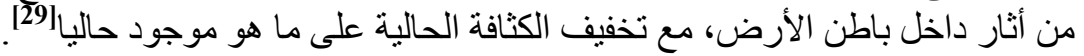

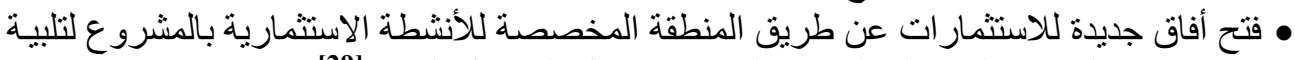

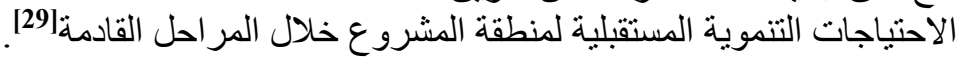

$$
\begin{aligned}
& \text { 3.3. المسكن في مشروع الطارف الجديبة. } \\
& \text { 1.3.3 مكونات المسكن: }
\end{aligned}
$$

طبقا لتقرير مركز المعلومات واتخاذ القرار بمحافظة الأقصر فقد تم وضع التصميم في مشروع الطسارف

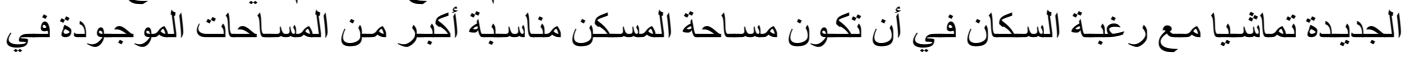


تصميمات التجارب السابقة في تهجير سكان القرنة[30]، ويوضح شكل 22 المسقط الأفقي للوحدة السكنية، وقد

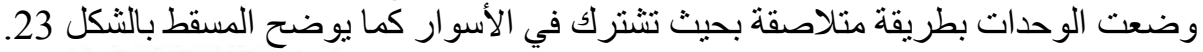

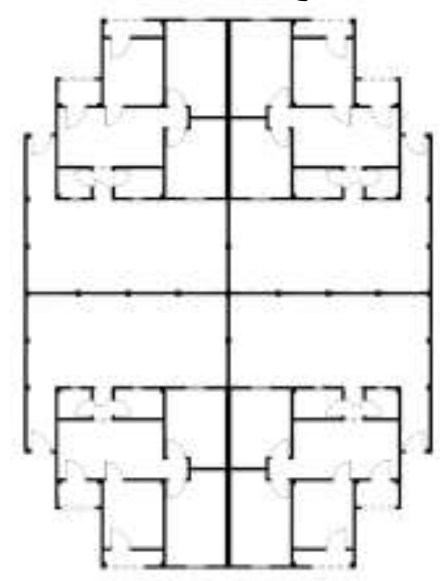

شكل (23): مسقط أفقي للبلوك بالطارف الجديدة (المصدر الباحث)

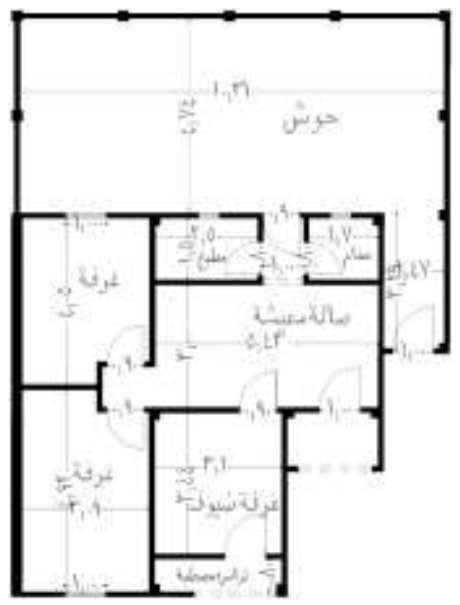

شكل (22): مسقط أفقي مسكن الطارف

الجديدة (المصدر الباحث) (22) مانطي

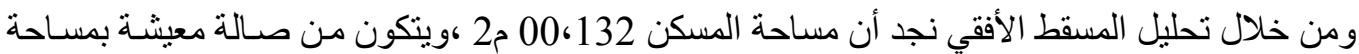

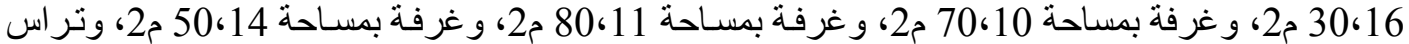

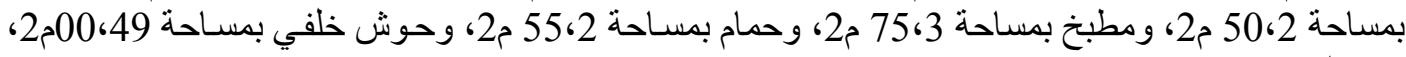

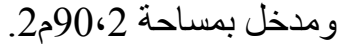

وتوضح الصور بالأشكال أرقام 24، 25 شكل المسكن من الداخل ومن الخارج.

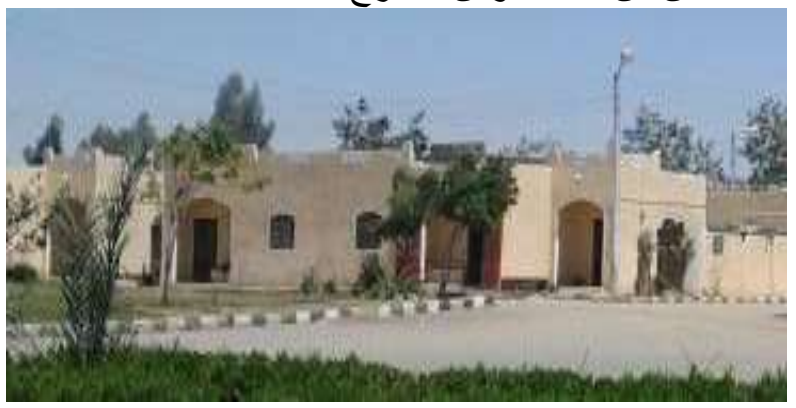

شكل (25): صورة من خارج مسكن الطارف الجديدة[25]

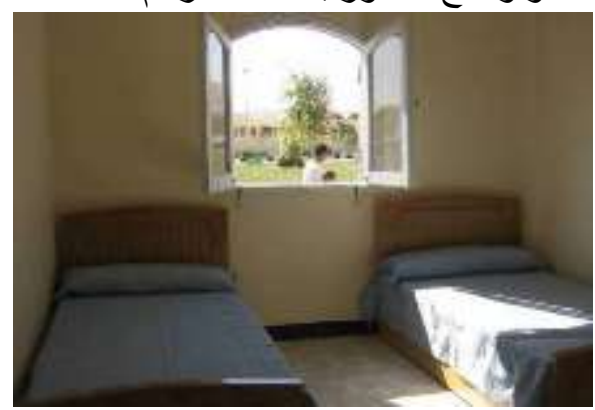

شكل (24): صورة من داخل مسكن

الطارف الجديدة]

2.3.3 العلاقات الوظبفية في المسكن: من خلال تحليل العلاقات الوظيفية للتصميم يتضح الونيف: الأتي: • احتوى المسكن على ثلاث مداخل المدخل الأول من الثـار ع الرئيسي إلى الحوش، و المدخل الثاني

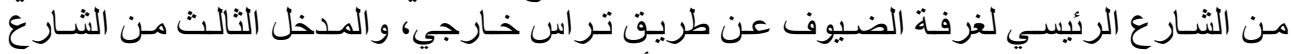

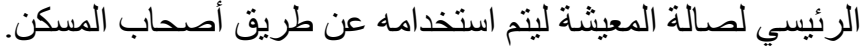

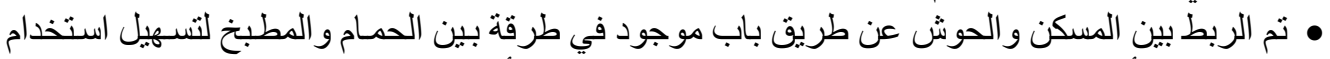

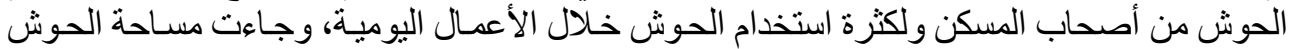
كبيرة نوعا ما حيث تبلغ أكثر من ثلث مساحة المسكن لكي يتسع لعدد من النشاطات المختلفة. 


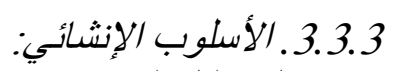

من خلال تحليل العناصر الانثشائية المستخدمة في المسكن يتضح الأتي:

• استخدم النظام الهيكلي عن طريق العناصر الخرسانية المسلحة.

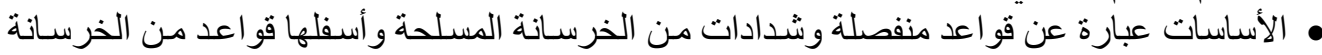

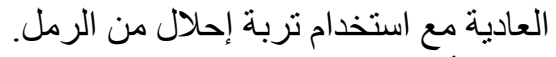

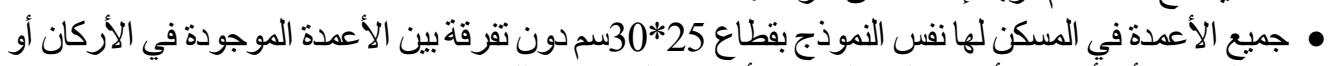

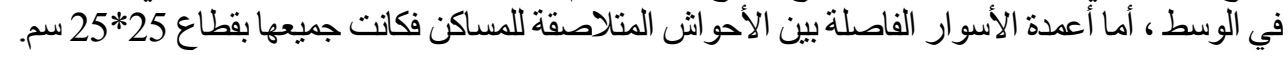

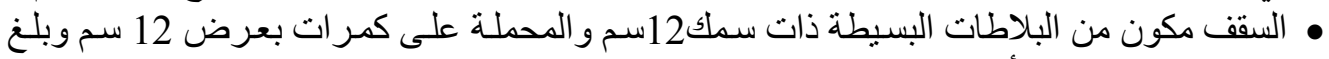

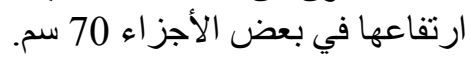

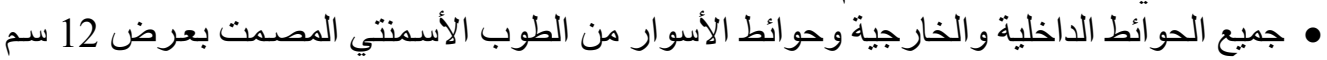
فيما عدا الحائط المشترك بين كل مسكنين الذي كان بعرض 25 سم.

\section{4. تقييم ما بعد الإشغال لمساكن الطارف الجديدة:}

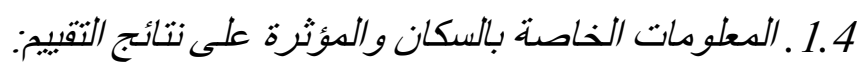

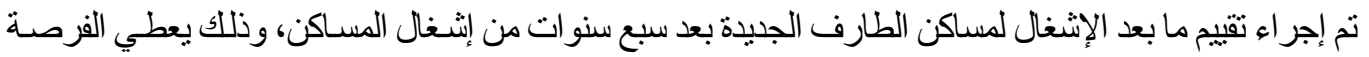

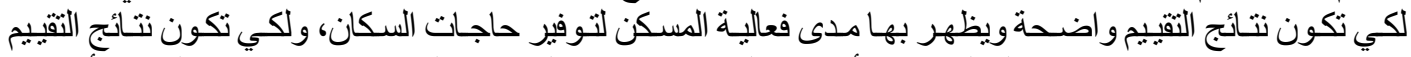

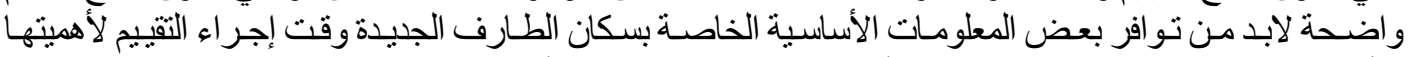

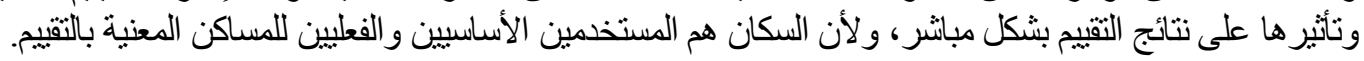

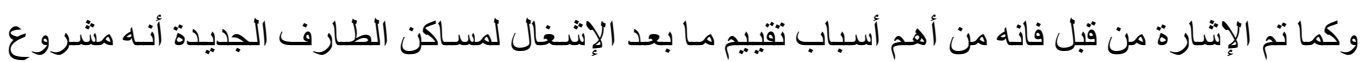

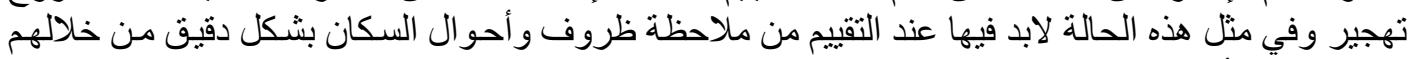

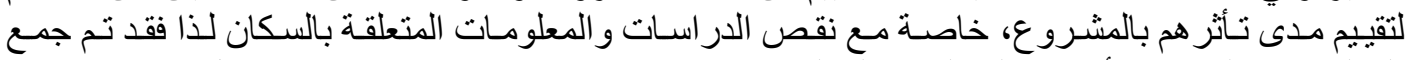

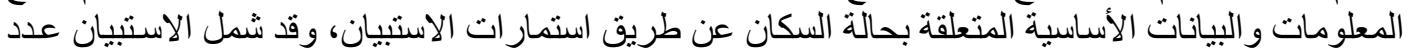

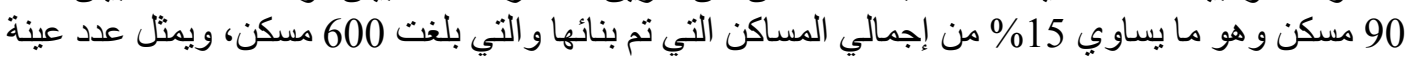

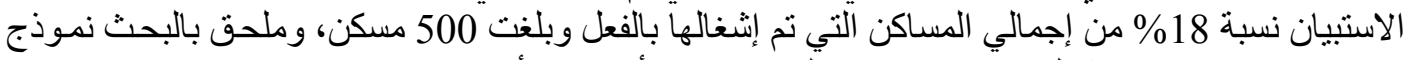

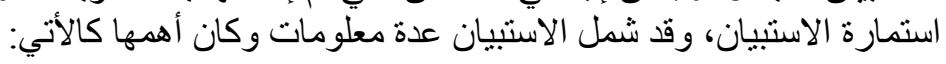

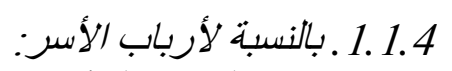

• الشريحة العمرية لأرباب الأسر: بلغت نسبة من هم في سن العمل 86،8\%؛ بينما من هم في سن

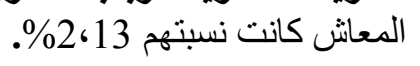

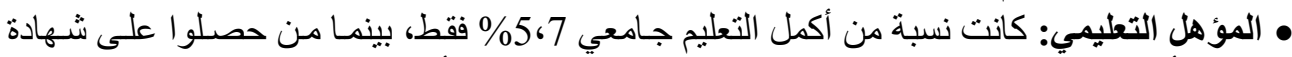

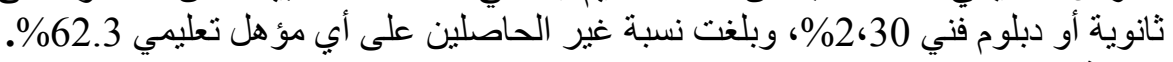

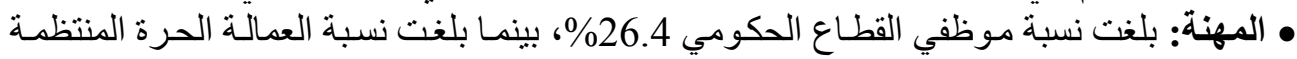

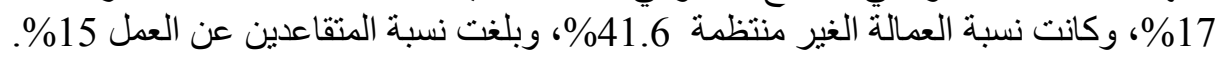

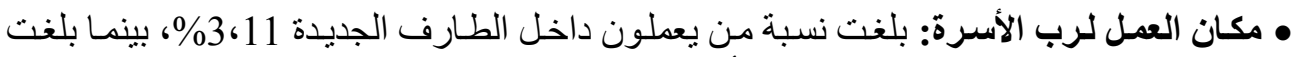

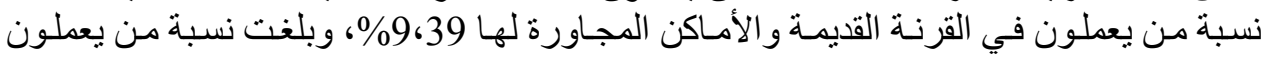

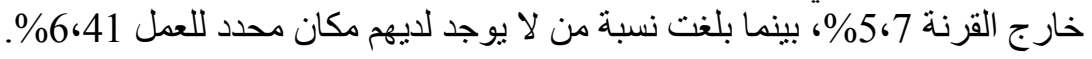

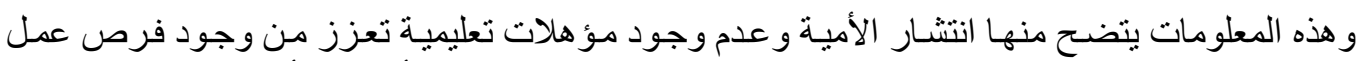

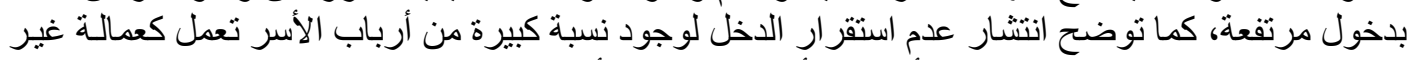
منتظمة، كما يتضح ارتباط الكثير من أرباب الأسر في مزاولة لونة أعمالهم بالقرنة القديمة. 
2. 2.4. بالنسبة لأفراد الأسر:

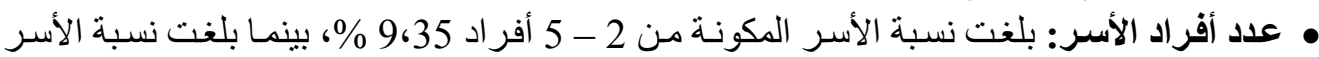

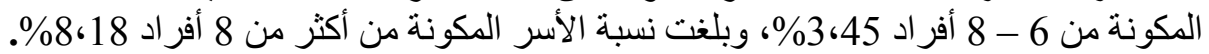

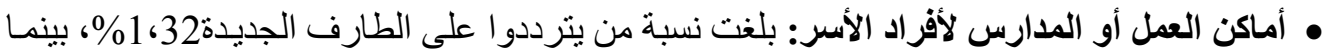

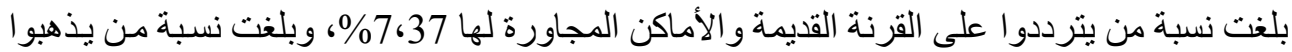
خارج القرنة 15، \% \%، وبلغت نسبة من لا يو جد لليهم مكان للعمل أو الدر اسة 15، 15\%.

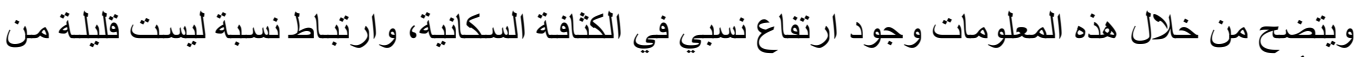
أفر اد الأسر بالقرنة القديمة.

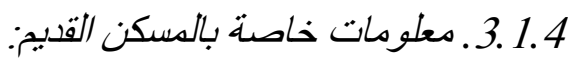
يقصد بالمسكن القديم المسكن قبل التهجير إلى الطارف الجديدة وقد جاءت نتائج المعلومات الخاصة به كالأتي:

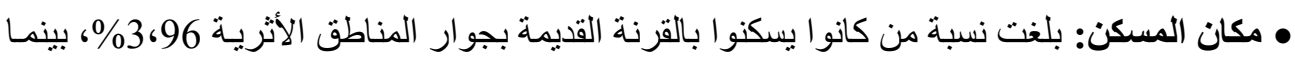

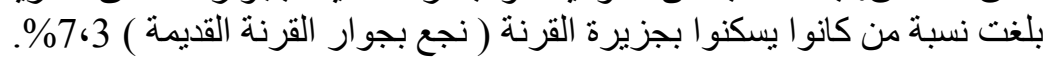

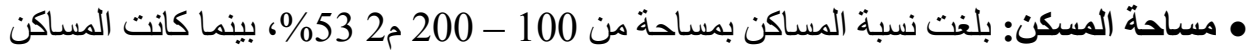

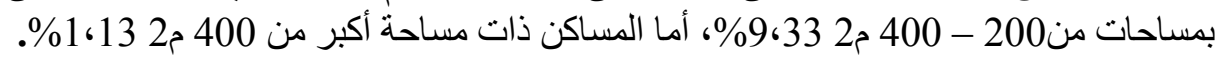

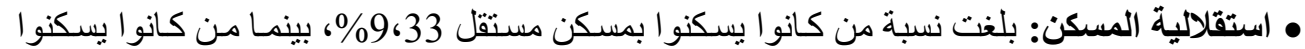

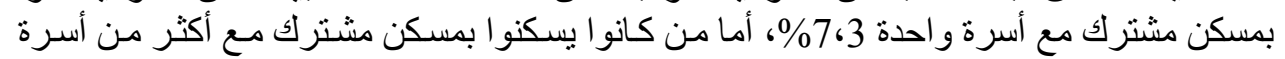

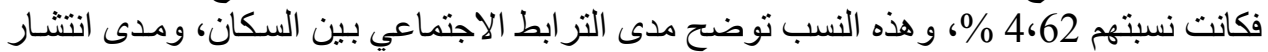
فكرة مسكن النواة الذي يمتد ليشمل العديد من الأسر.

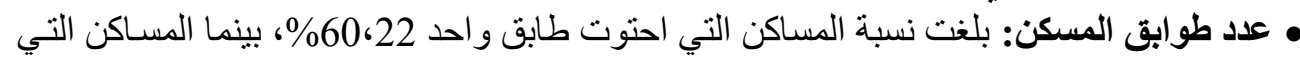

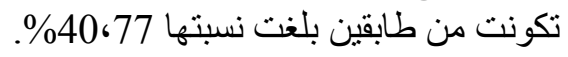

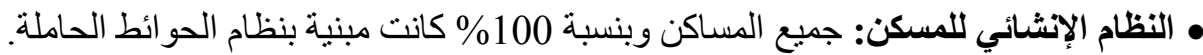

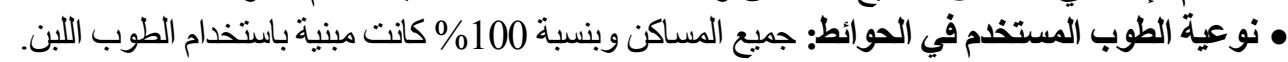

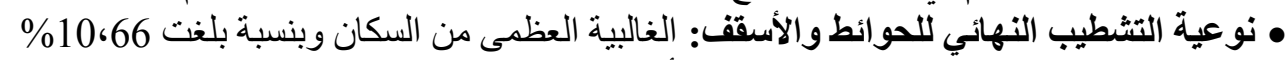

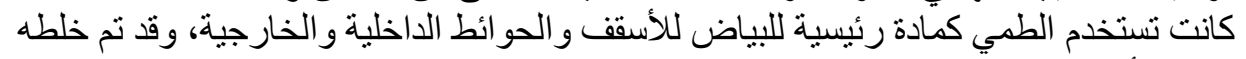
بالرمل أو القش الناعمب(التبن).

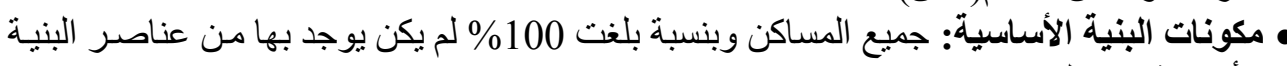
الأساسية سوأ الكهرباء. 2.4. نتائج تقييم ما بعد الإشغال للعناصر المختلفة لمساكن الطارف الجديدة:

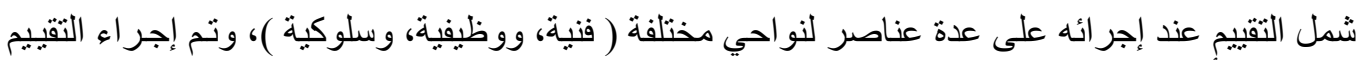

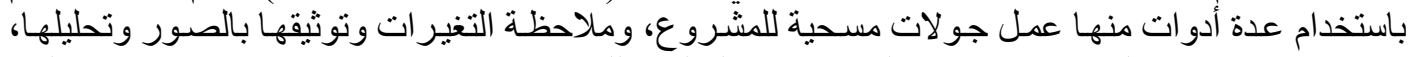

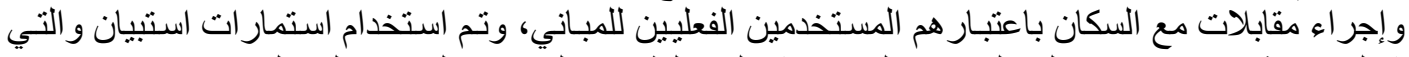

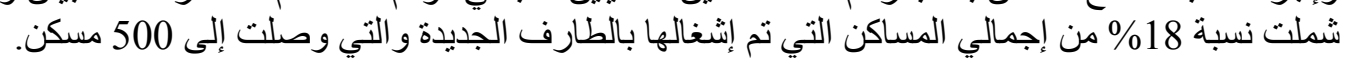
1.2.4 تقبييم العناصر الفنبة:

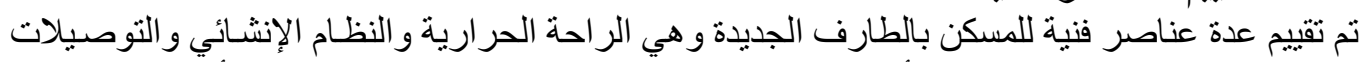

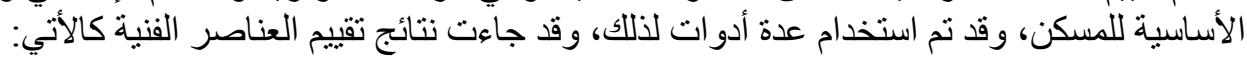




\section{أولا تقييم الراحة الحرارية للمسكن:}

تعتبر الر احة الحر ارية داخل المسكن من أهم العناصر التي تم تقييمها في مساكن الطارف الجديدة خداصـة

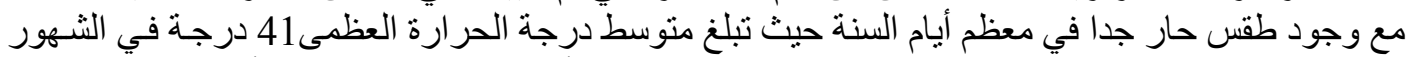

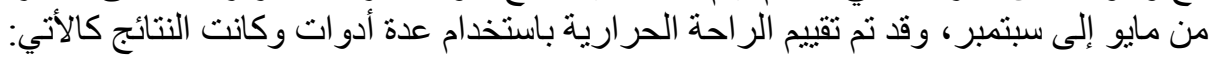

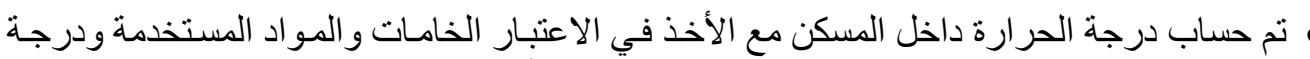

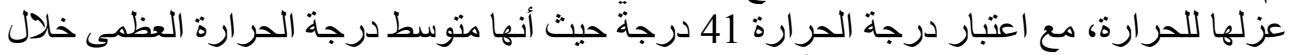

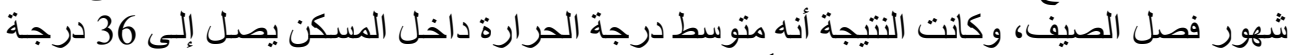

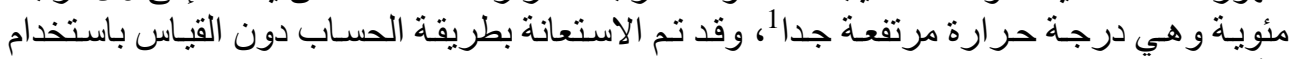

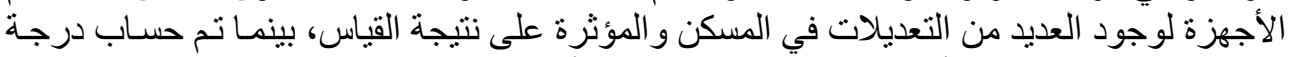

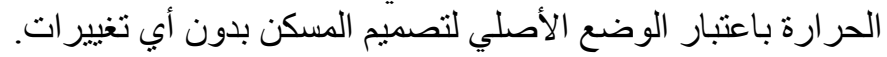

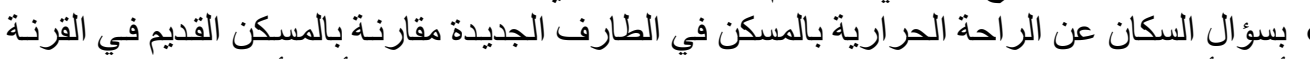

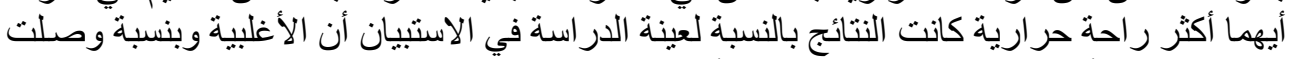

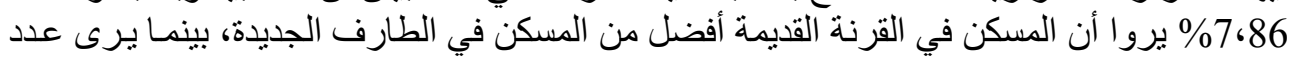

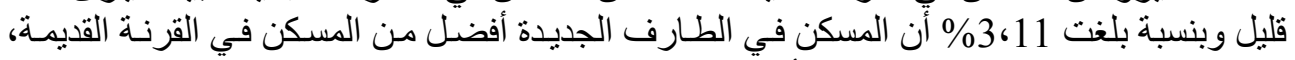

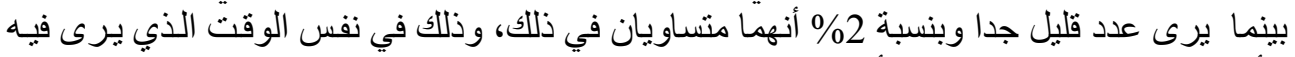

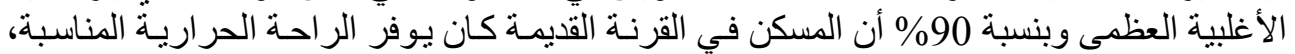

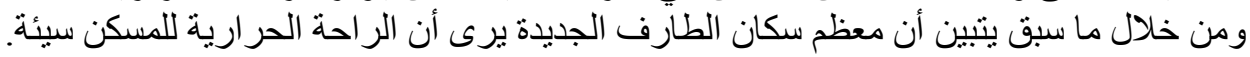

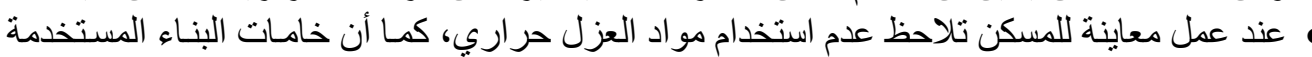

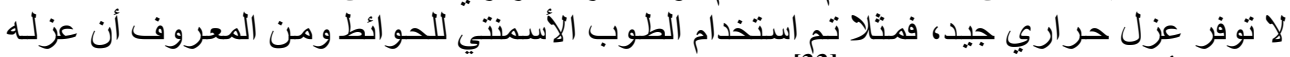

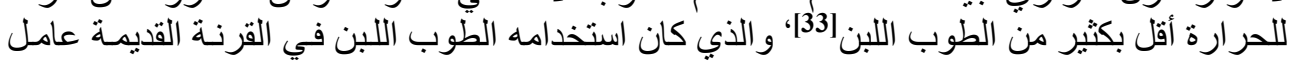

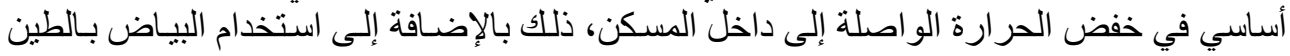

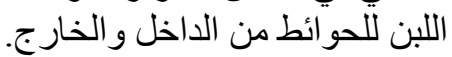

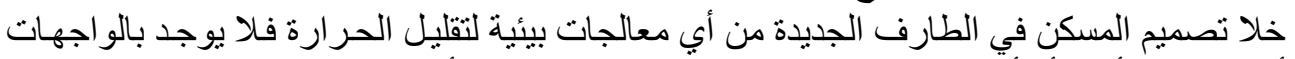

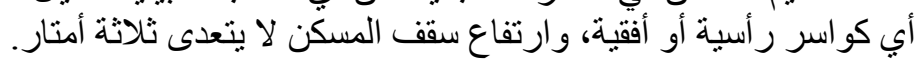

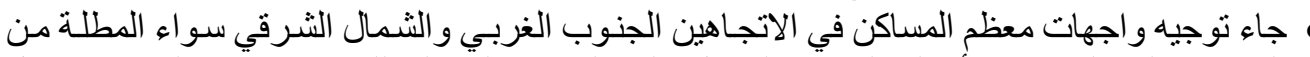

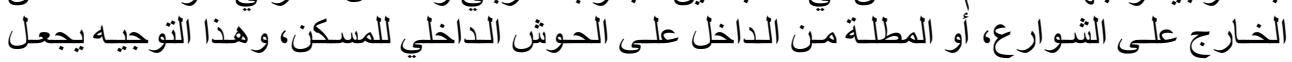

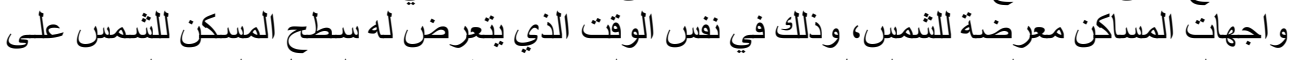

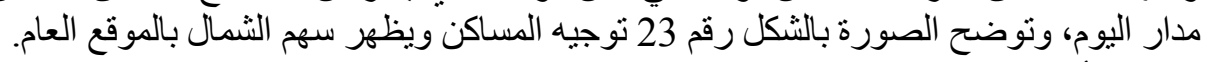

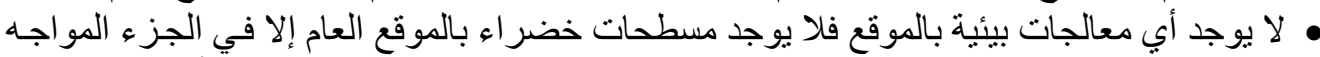

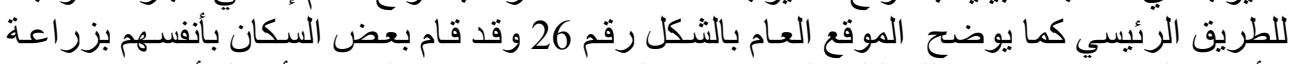

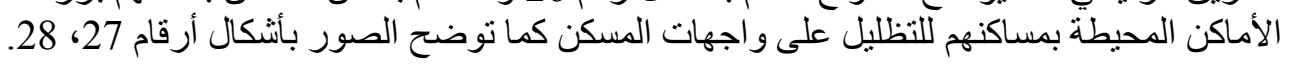

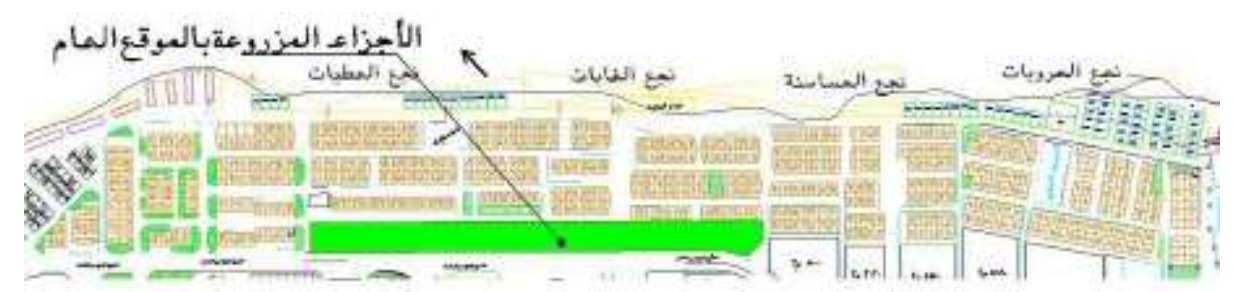

شكل (26): موقع عام لتوجيه المساكن في الطارف الجديدة

1 ـ تم الاستعانة بمهندس متخصص في تصميم التكييفات لحساب درجة الحر ارة داخل المسكن. 


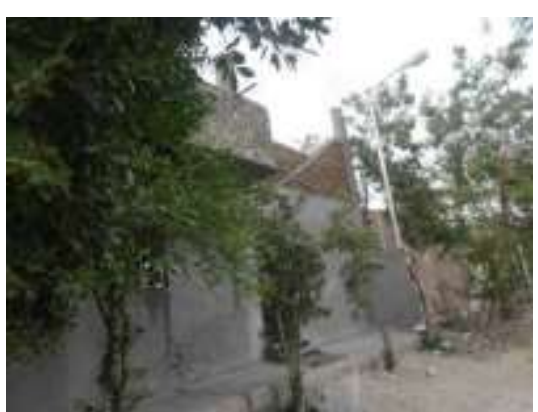

شكل (28): صورة لاستخدام الأشجار لتظليل

في مساكن الطارف الجديدة :25)

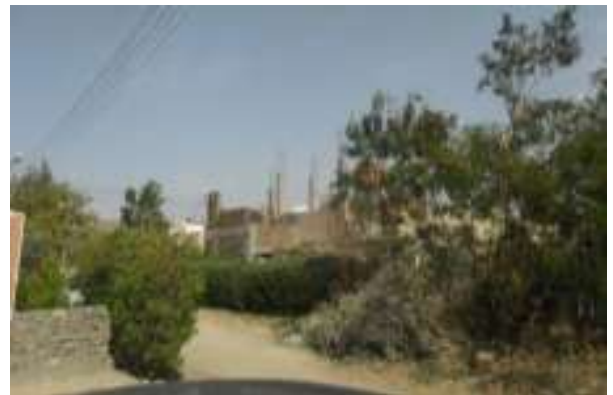

شكل (27): صورة لاستخدام الأشجار للتظليل في

مساكن الطارف الجديدة [25:

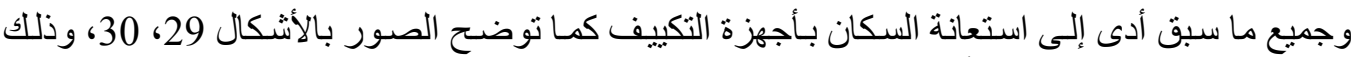

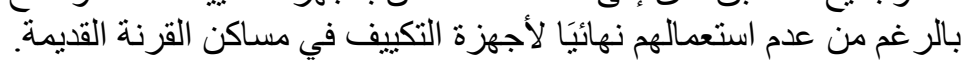

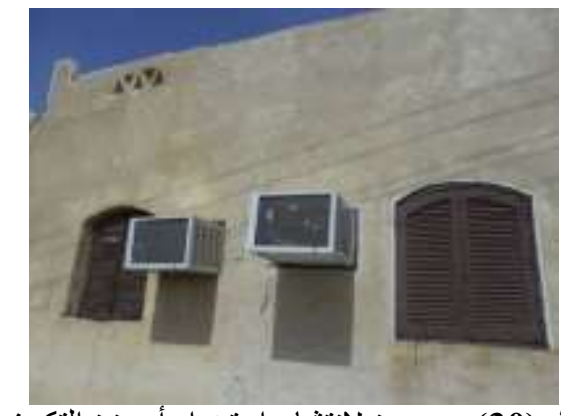

شكل (30): صورة لانتشار استخدام أجهزة التكييف

في الطارف الجديدة: [25)

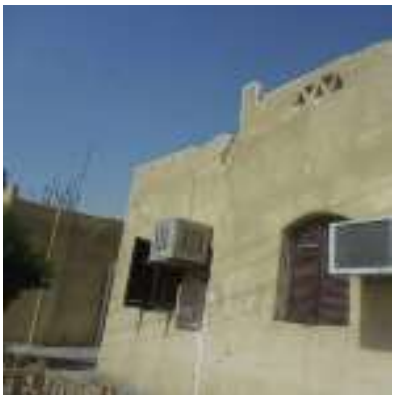

شكل (29): صورة لانتشار استخدام

أجززة التكييف في الطارف الجديدة [25:

ثانيا تقييم النظام الإنشائي والعناصر الإنشائية:

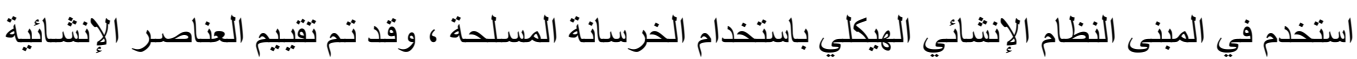

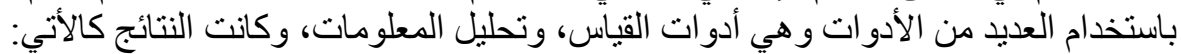

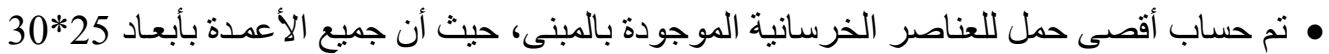

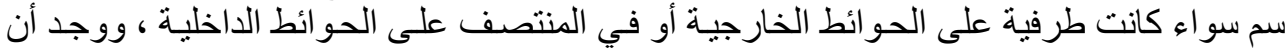

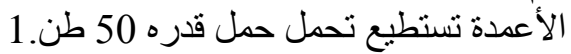

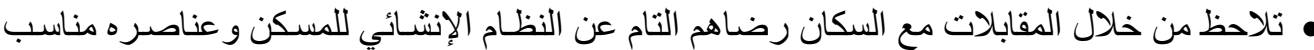

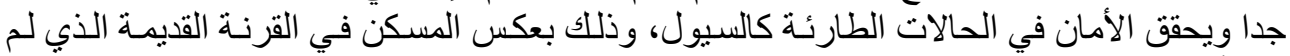

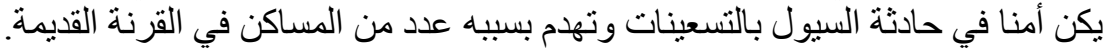

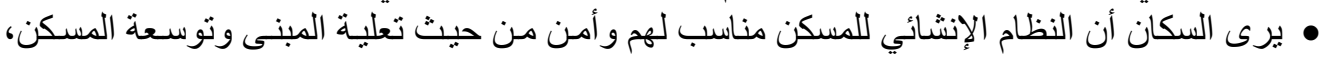

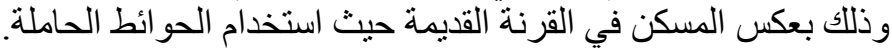

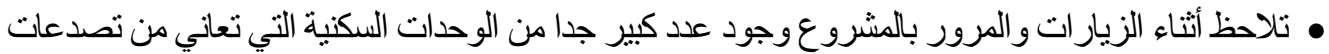

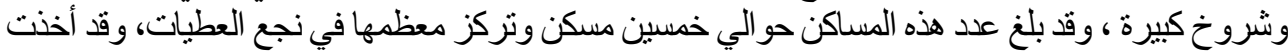

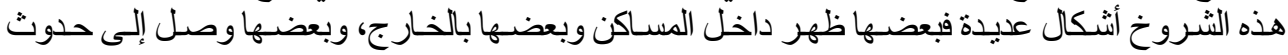


رضا محمود حمادة و محمد عبد الحمبي فاوي، تقبيم ما بعد الإشغال لمساكن الطارف الجبيدة

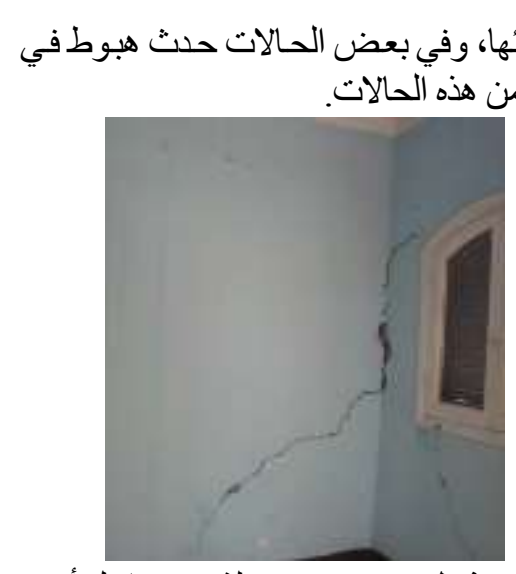

شكل (32): صورة لشروخ داخل أحد

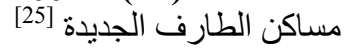

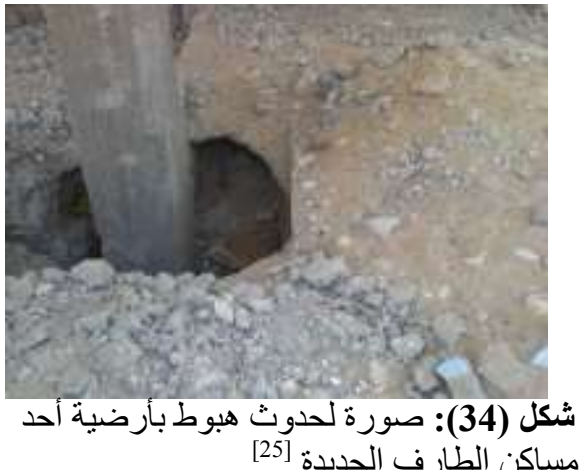

شكل (31): صورة لنروخ داخل أحد

مساكن الطارف الجديدة: [25: منورة

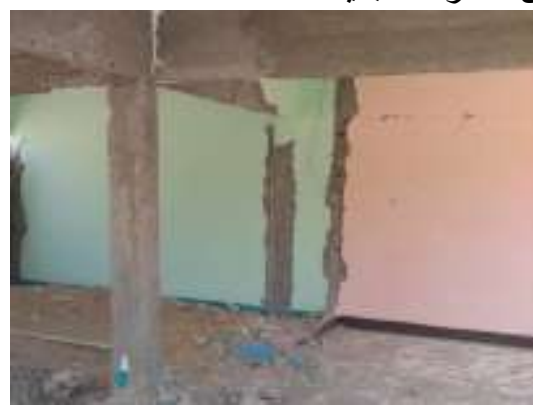

شكل (33): صورة لمسكن حدثت بهاه شروخ

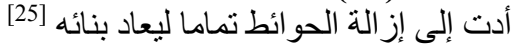

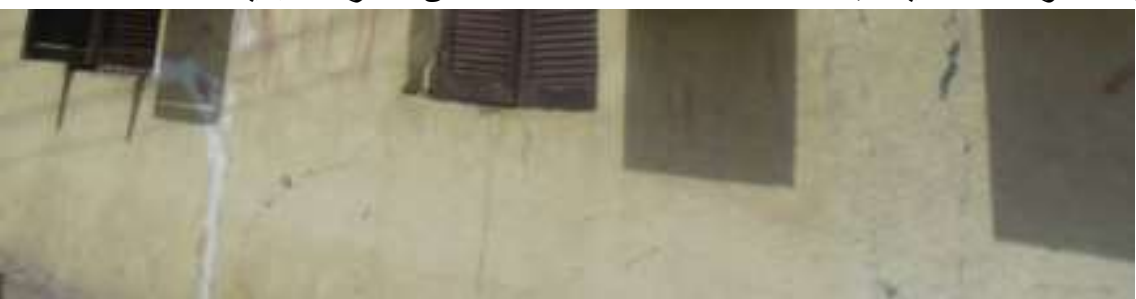

شكل (35): صورة لشروخ خارجية بأماكن مختلفة بأحد المساكن [25]

ومن خلال الصور التي تظهر الشروخ نجد أنها تأخذ شكل مائل بزاوية 45 وتنتشر حول الفتحات، وهذه وهذه

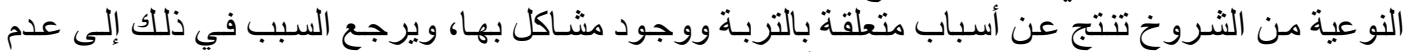

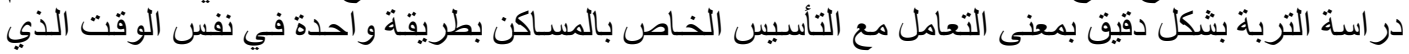

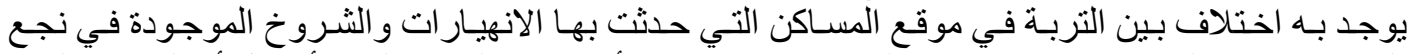

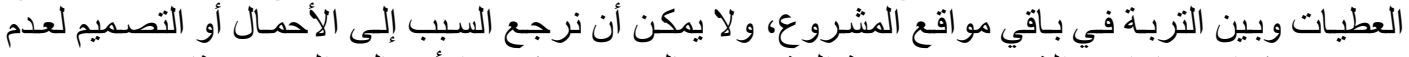

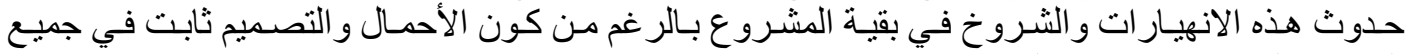

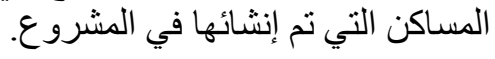

\section{ثالثا تقييم توصيلات المياه:}

يعتبر إمداد شبكات الميـاه في الطـارف الجديدة أحد أهم المميز ات في مسكن الطـارف الجديدة بالنسبة

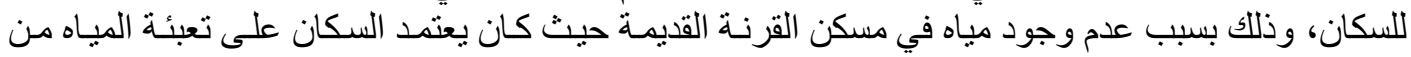


خارج منطقة سكنهم بالجبل ونقلها إلى مساكنهم كما توضح الصور بالأشكال 36، 37، وقد سبب ذلك المعاناة

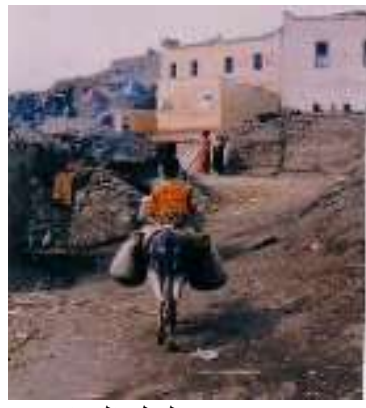

شكل (37): صورة لنقل المياه

بالدو اب في القرنة القديمة [30) وصعوبة المعيشة في القرنة القديمة.

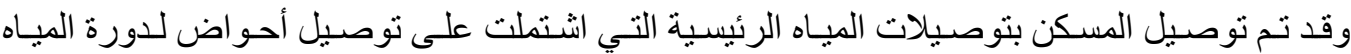

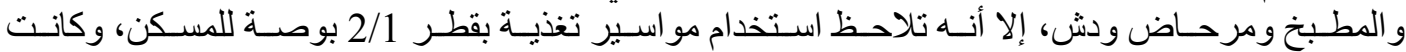
التوصيلات تشمل خطوط تغذية بـاردة فقط، وبعد استخدام المسكن وجد السكان أن تلك التوصيلات لم تكن

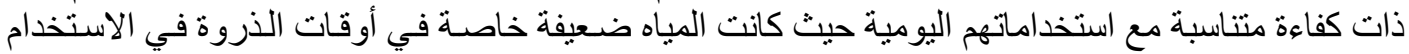

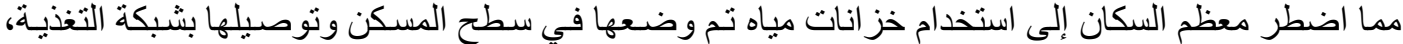

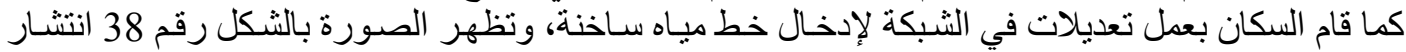

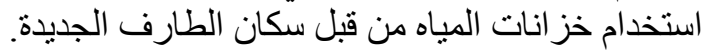

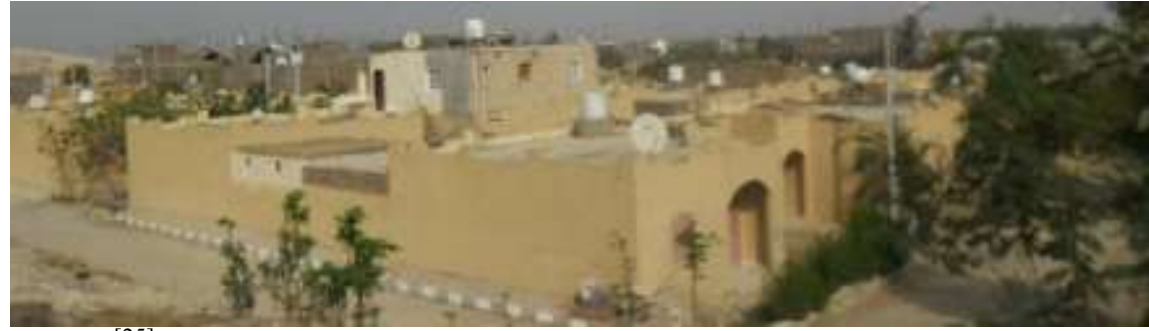

شكل (38): صورة لانتشار استخدام خزانات المياه في الطارف الجديدة [25]

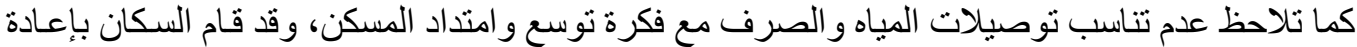

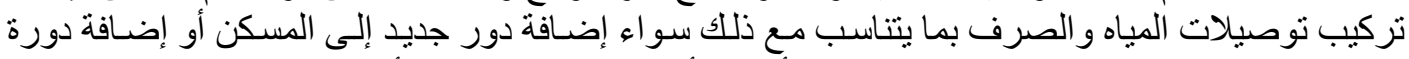

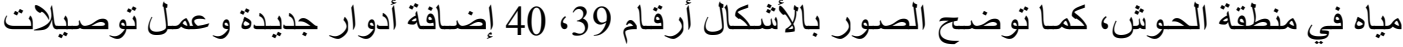

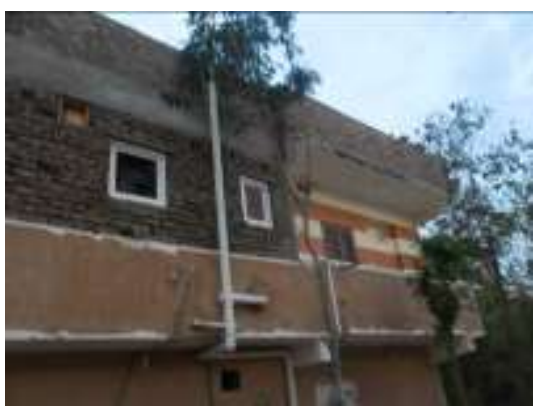

شكل (40): صورة لإضافة توصيلات

[25] لتنتاسب مع تعلية الأدوار (40)

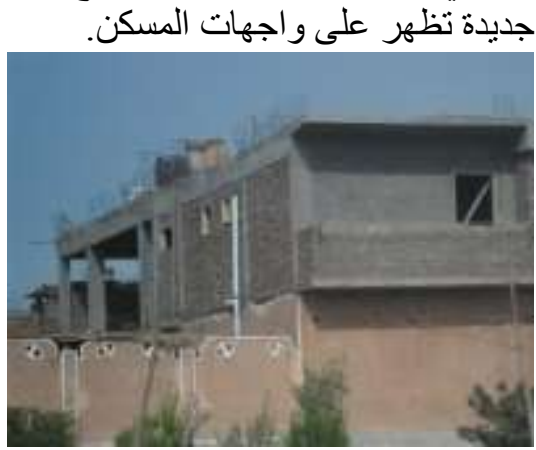

شكل (39): صورة لإضافة توصيلات

لتنتاسب مع تعلية الأدوار [25) 
رضا محمود حمادة و محد عبد الحمبل فاوي، تقبيم ما بعد الإشغال لمساكن الطارف الجديدة

ومما سبق يتضح أن توصيلات المياه و الصرف بمسكن الطسارف لم تكن متتاسبة مـع استخدامات السكان

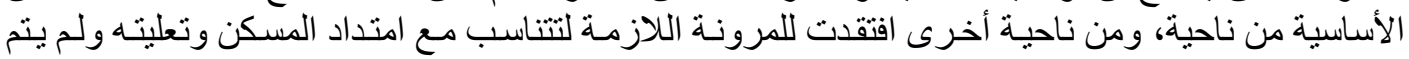

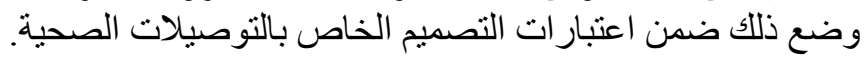

2.2.4 تقبيم العناصر الوظبفية:

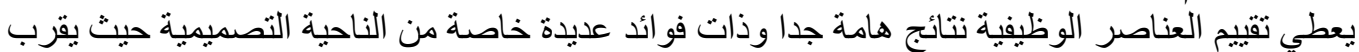

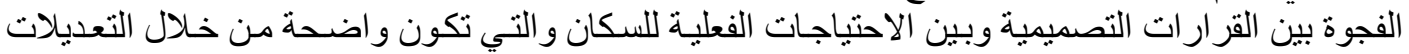

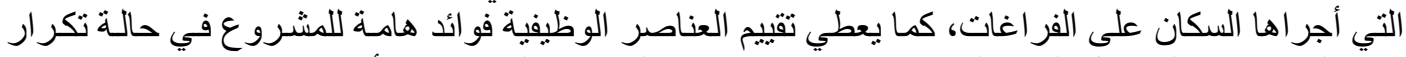
تنفيذ المسكن في المر احل المستقبلية، وقد كانت نتائج تقييم العناصر الفئي الوظيفية كالأتي:

\section{أولا تقييم مساحة المسكن:}

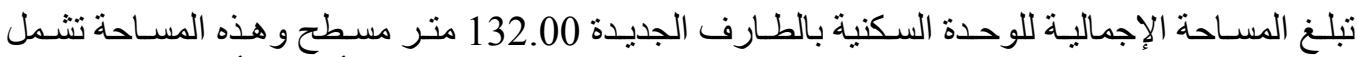

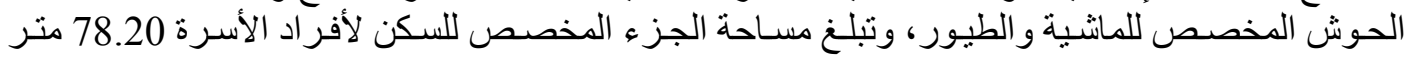

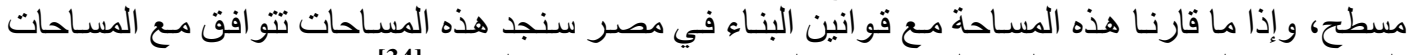

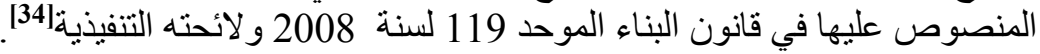

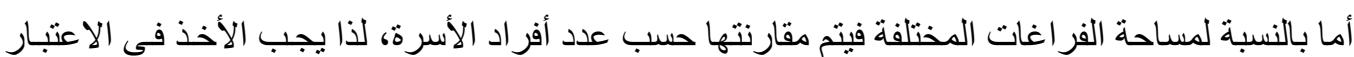

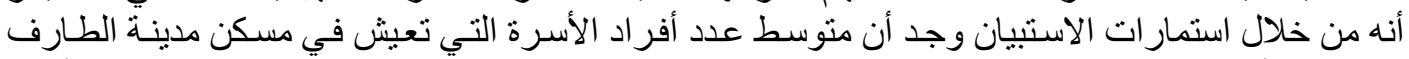

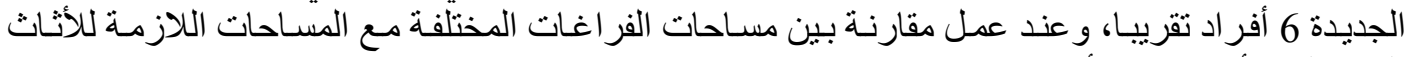
الكافي لستة أفر اد نجد الأتي:

• بالنسبة لصالة المعيشة فان مساحتها في مسكن الطارف الجديدة 16،30 متر مسطح، و هذه المسـاحة

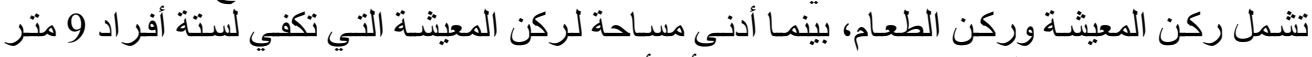

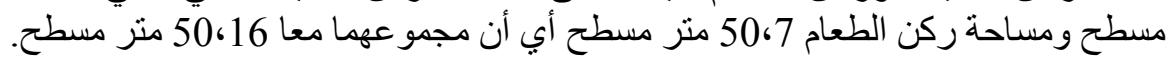

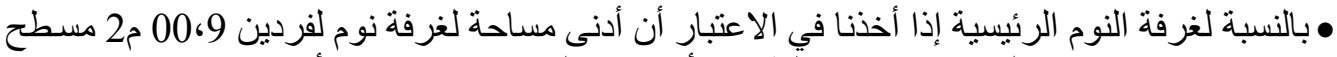

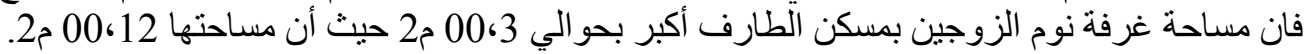

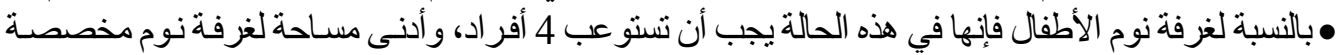

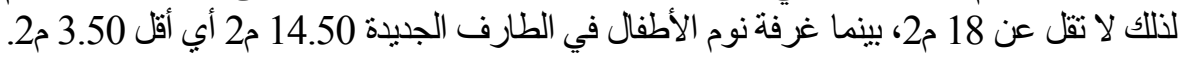

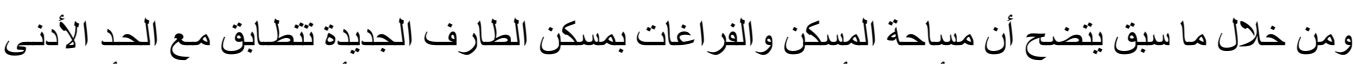

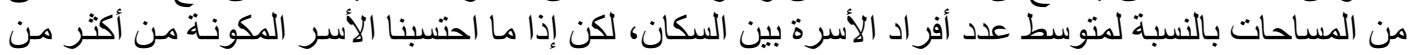

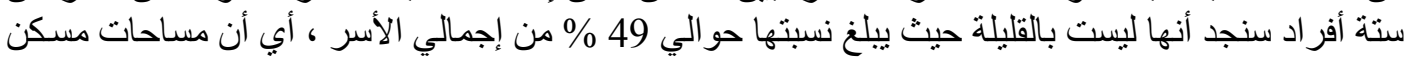

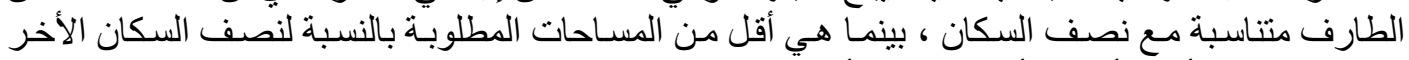
والذين يبلغ عدد أفر اد أسر هم أكثر من سنة أفر اد.

و النتيجة السابقة لتقييم المساحات باستخدام المقارنـة تتطابق إلى حد كبيـر جدا مـع نتيجـة التقيهم باستخدام الاستبيانات الذي تم إجرائه على عينة الدراسة وكاته بانت نتائجه كالأتي:

• يرى 41.5 \% من السكان من عينة الاستبيان أن مساحة مسكن الطارف أفضل من مساحة المسكن في القرنة القديمة. • يرى 5.7 \% من السكان من عينة الاستبيان أن مساحة مسكن الطارف الجديدة متساوية مع المسكن في القرنة القديمة. • يرى 52.8 \% من السكان من عينة الاستبيان أن مساحة المسكن في الطارف الجديدة غير مناسبة وأن مساحة المسكن في القرنة القديمة أفضل من عن الانها. 


\section{ثانيا تقييم العوامل الإنسانية المرتبطة بالفراغات:}

من أهم العو امل الإنسانية المرتبطة بفر اغات المسكن الأنشطة الاجتماعية، والأنشطة الاقتصـادية، وقد تم

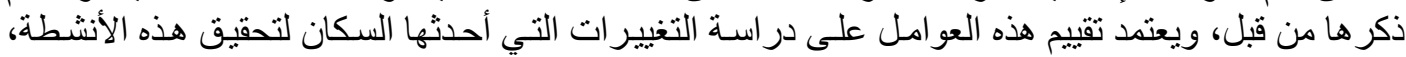

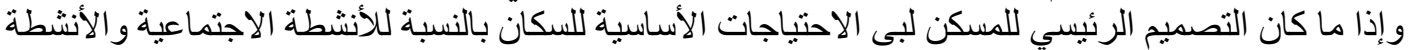

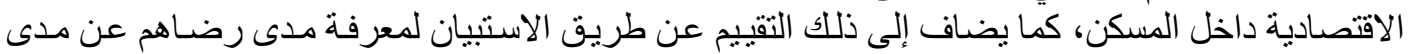
توفر هذه الأنشطة و إذا ما كان المسكن في الطارف الجي ذلفيدة قد أثنر على هذه الأنشطة سلبا أو إيجابا.

\section{بالنسبة للأنشطة الاجتماعية:}

احتوى التصميم الرئيسي للمسكن على عنصرين أساسيين لتحقيق المتطلبات الخاصة بالأنشطة الاجتماعية

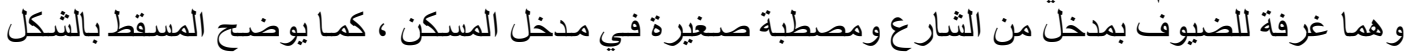

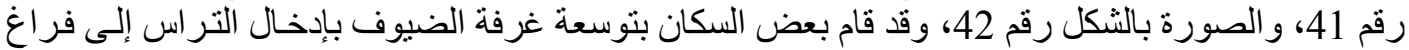

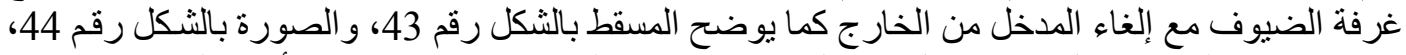

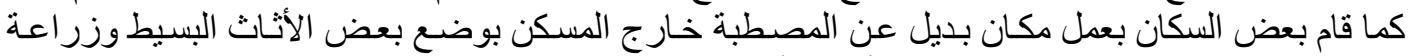
بعض المزرو عات كما توضح الصور بعل بان بائشكال أرقام 45، 46.

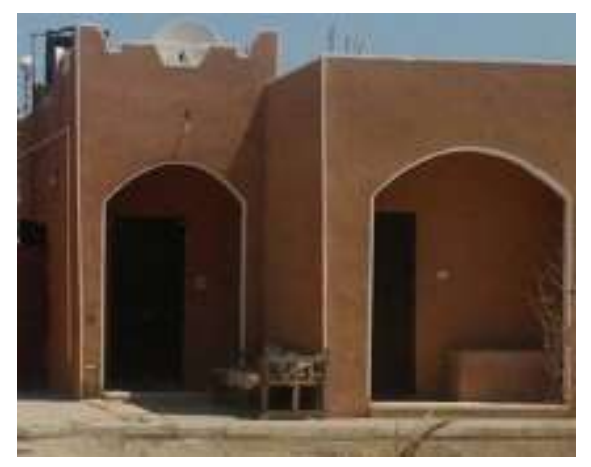

شكل (42): صورة للتر اس و المصطبة

بمسكن الطارف الجديدة [25)

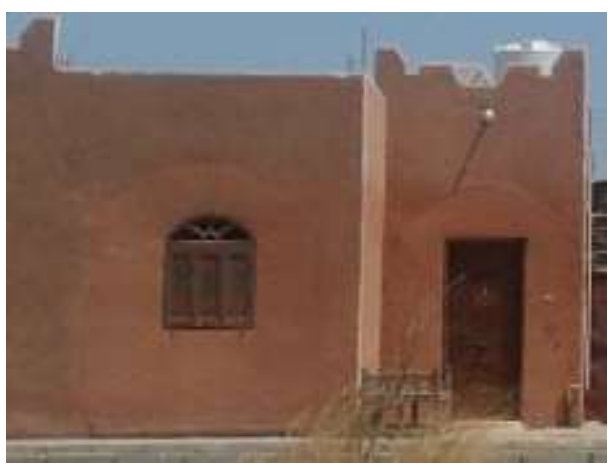

شكل (44): صورة لتوسعة غرفة الضيوف

بإضافة التر اس [25

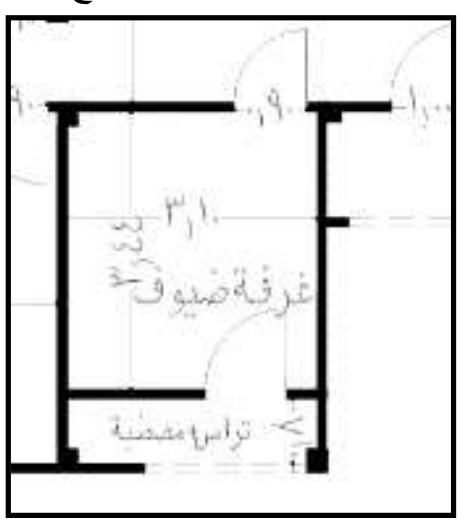

شكل (41): مسقط الجزء المخصص للأنشطة

الاجتماعية بمسكن الطارف الجديدة (المصدر الباحث)

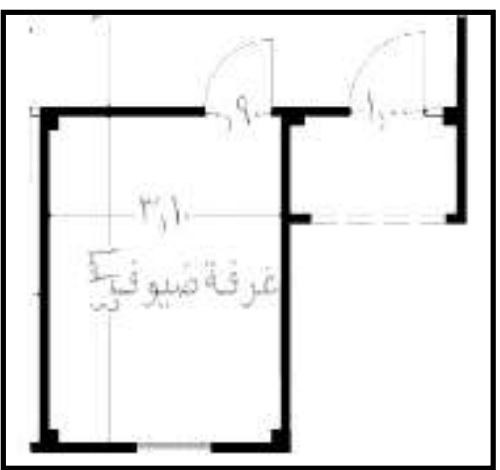

شكل (43): مسقط لتوسعة غرفة الضيوف

بإضافة التر (اس (المصدر الباحث) 
رضا محمود حمادة و محد عبد الحمبد فاوي، تقبيم ما بعد الإشغال لمساكن الطارف الجديبة

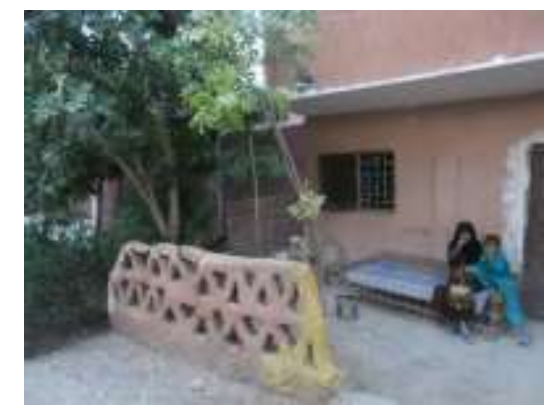

شكل (46): صورة لمكان بديل عن التر اس [25]

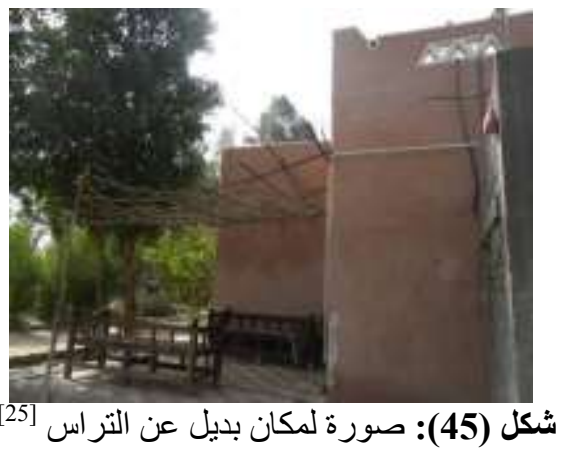

بالنسبة للأنشطة الاقتصادية:

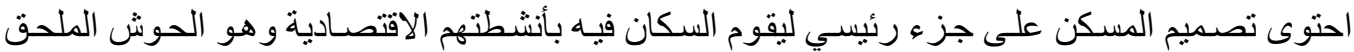

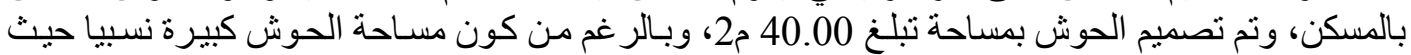

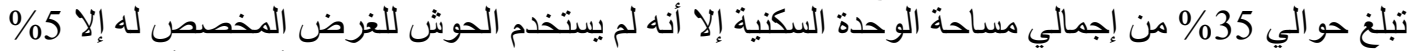
فقط من السكان، وقام الكثير من السكان بالتخلي عن تربية المو اشتي والطيوة الطيور وذللك لعدة أسباب و أهمها: • بعد المسافة بين المسكن في الطارف الجديدة والأراضي الزر اعية التي كان بزر عها السكان، حيث

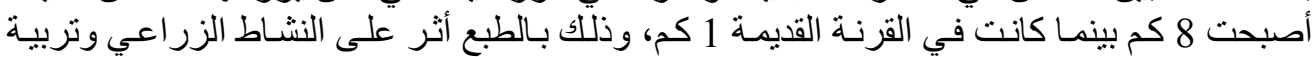
المو اشي و الطيور.

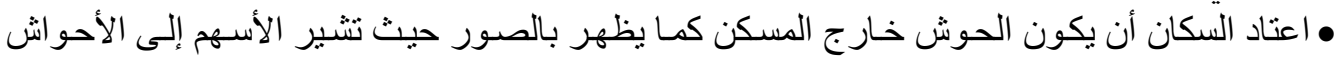

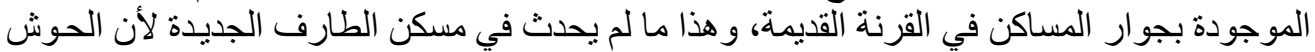

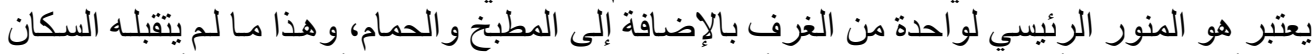

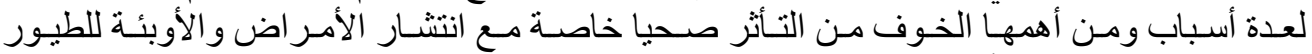

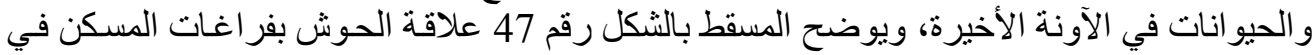

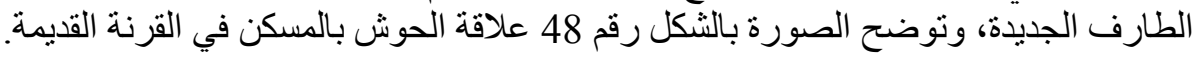

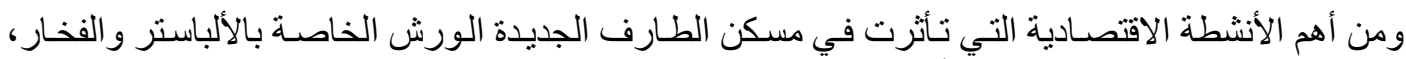

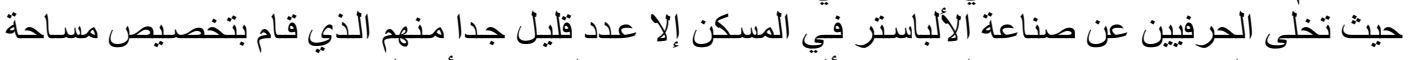
صغيرة من المسكن لإقامة ورشة لصناعة الألباستر كما توضح الصن الصور بالأشكال 52، 53.

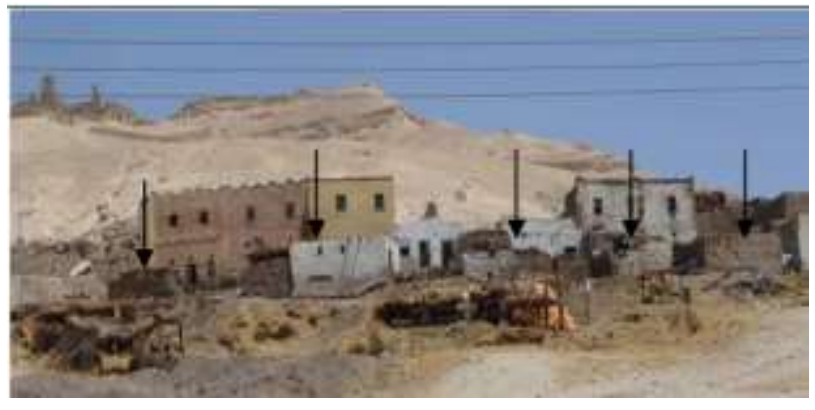

شكل (48): صورة لعلاقة الحوش بالمسكن في القرنة القديمة [30]

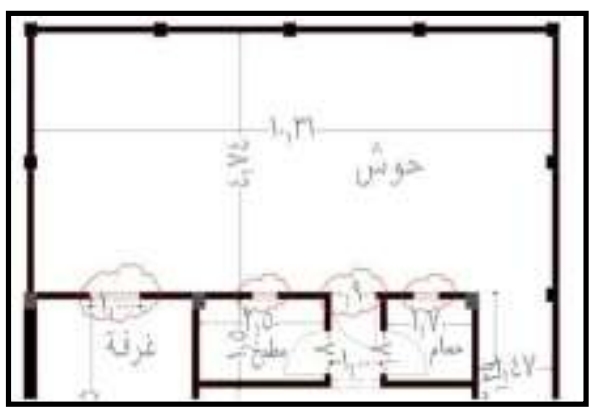

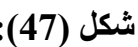

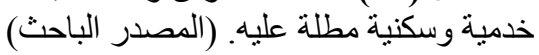

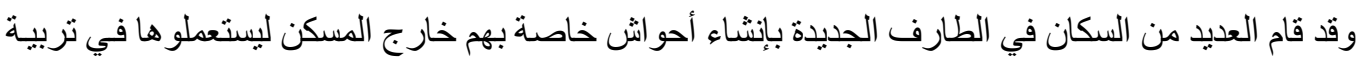

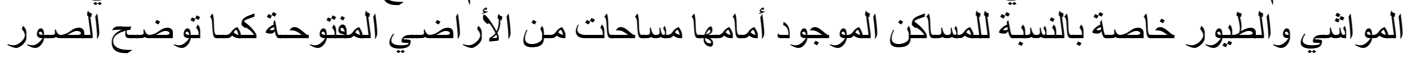




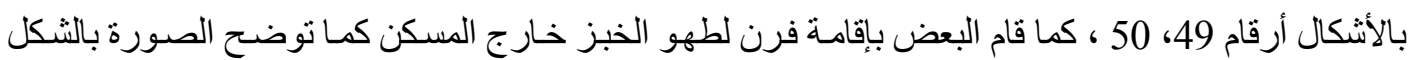

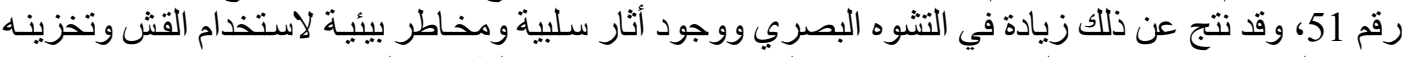

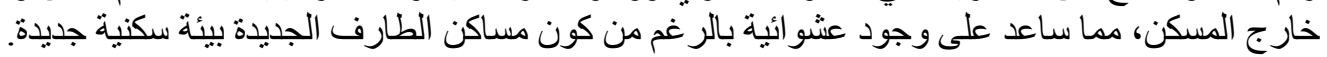

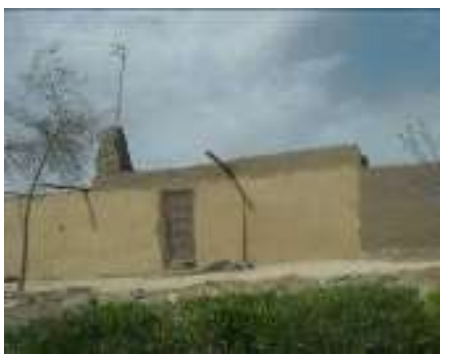

شكل (50): صورة لحوش مبني مو اجه للمسكن[25]

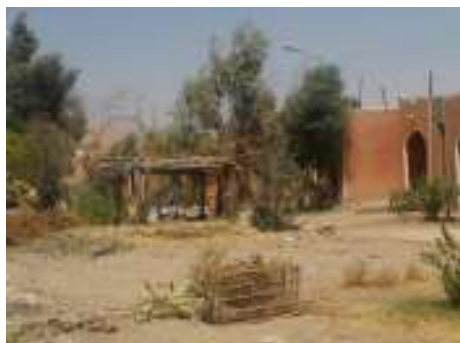

شكل (49): صورة لحوش مفتو ح مو اجه للمسكن [25]

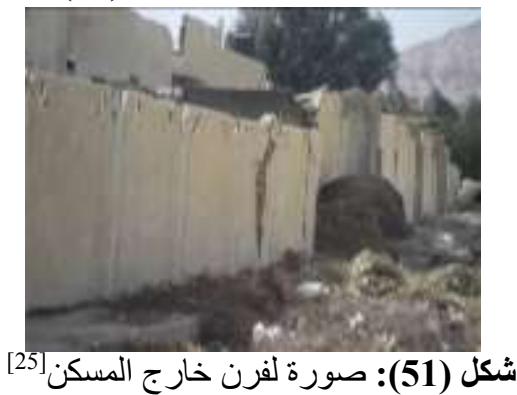

ومن الجدير بالذكر ظهور أنشطة اقتصادية جديدة لم تكن موجودة في القرنة القديمة ألا وهي عمل محلات

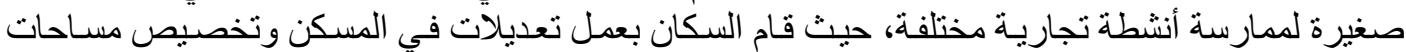

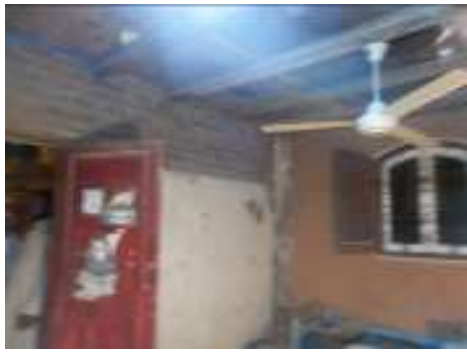

شكل (53): صورة لورشة أقامها أحد

السكان في مسكنه [25)

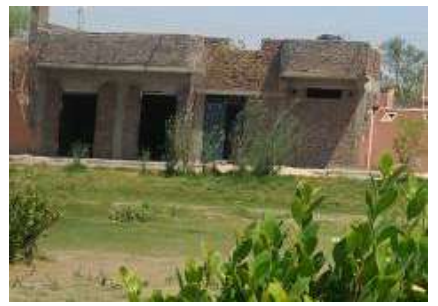

شكل (55): صورة لمسكن قام بعمل محلات تجارية[25]
كمحلات تجارية، كما توضح الصور بالأشكال أرقام 54، 55.

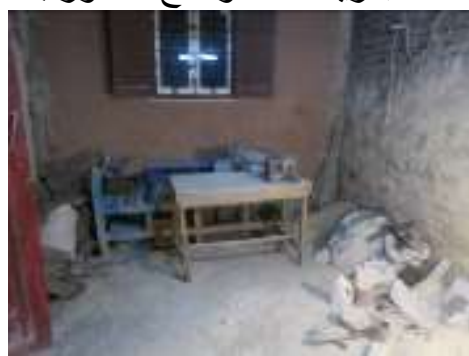

شكل (52): صورة لورشة أقامها أحد

السكان في مسكنه [25]

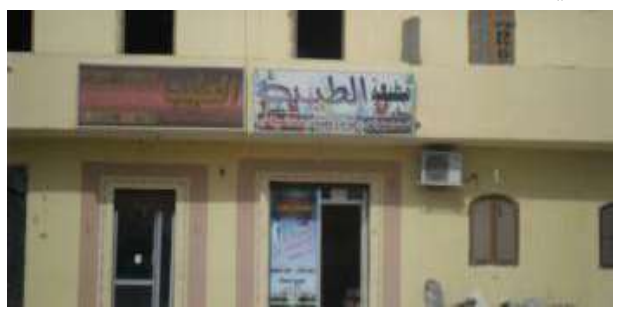

شكل (54): صورة لمسكن قام بعمل محلات تجارية[25] 
و عند عمل تقييم عن استخدامات المسكن المختلفة ومدى ملائمة فر اغات المسكن لهذه الاستخدامات مـع مقار نتها

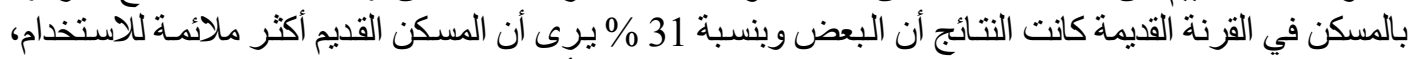

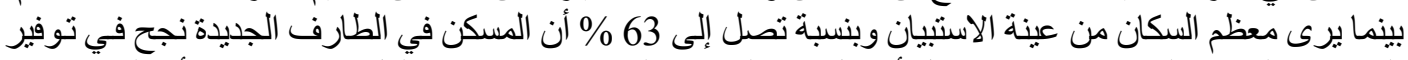

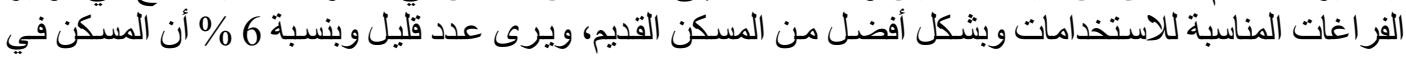
الطارف الجديدة يتساوى مع المسكن في القرنة القديمة في ملائمة الفراغات الفين للاستخدامات المنات المختلفة.

\section{ثالثا تقييم مرونة المسكن وتكيفه مع التغييرات:}

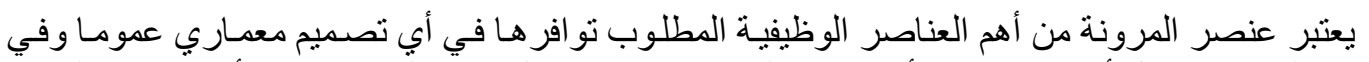

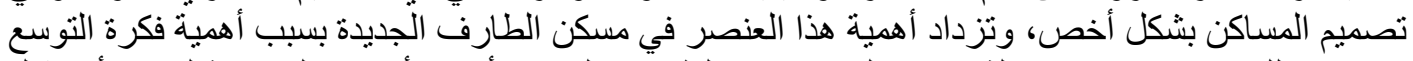

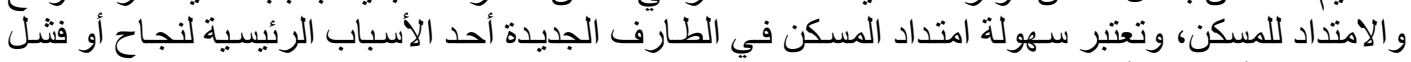

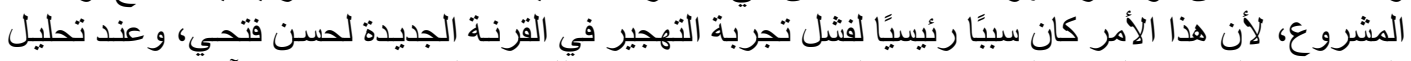

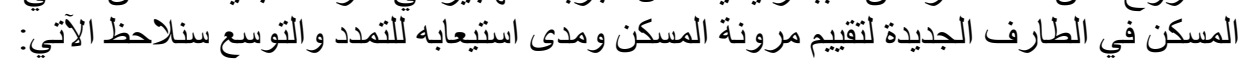

$$
\text { • خلا التصميم من وجود سلم يوصل إلى السطح. }
$$

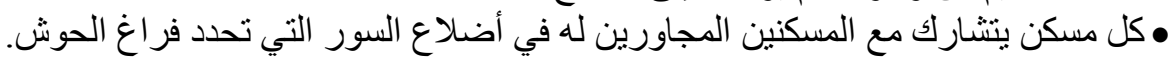

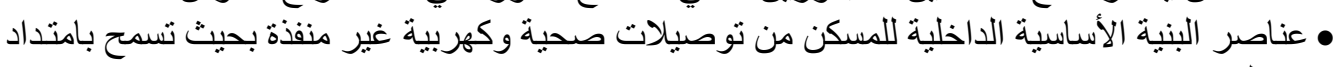
في المسكن.

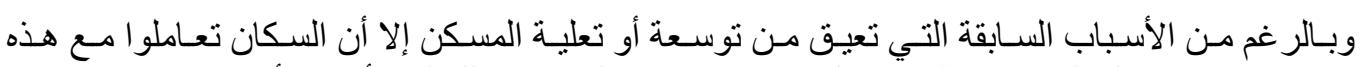

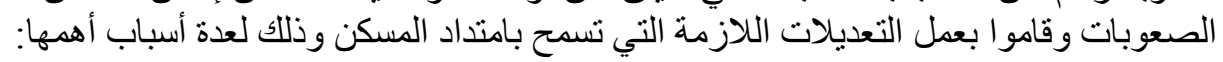

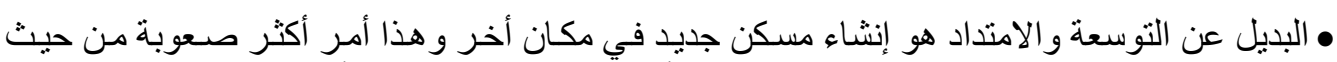

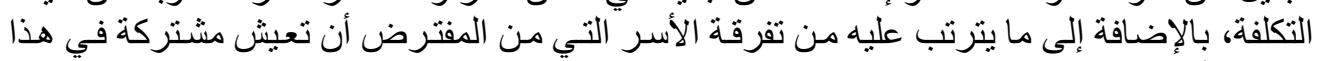

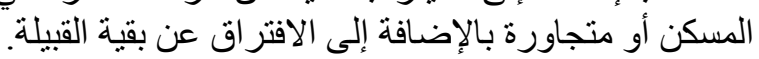

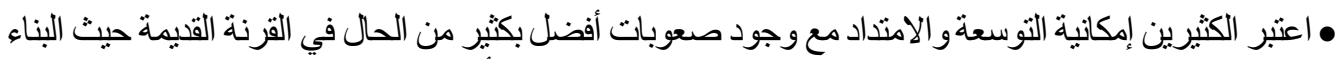

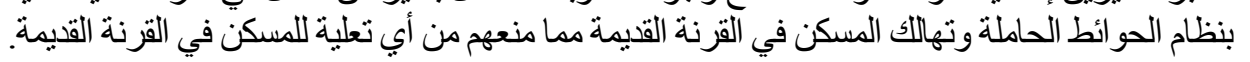

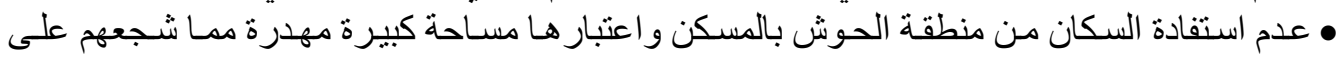
استغلالها في توسعة المسكن.

• ضيق مساحة المسكن بالنسبة للأسر التي يزيد عدد أفر ادها عن ستة أفراد، ويمثلو ا نصف السكان تقرييا.

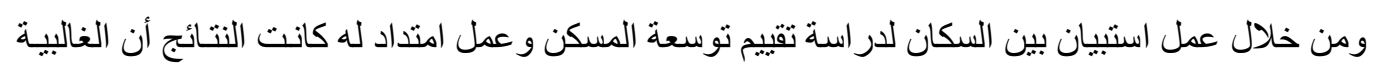

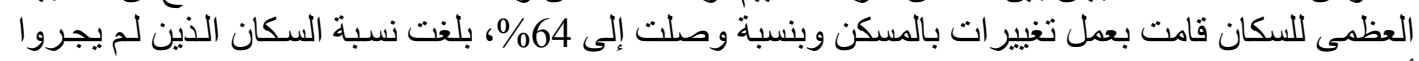

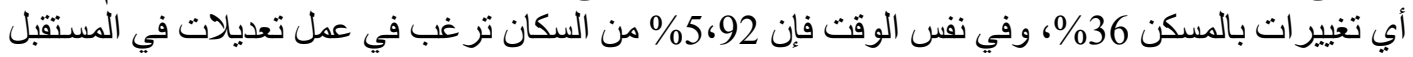
منى توفرت الإمكانيات المادية.

ومن خلال ملاحظة التغبير ات التي قام بها السكان بغرض عمل امتداد للمسكن بتضح لنا العديد من الملاحظات:

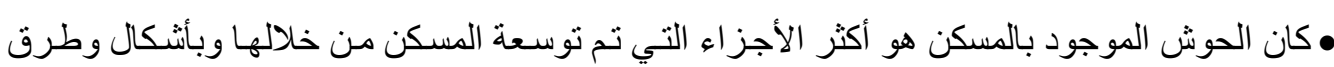

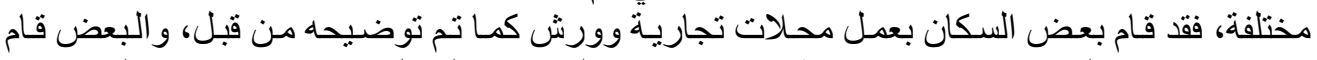

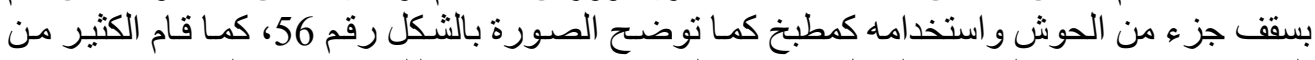

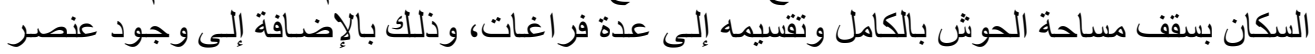

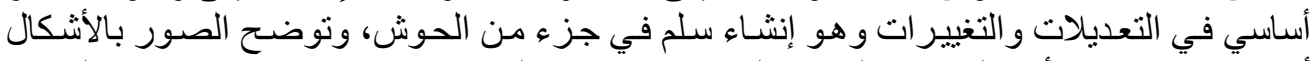

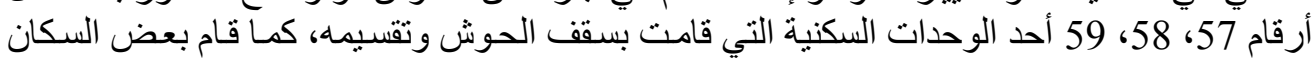



بإلغاء الفاصل بين الأحو اش ودمج مسكنين معا، وفي بعض الأحيان تم إنشاء مسكن جديد بالكامل في

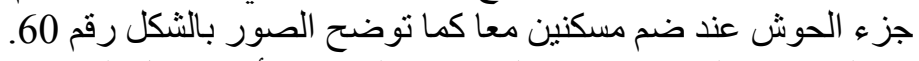

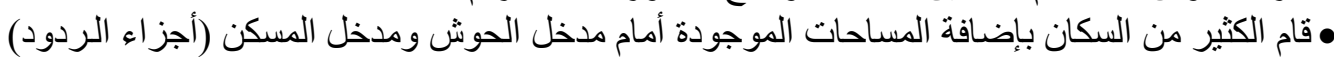

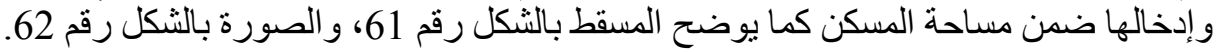

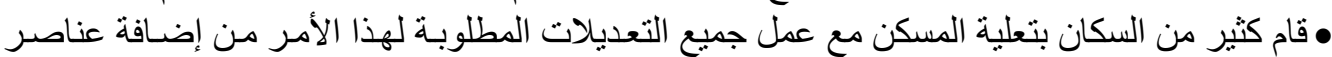

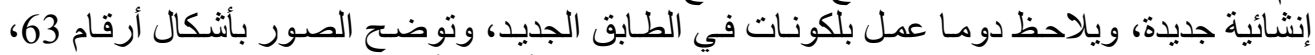

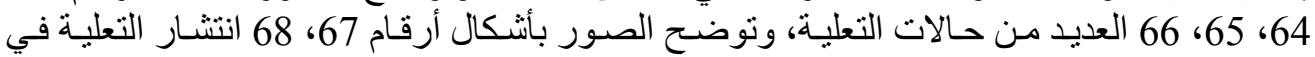
الطارف الجديدة و العشوائية الناتجة عنها.

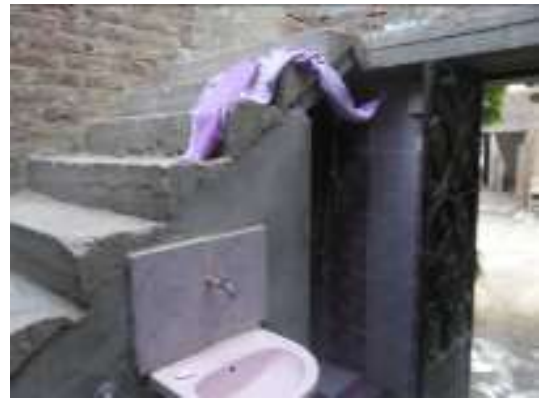

شكل (57): صورة لمسكن قام بعمل مدخل

وحمام وسلم بالحوش (25]

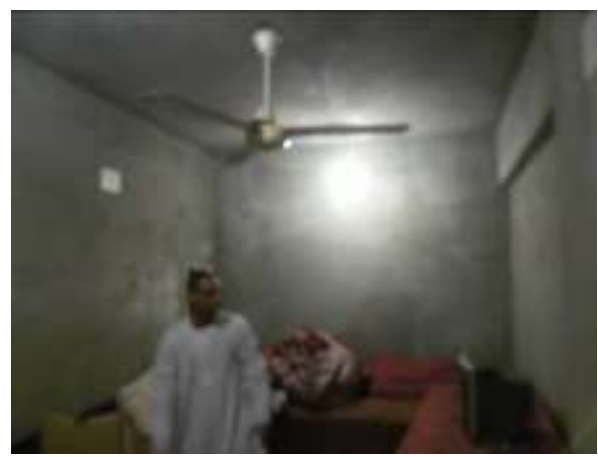

شكل (59): صورة لصالة المعيشة لنفس المسكن [25]

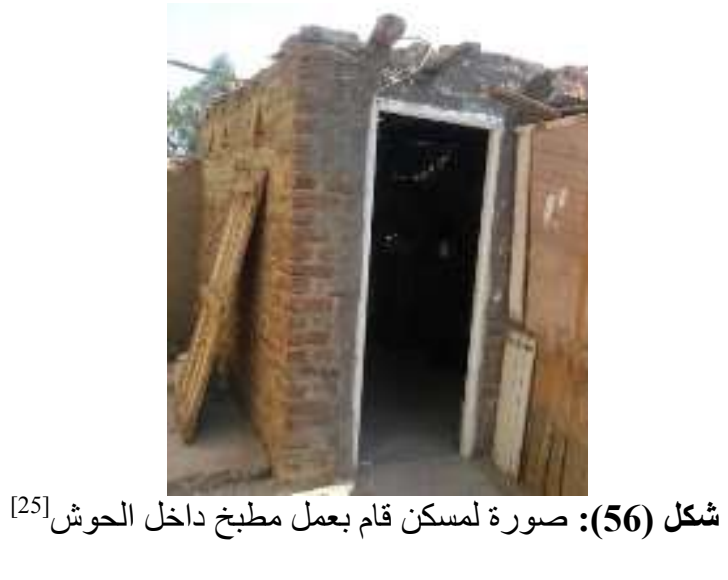

شكل (56): صورة لمسكن قام بعمل مطبخ داخل الحوش[25]

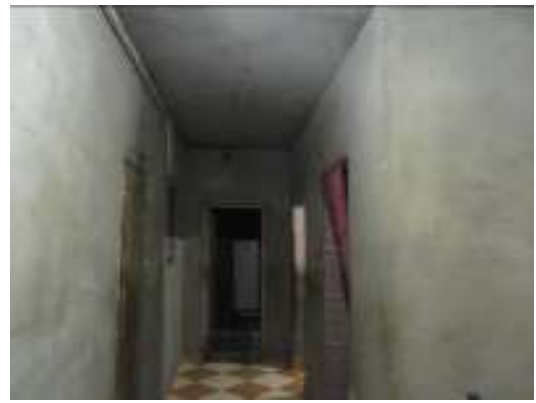

شكل (58): صورة الطرقة و الفر اغات لنفس المسكن[25]

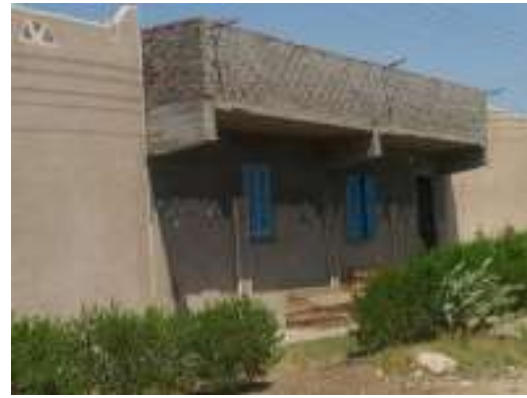

شكل (60): صورة لمسكنين أقاما مسكن في أجزاء الحوش بينهما [25] 
رضا محمود حمادة و محدد عبد الحمبي فاوي، تقبيم ما بعد الإشغال لمساكن الطارف الجديبة

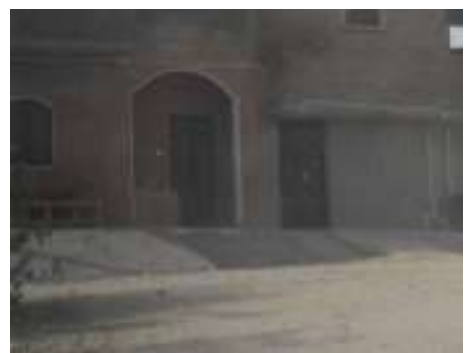

شكل (62): صورة لمسكن قام بتعديلات منها

إضافة الردود إلى مساحة المسكن [25:

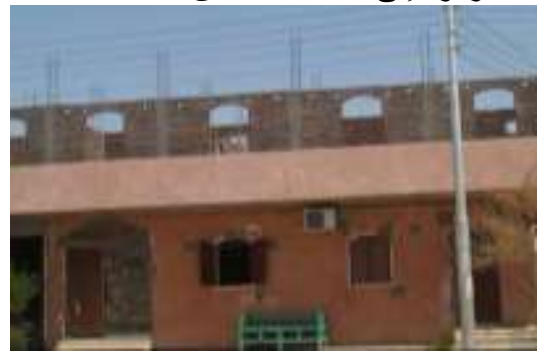

شكل (64): صورة من واجهة المدخل لمسكنين نم

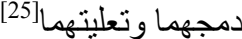

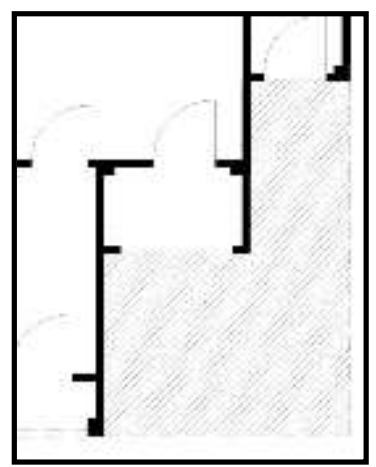

شكل (61): مسقط لجزء الردود

الذي تم اضافته لبعض المساكن [25]
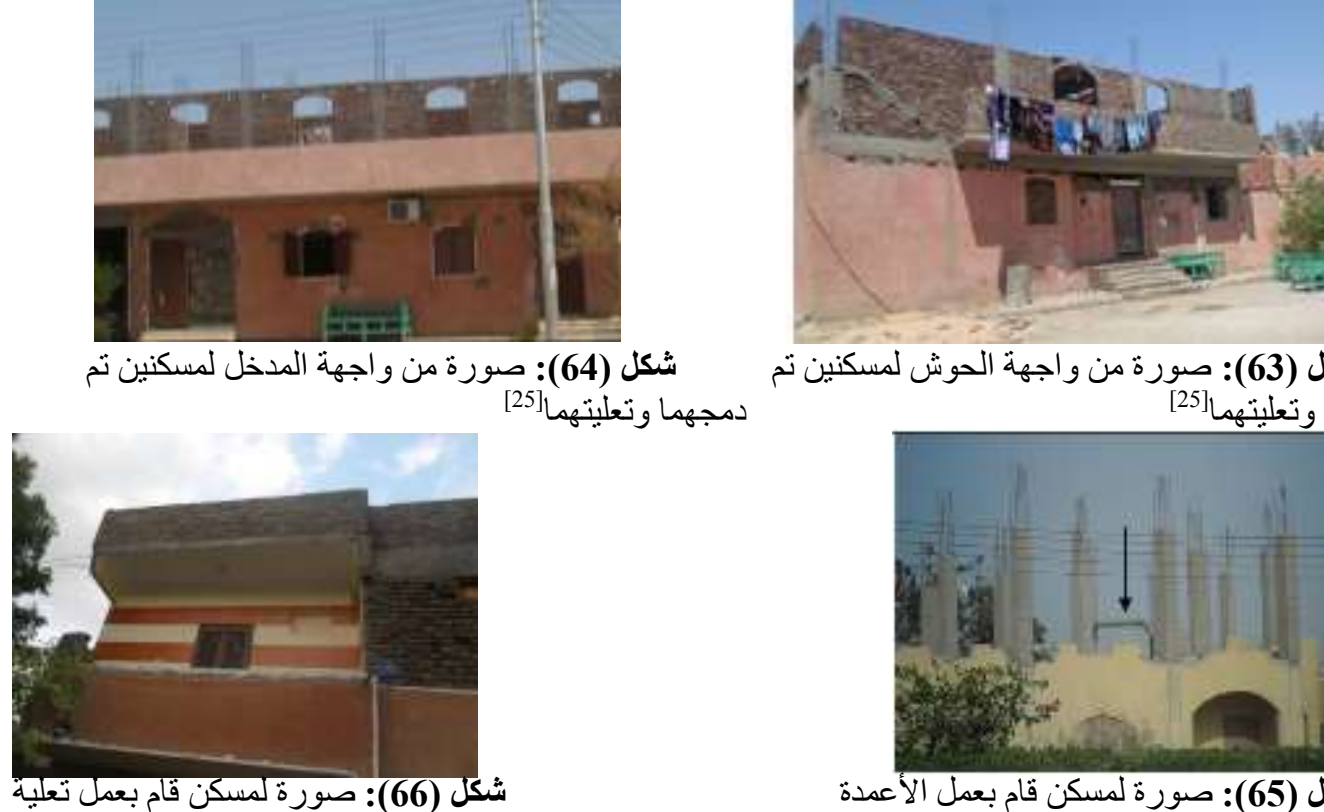

شكل (63): صورة من واجهة الحوش لمسكنين تم

دمجهما وتعليتهما[25)

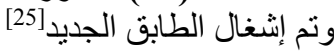

شكل (66): صورة لمسكن قام بعمل تعلية

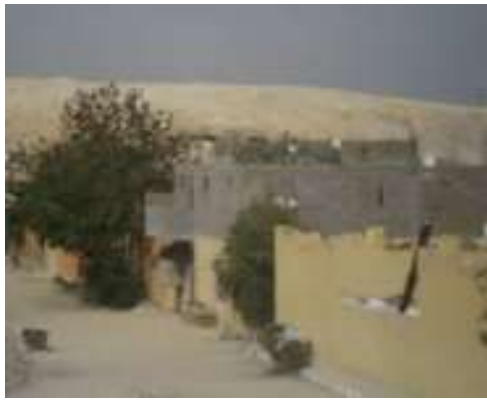

شكل (68): صورة لانتشار التعلية

في مساكن الطارف الجديدة:

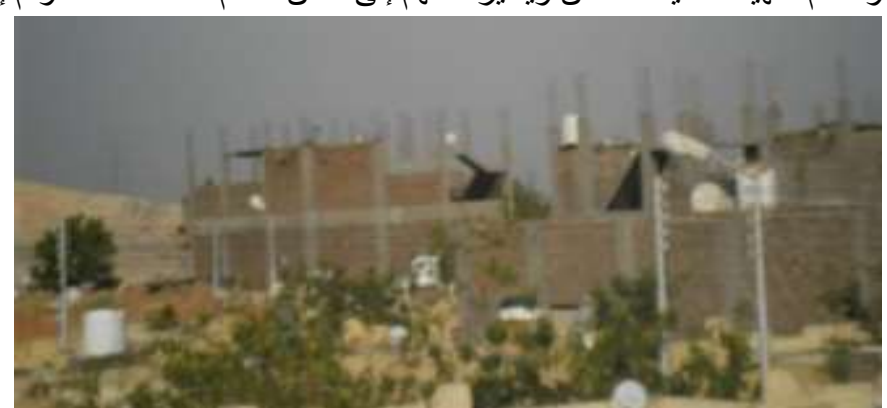

شكل (67): صورة لانتشار التعلية في مساكن الطارف الجديدة[25]
شكل (65): صورة لمسكن قام بعمل الأعمدة

و السلم تمهيدا لتعلية المسكن ويشير السهم إلى مكان السلم [25 الأعدة

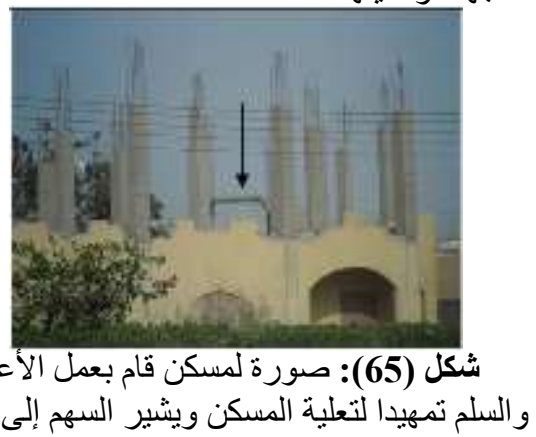


3.2.4 تقبيم العناصر السلوكبة:

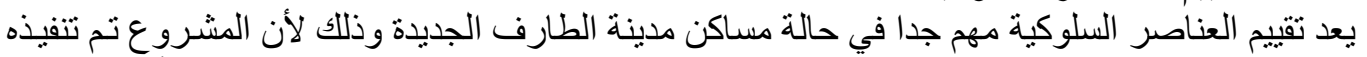

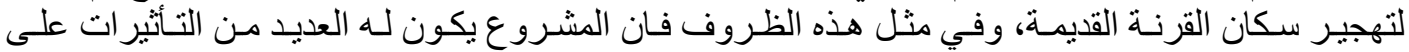

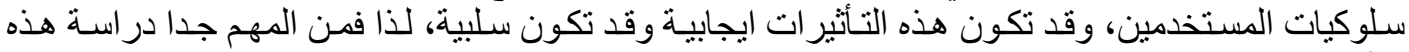

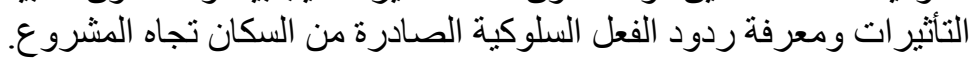

\section{أولا تقييم الخصوصية :}

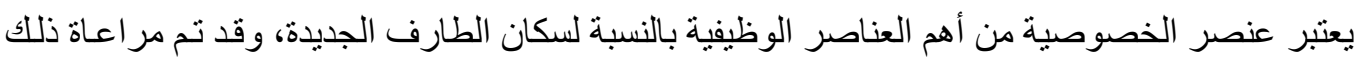

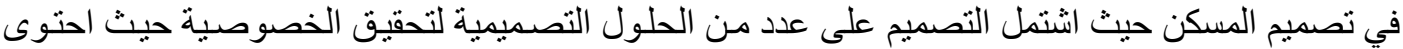

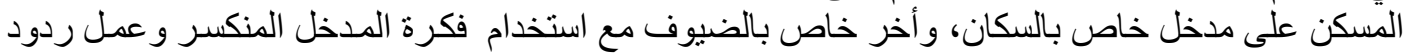

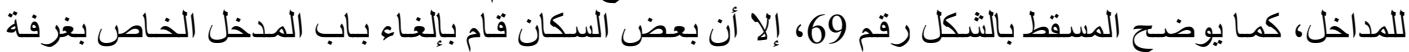

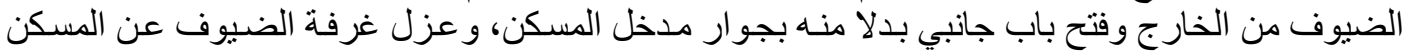

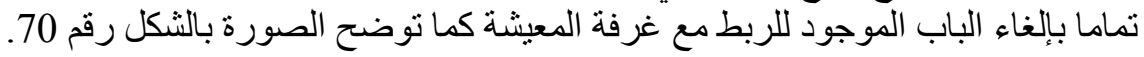

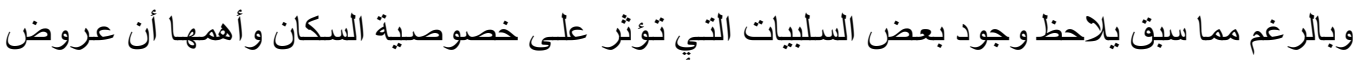

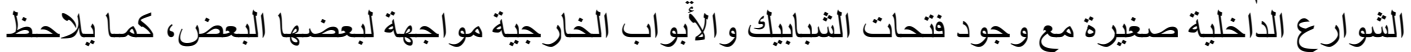

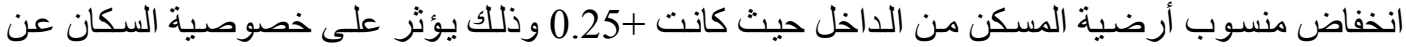

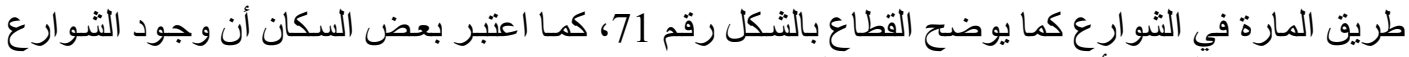
بدون نهايات مغلقة هو أمر يؤثر بعدم توفير الخصوصيار بوحية.

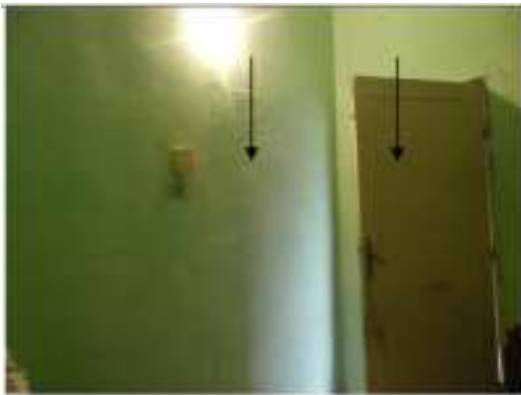

شكل (70): صورة لمسكن قام بتعديل مدخل

غرفة الضيوف وعزلها عن المسكن[25]

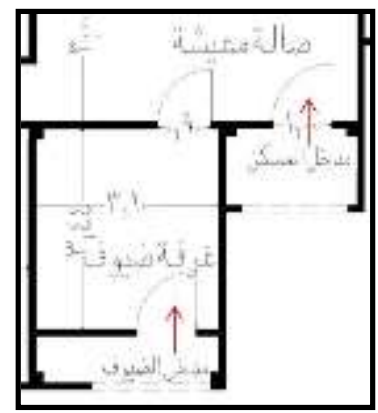

شكل (69):مسقط لمدخل السكان ومدخل الضيوف (لبه

لتحقيق الخصوصية. (المصدر الباحث)

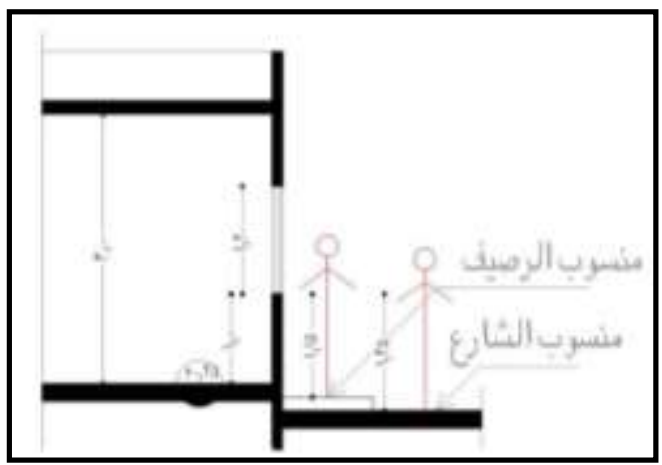

شكل (71): قطاع يوضح نأثير انخفاض منسوب المسكن بعدم توفير الخصوصية (الدصدر الباحث) 


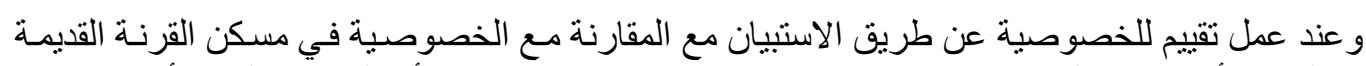

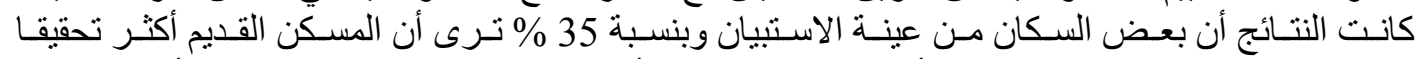

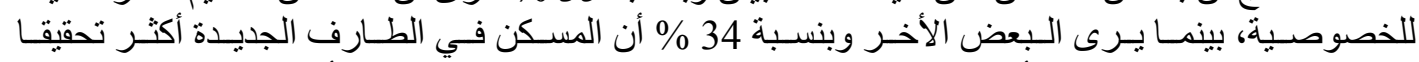

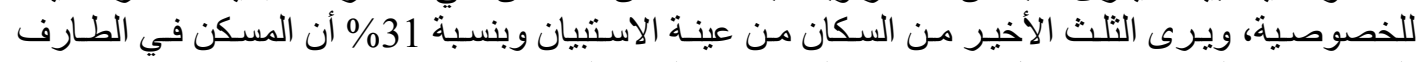
الجديدة يحقق الخصوصية بشكل يتساوى مع المسكن في القرنة القديمة.

\section{ثانيا تقييم السلوكيات الاجتماعية:}

كما تم التوضيح من قبل فإن مجتمع و أهالي القرنة الذين تم تهجير هم إلى الطسارف الجديدة يتميزو البنسام

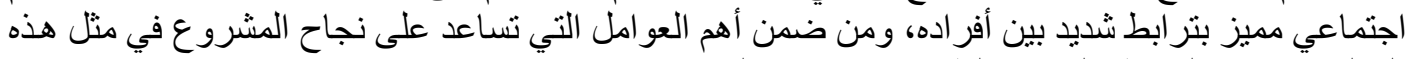
الحالة ضرورة الحفاظ على هذا الطابع الاجتماعي المميز.

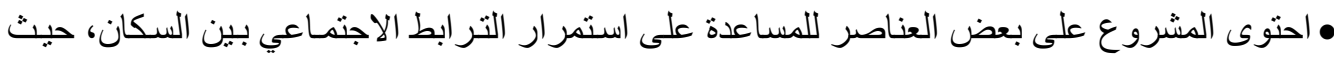

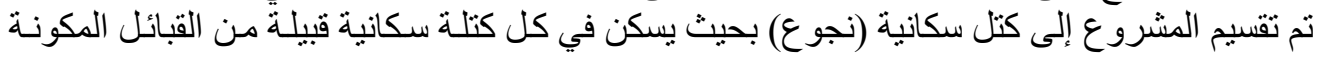

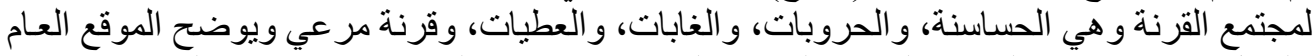

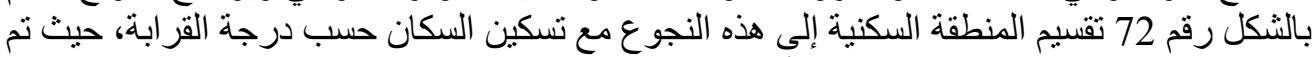

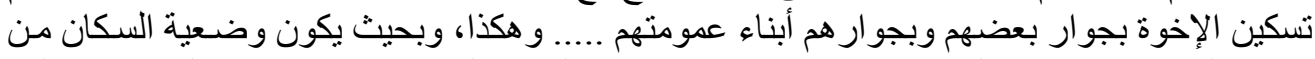

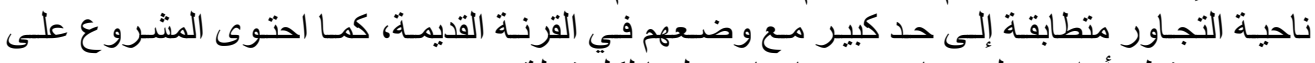

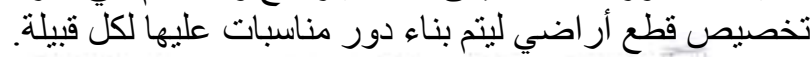

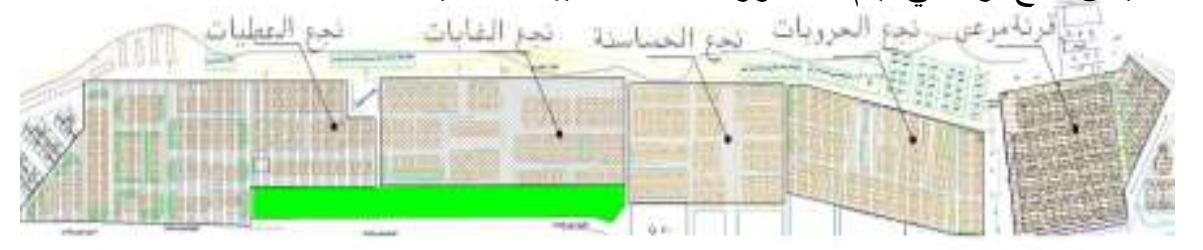

شكل (72): موقع عام لتقسيم الطارف الجديدة إلى نجوع لتسكين كل أبناء قبيلة بنجع

• لوحظمن خلال المقابلات مع السكان وجود انخفاض في الروابط الاجتماعية بين السكان وهذا أمر طبيعي نتيجة الإنة

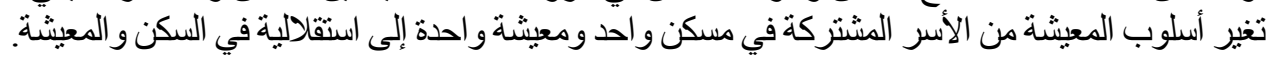
و عند عمل استبيان بين السكان حول العلاقات الاجتماعية على مختلف المستويات مـع مقارنتها بالعلاقات أنتاء السكن بالقرنة القديمة كانت النتائج كالأتي:

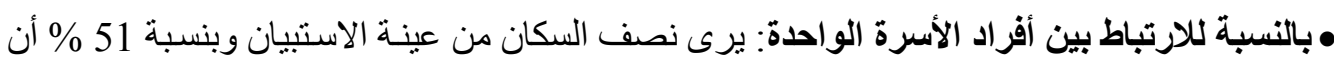

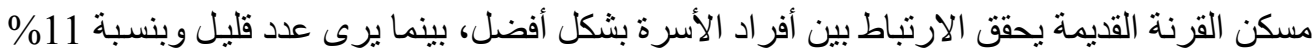

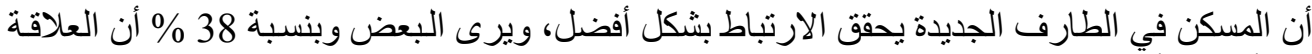

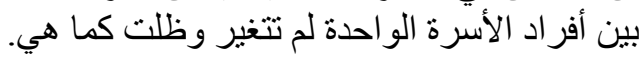

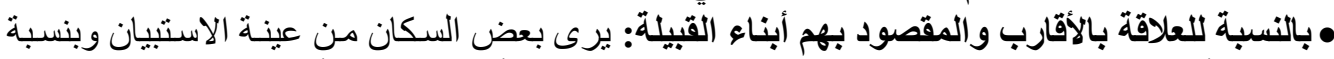

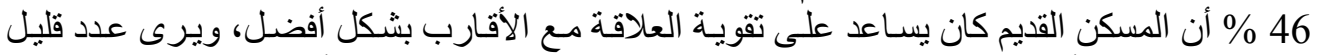

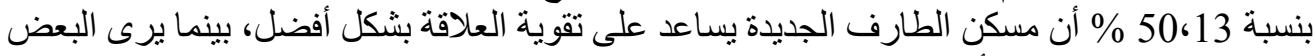

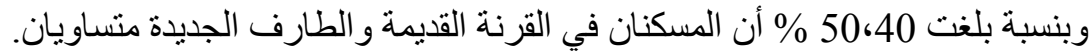

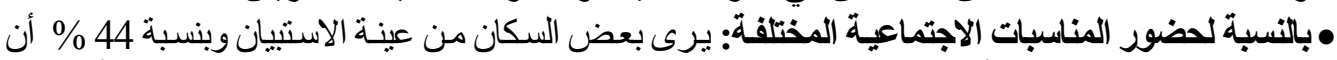

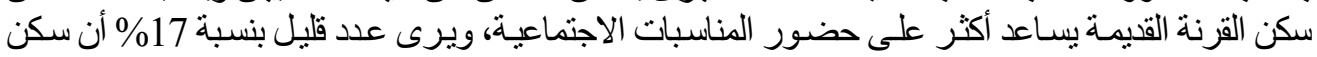

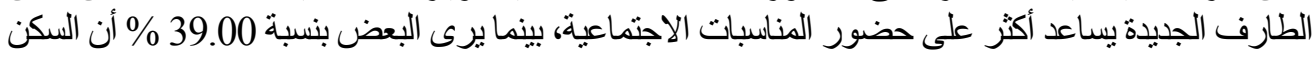
في الطارف الجديدة يتساوى مع السكن في القرنة القديمة في المساعدة على حضور المناسبات العنات الاجتماعية. 


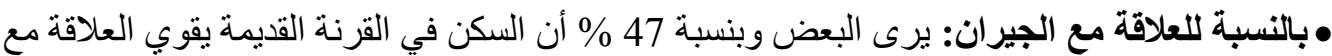

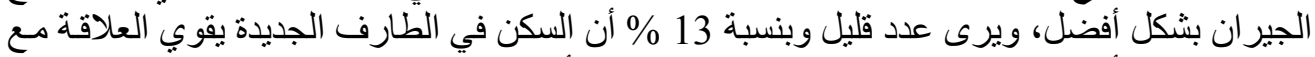

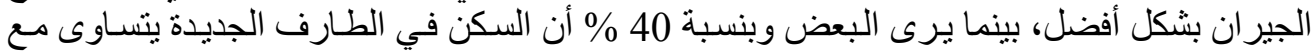
القرنة القديمة من حيث تقوية العلاقة مع الجيران.

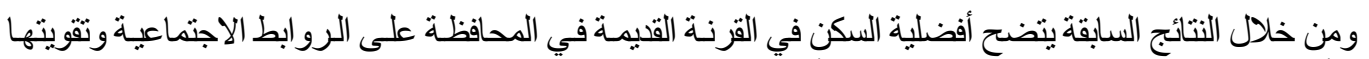

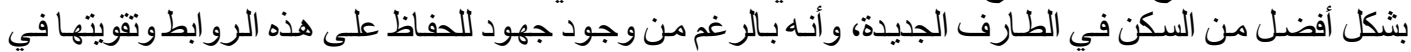
الطارف الجليدة إلى أن هذه العلاقات و الرو ابط الاجتماعية تأثرت وبشكل ليس بالقليل و لا يمكن تجاهل هذا التأثير.

\section{ثالثا تقييم السلوكيات الاقتصادية :}

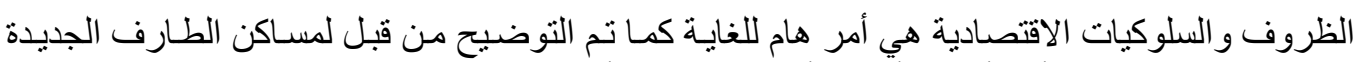

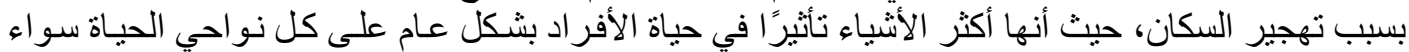

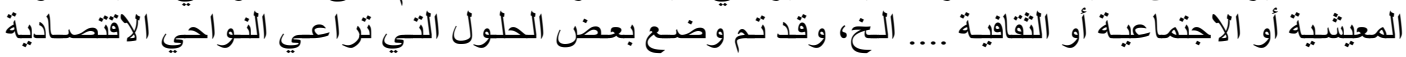
للسكان في مشروع الطارف الجديدة وهي:

• تـم تخصيص قطع أر اضـي بالمشـروع ليقام عليها مشرورعات وتنمويـة مفيدة لسكان المنطقة، ومنهـا

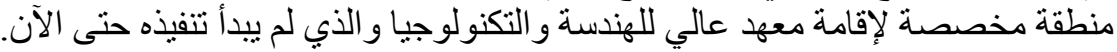

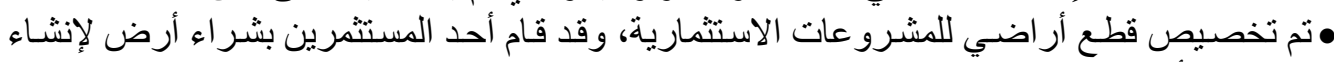

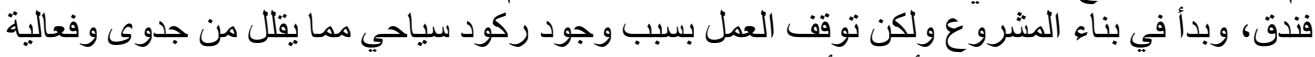

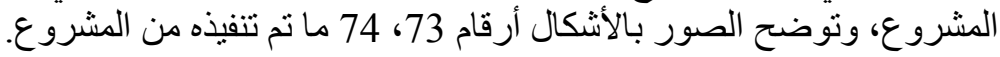
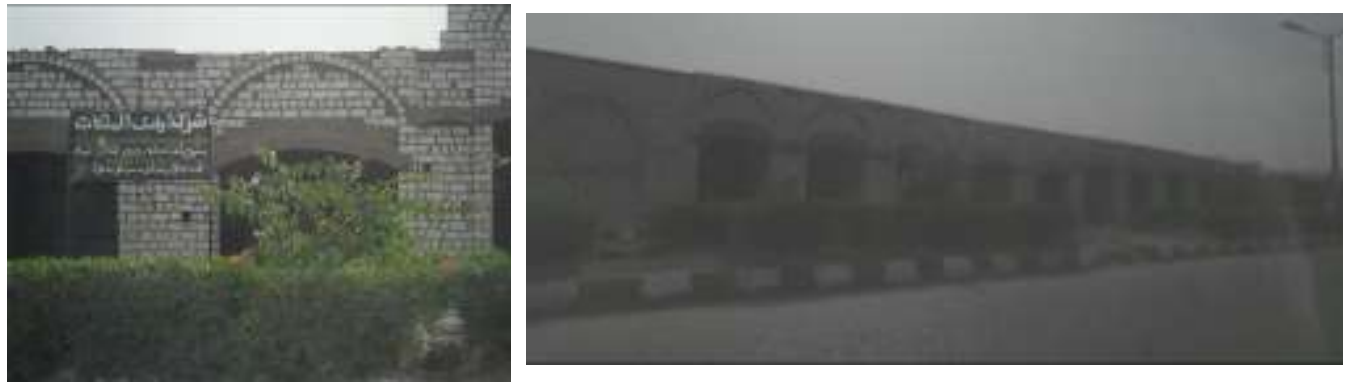

شكل (74): صورة أخرى لمشروع الفندق[25]

شكل (73): صورة لمشروع الفندق بالمنطقة الاستثمارية [25] • تم إنشاء سوق تجاري يحتوي على عدد كبير من المحلات التجارية لتوفير الخدمات للسكان من ناحية التهاء

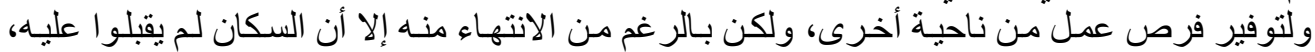

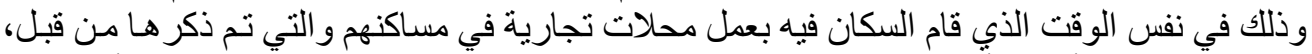

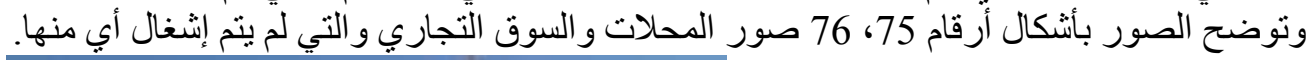

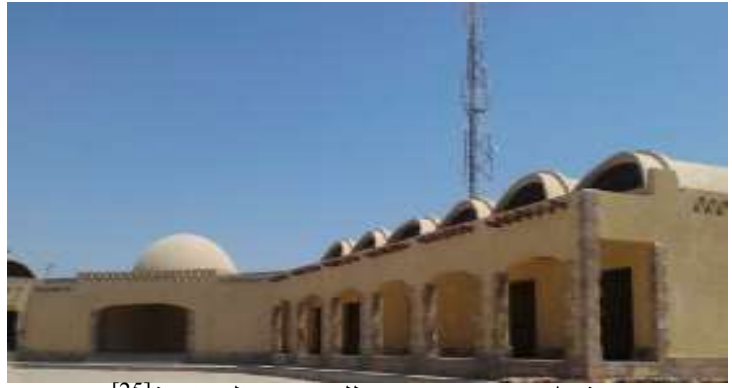

شكل (76): صورة للمحلات التجارية[25]

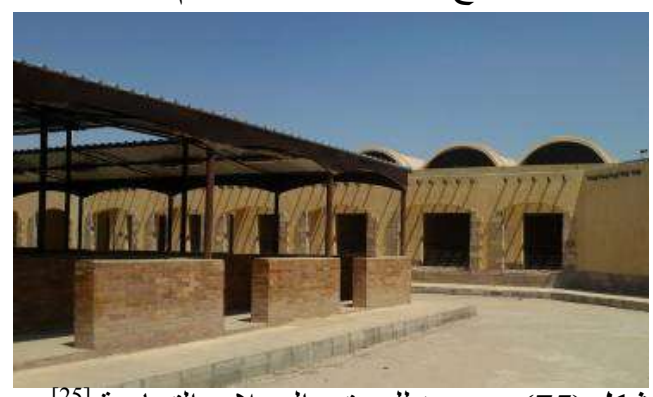

شكل (75): صورة للسوق و المحلات التجارية [25] 
رضا محمود حمادة و محد عبد الحمب فاوي، تقبيم ما بعد الإشغال لمساكن الطارف الجديدة

وقد تم عمل استبيان بين السكان فيما يخص الحالة الاقتصادية للسكان بعد السكن بمساكن الطارف الجديدة

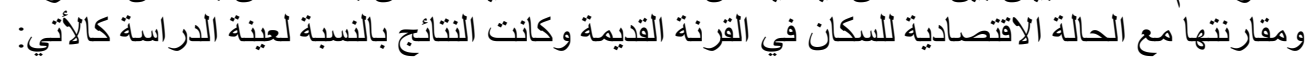

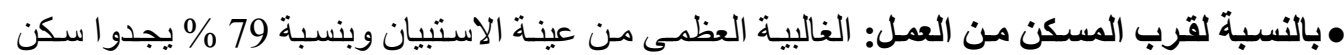

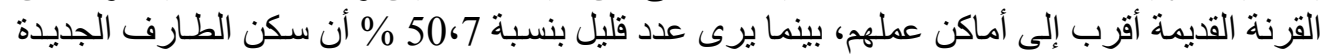

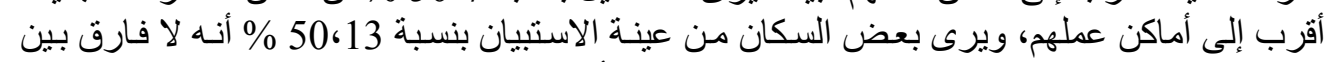

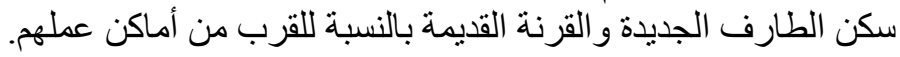

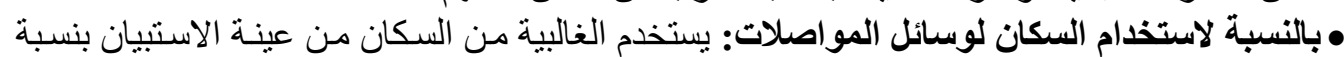

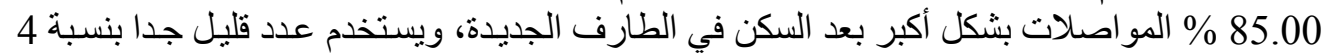

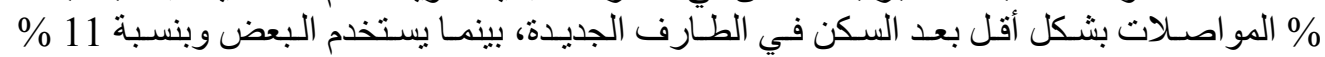

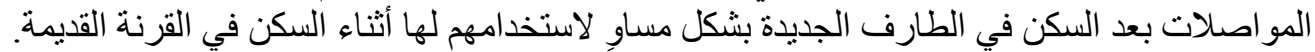

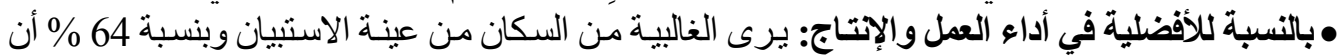

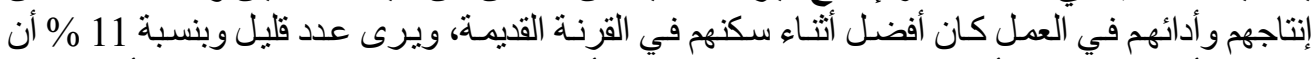

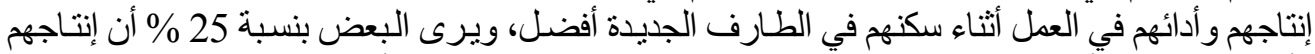

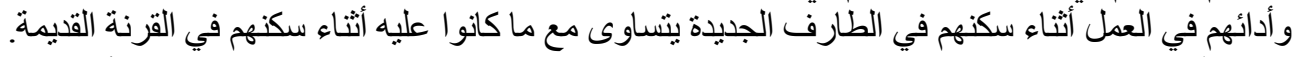

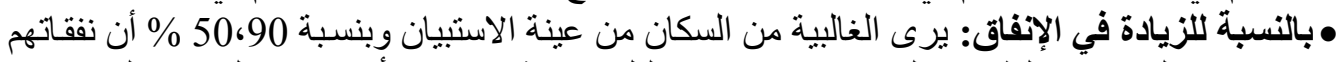

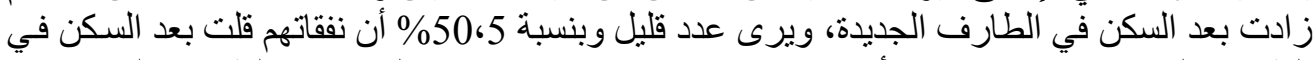

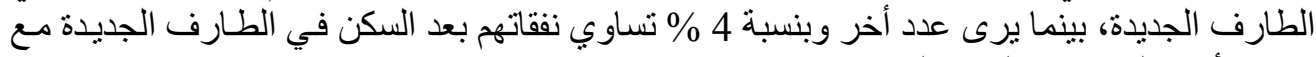

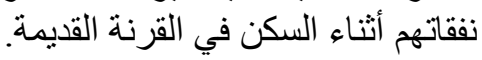

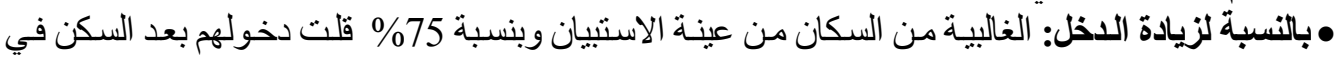

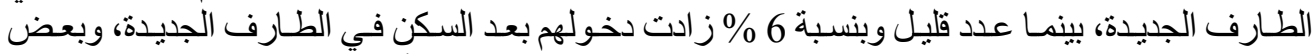

السكان بنسبة 19 \% تساوت دخولهم بعد السكن في الطارف الجديدة معها أنثاء سكنهم في القرنة القديمة. ودن خلال النتائج السابقة يتضح مدى وجود تأثير سلبي كبير على الحياة الاقتصادية للسكان وذلك يرجع لعدة أسباب: • حدوث بطالة بشكل كبير جدا بعد السكن في الطارف الجديدة ، وذللك لغياب النشاط الرئيسي لأكثريـة السكان

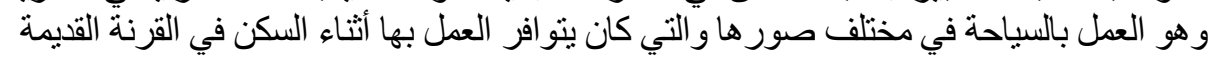

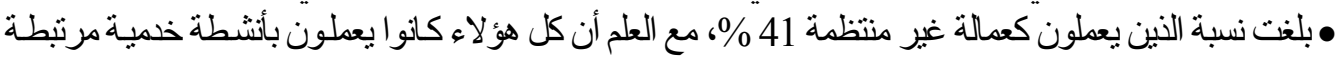

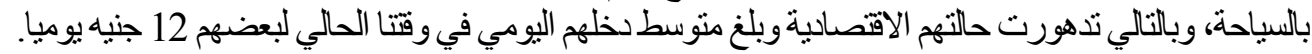

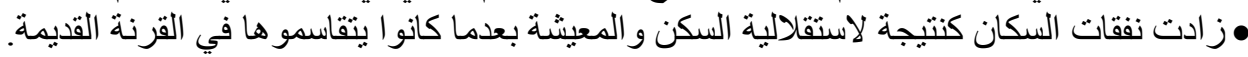

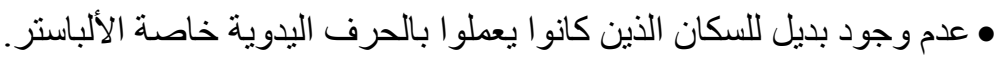

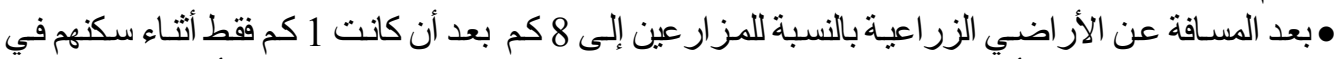

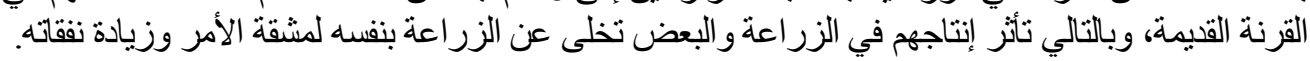

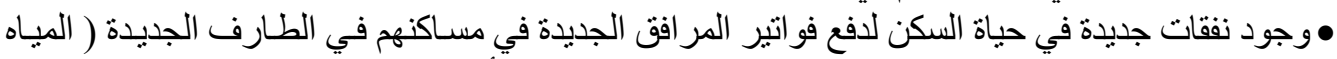

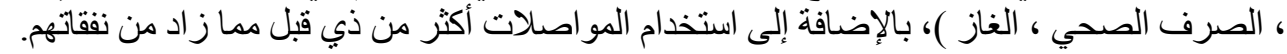

\section{5. النتائج النهائية والتوصيات:}

1.5

• نبين وجود نقص كبير في در اسات المشروع خاصة المتعلقة بالسكان من حيث المعلومـات الإحصسائية الخاصـة

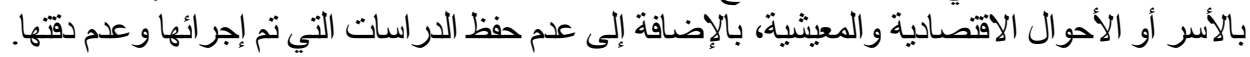

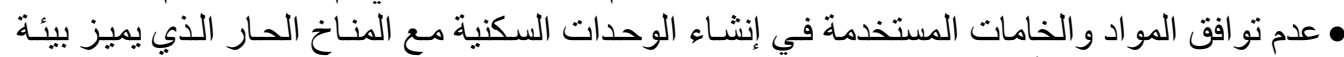

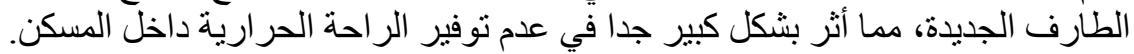


• النظام الإنشائي المستخدم مناسب إلى حد كبير مع وجود بعض الصعوبات المتعلقة بامتداد المسكن.

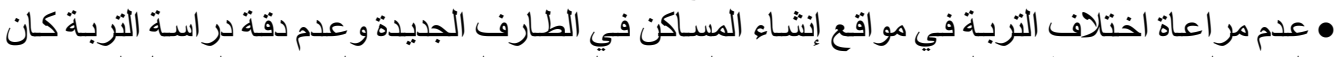

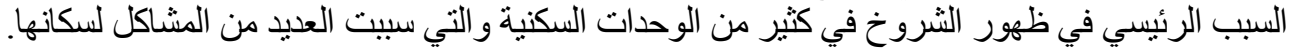

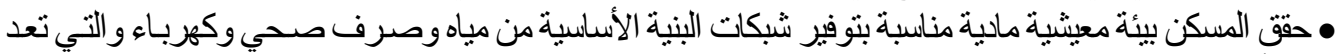

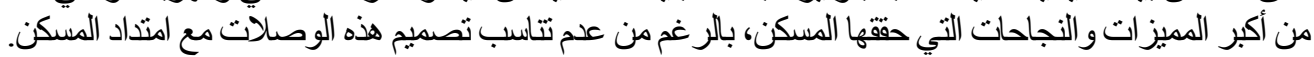

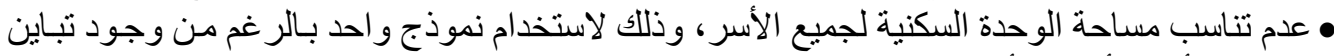
كبير بين أعداد أفر اد الأسر.

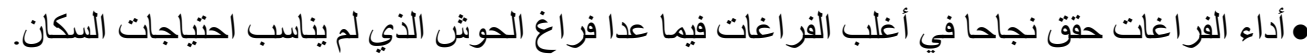

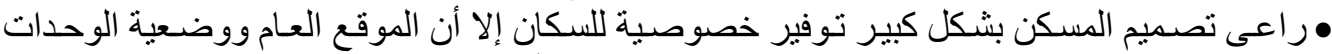

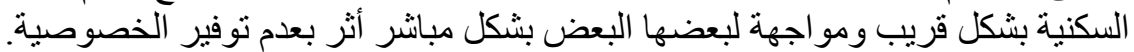

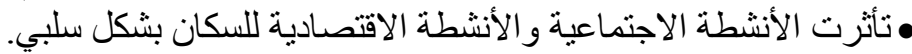

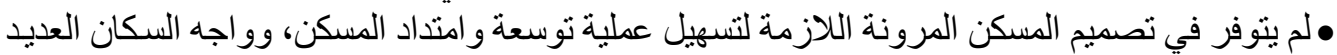

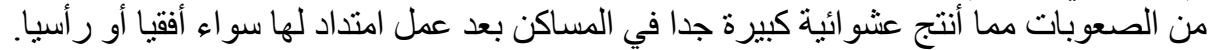

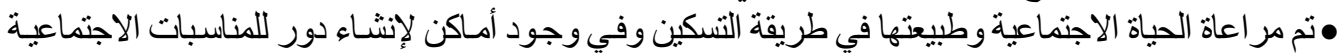

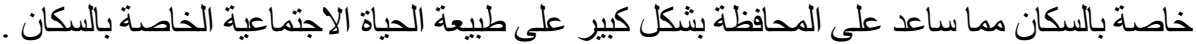

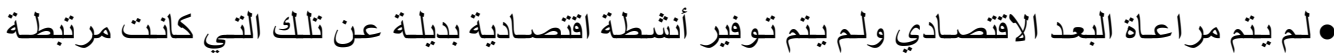

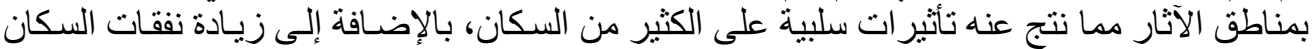

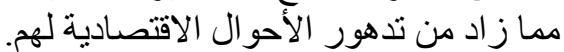

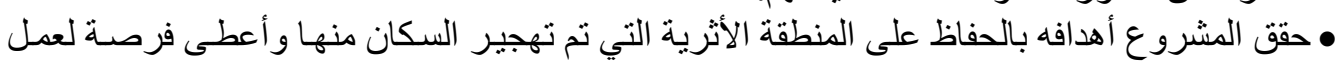
الصيانة اللازمة لهان. • حقق المشروع هدفه بإعادة توطين السكان في بيئة عامـة مناسبة و أفضلـل بكثير من البيئة السكنية في

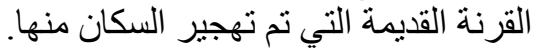
• فثنل المشروع بشكل كبير في توفير استثمار ات وتنمية اقتصادية للسكان و المنطقة المحيطة بالمشروع.

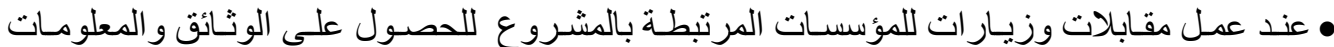

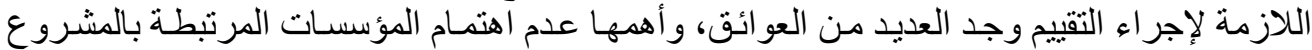

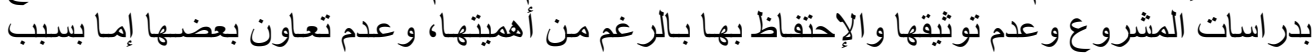

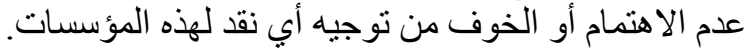
2.5 توصيات خاصة بتقبيم ما بعد الإشغال بشكل عام:

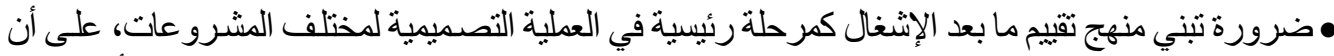

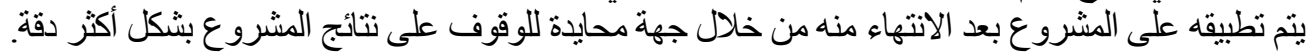

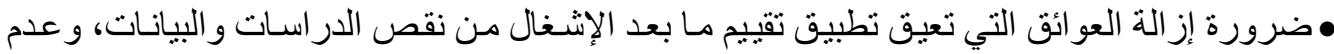

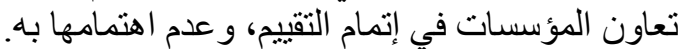

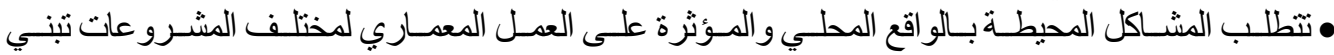

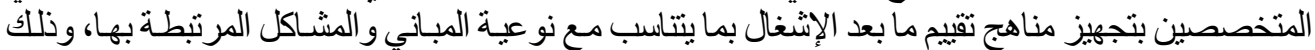

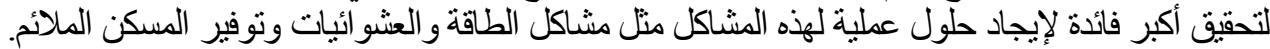

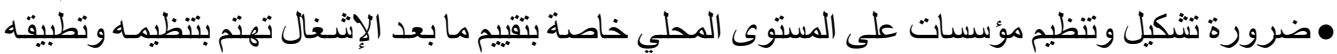
وتطوير أدو اته، والعمل على نشر نتائجه بين المتخصصين في العملية المعمارية ومتخذي القرار. 


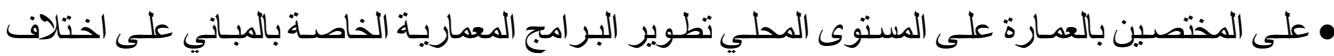

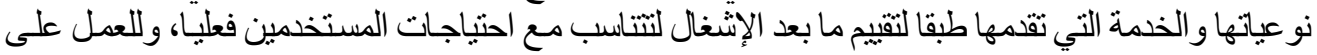

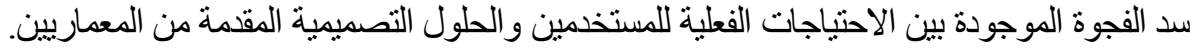

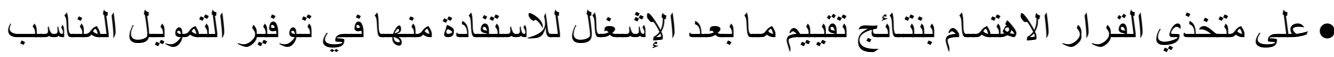

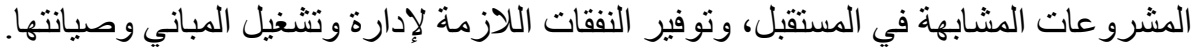

$$
\text { 3.5.توصبات خاصة بمساكن الطارف الجدبية. }
$$

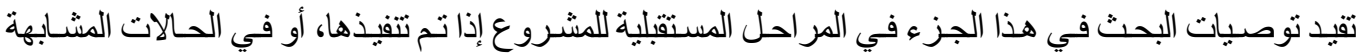

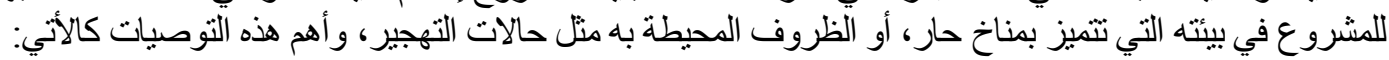

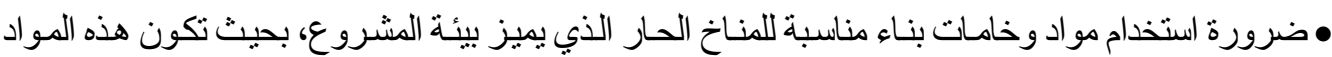

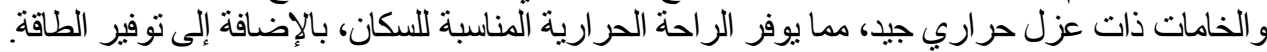

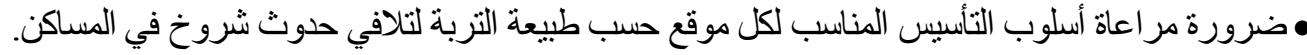

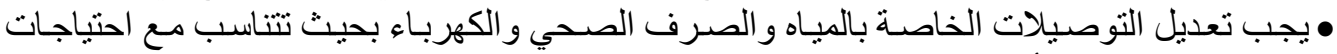

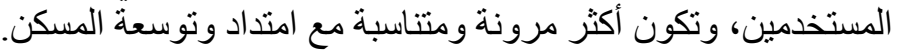

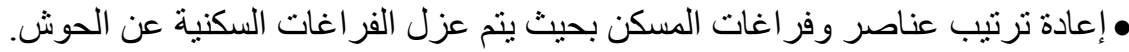

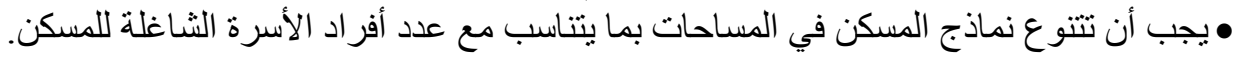

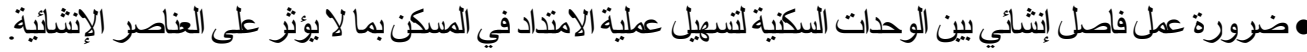

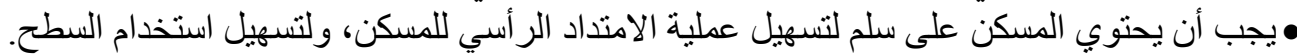

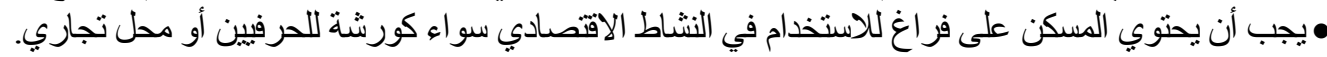

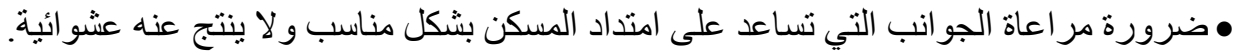

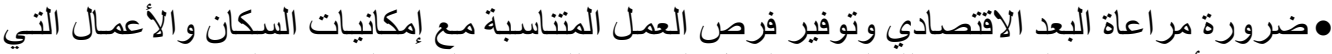

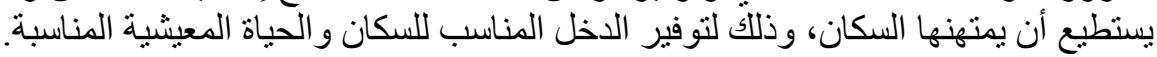

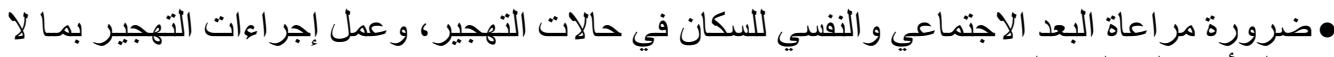
يترك أثر سلبي لدى السكان.

$$
\text { مر اجع البحث }
$$

[1] عرفـان سـامي، كتـاب نظريـات العمـارة الجـزء الأول، 1970، مركـز الدراسـات التخطيطيـة والإقليميـة، .http://www.cpas-egypt.com

[2] Federal Facilities Council, Board on Infrastructure and the Constructed Environment, National Research Council Learning from Our Buildings: A State-of-the-Practice Summary of Post-Occupancy Evaluation, 2002.

[3] Chris Watson 'management between buildings and people (defending of post occupancy evaluation), www.postoccup--ancyevaluation.com.

[4] إيهاب إبر اهيم عبد العزيز، تقييم الأداء و أثره على العملية التصميمية لتتسيق الموقع في مصر، بحث دكتور اه،

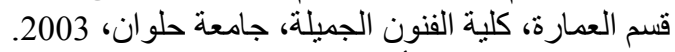

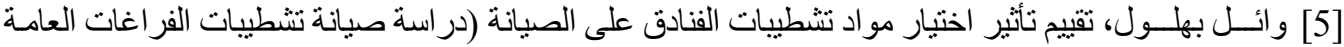

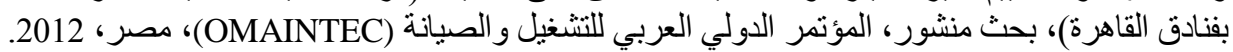

[6] Michigan State University - Implementation of Post-occupancy Evaluation: A Potential Tool for Building Asset Management and Creating More Productive، Cost- Effective and Sustainable Buildings at MSU، Michigan University, 2008.

[7] أحمد حسين كامل حنفي، نحو تحسين أداء الأحياء السكنية القائمـة من خـلال تقياءيم أداء البيئة المبنية، ورقية

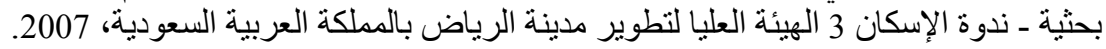


JES, Assiut University, Faculty of Engineering, Vol. 43, No. 4, July 2015, pp. 558 - 592

[8] University of California، San Francisco، Post Occupancy Evaluation Report of Findings (Helen Diller Family Cancer Research Building), 2011.

[9] هابي حسني مصطفى أحمد، تقيبم مـا بعد الإشغال لمباني التعليم الجامعي بمصر ( أداة تقييم مباني كليات

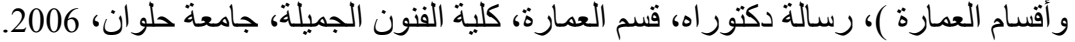

[10]Estates and Facilities, University of Westminster - Guide to Post Occupancy Evaluation the Higher Education Funding Council for England (HEFCE), 2006.

[11]Elçin Akman, POST OCCUPANCY EVALUATION WITH BUILDING VALUES APPROACH, MASTER OF FINE ARTS, THE DEPARTMENT OF INTERIOR ARCHITECTURE AND ENVIRONMENTAL DESIGN AND THE INSTITUTE OF FINE ARTS OF BILLKENT UNIVERSITY, 2002.

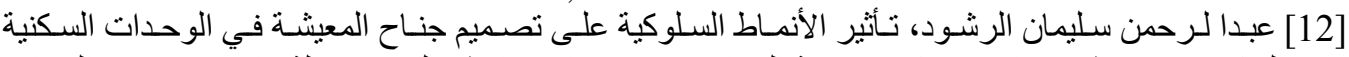

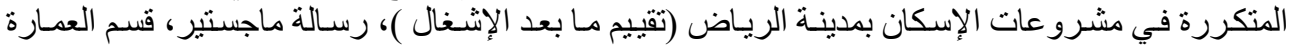

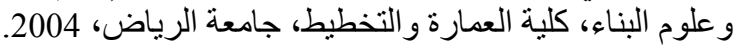

[13] Dr. Mohammad A. Hassanain, Uses and Benefits of Post-Occupancy Evaluation, Course

Paper for King Fahd University of Petroleum and Minerals Architectural Engineering, 2013.

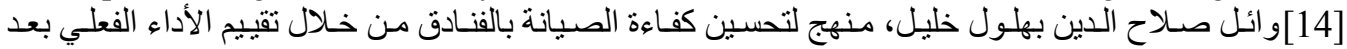

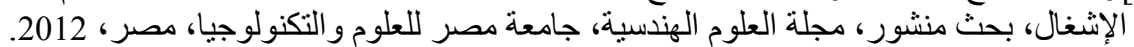

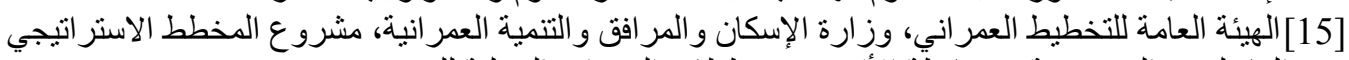
العام لقرى الجمهورية ( محافظة الأقصر، مخططات الوحدات الإنية المحلية للقرى، ديسمبر 2009.

[16] http://www.marefa.org/index.php

[17] http://www.luxor.gov.eg

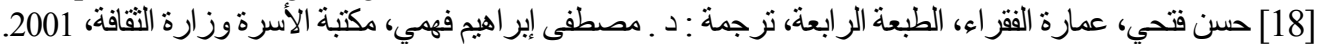

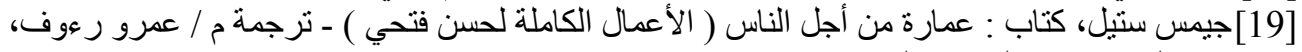

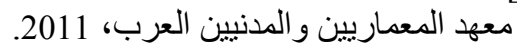

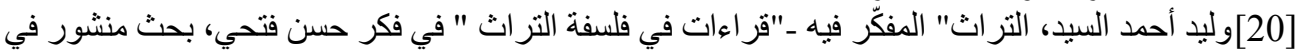

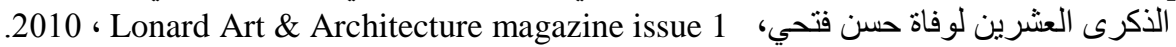

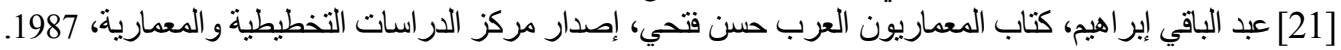

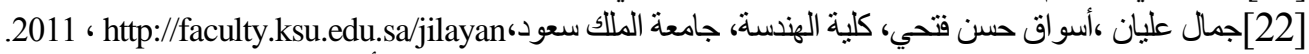

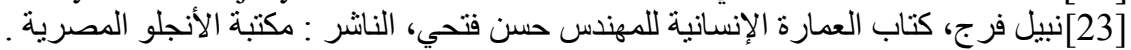

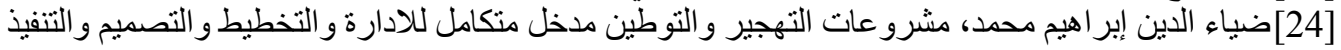

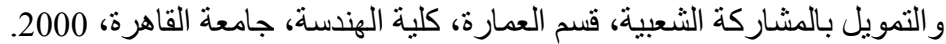

[25]

[26] أحمد يحيى ر اثند ، "مستقبل الأقصر : بين استثمار الفرصة وفرص الاستثمار "، بحث منشور ، مؤتمر المدن

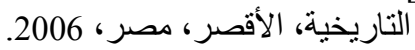

[27]ناهد نجا عباس الإبياري، النمو العمر اني للمدن المصرية ونأنثيره على المناطق الأثرية، رسالة دكتور اه، قسم

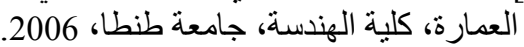

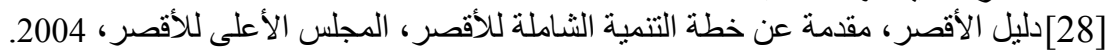

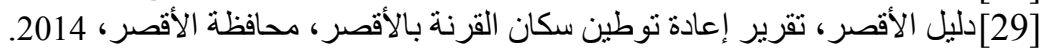

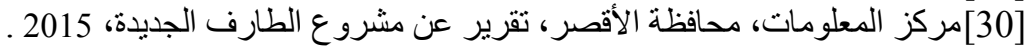

[31] Gabriel Abraham, Ashraf Bakr ، Jonathan Lane, The Comprehensive Development of the City of Luxor Project, Egypt - Final Structure Plan, Volume I - Technical Report - Ministry of Housing, Utilities and Urban Communities / Research and Studies Organization, 2000.

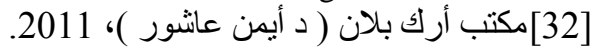

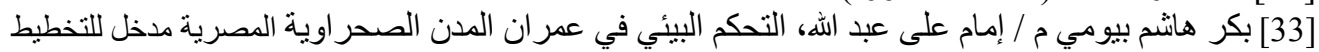
البيئي المستدام، [34] المسوده النهائية للائحة التقفيذية لقانون البناء الموحد قانون رقم 119 لسنة 2008، http://buldings-world.blogspot.com 
رضا محمود حمادة و محد عبد الحمبد فاوي، تقبيم ما بعد الإشغال لمساكن الطارف الجديبة

\title{
POST OCCUPANCY EVALUATION OF THE NEW EL TAREF CITY HOUSES
}

\begin{abstract}
Due to the importance of archaeological areas of the western mainland in Luxor as a rare historical and cultural value which made a national regional، and international issue. And as the New El Taref project has special case concern with displace the inhabitants of the village from their home besides the archaeological areas of the Western mainland in Luxor to set up a new society in El Taref. So the research will handle this case to evaluate how far the project succeeded or failed in achieving the goals of the project and save these areas ، and the research will handle that by applying the approach of post occupancy evaluation on the houses in The New El Taref.

The research starts with simple theoretical explaining to post occupancy evaluation approach by showing some definitions to understand its components، there is no doubt that there is problem with the unconcerned with applying the post occupancy evaluation approach ' so the research will present the most important points showing its importancer especially with a lot of benefits in all aspects related with building and throughout the life of building. Then the research will give a general glance about this village. And we move to explain the project of the new village of Hassan Fathy which considers the most important past displacement efforts with showing its causes and results. Then the research will explain the components of The New El Taref project and applying post occupancy evaluation to technical functional and behavioral aspects of the houses. then the research ends with displaying evaluation results and recommendations، which recommend the necessity of applying post occupancy evaluation and its vast benefits especially in this case which leads to achieving the purposes of displacements projects and solving all problems concerning it.
\end{abstract}

